\title{
Organophosphate Ester Contaminants in Herring Gulls (Larus argentatus) from the Great Lakes of North America: Bioaccumulation, Exposure, Pharmacokinetics and Trends
}

\author{
by
}

\author{
Alana K. Greaves
}

A thesis submitted to the Faculty of Graduate and Postdoctoral Affairs in partial fulfillment of the requirements for the degree of

Doctor of Philosophy

in

Chemistry, with specialization in Chemical and Environmental Toxicology

Carleton University

Ottawa, Ontario

(C) 2016, Alana K. Greaves 


\section{ABSTRACT}

The pharmacokinetics of OPEs in wildlife is extremely limited, even though OPEs are being manufactured and used in products at record-high levels, and have been shown to cause numerous deleterious effects. This thesis aims to analyze the behaviour of OPEs in an avian model, the herring gull (Larus argentatus) and their eggs, with an emphasis placed on understanding OPE accumulation and metabolism in the body. Herring gull eggs were collected over a 20 year span from multiple sites across the Great Lakes. OPE profiles varied slightly between colony sites and collection years, although at all sites only tris(2-chloroisopropyl) phosphate (TCIPP), tris(2-chloroethyl) phosphate (TCEP), tris(2-butoxyethyl) phosphate (TBOEP) and triphenyl phosphate (TPHP) were detected. In general, $\Sigma$ OPE concentrations in 2010 were significantly higher $(p<0.05)$ than they were between 1990 and 2004. In a preliminary food web study, only TBOEP was consistently detected among multiple fish species from the Great Lakes, and showed weak biomagnification in the aquatic food web. OPE distribution among eight tissues in maternal gulls and their eggs showed that OPEs accumulate most in fat, followed by egg yolk $\approx$ egg albumen, whereas OPEs were not detectable in liver, and brain. In the first study of its kind, OP diesters were detected and quantified in herring gull plasma, indicating OP triester metabolism in vivo. The rate of metabolism of six OP triesters was assessed in herring gull liver microsomes. Tri-n-butyl phosphate (TNBP) was metabolized the fastest, followed by TBOEP, TCIPP, TPHP, and finally tris(1,3-dichloro-2-propyl) phosphate (TDCIPP). Triethyl phosphate (TEP) was not metabolized, regardless of administered concentration. Biotransformation of OP triesters to diesters varied greatly between compounds, with up to 10-fold differences between OP triesters. In general, structure-dependent 
biotransformation differences were observed, with halogenated alkyl triesters being transformed to their respective diesters more-so than non-halogenated alkyl triesters. It is evident that OP triesters are, in many cases, rapidly metabolized in vivo, and thus OPE concentrations observed in tissues samples represent post-metabolic residues. This thesis is critical in understanding the pharmacokinetics of OPEs in an avian species, and emphasizes the importance of identifying and monitoring OPE metabolite concentrations in biota. 


\section{LIST OF WORKS ASSOCIATED WITH THESIS:}

\section{Refereed Journal Publications:}

A.K. Greaves, R.J. Letcher. 2016. A Review of Organophosphate Esters in the Environment from Biological Effects to Distribution and Fate. Bulletin of Environmental Contamination and Toxicology, Accepted, DOI: 10.1007/s00128-016-1898-0 (Chapter 1)

A.K. Greaves, G. Su, R.J. Letcher. 2016. Environmentally relevant organophosphate triester flame retardants in herring gulls: In vitro biotransformation and kinetics and diester metabolite formation using a hepatic microsomal assay. Toxicology and Applied Pharmacology, Accepted (Chapter 6)

A.K. Greaves, R.J. Letcher, D. Chen, D.J. McGoldrick, L.T. Gauthier, S.M. Backus. 2016. Retrospective analysis of organophosphate flame retardants in herring gull eggs and relation to the aquatic food web in the Great Lakes. Environmental Research, 150, 255-263. (Chapter 3)

G. Su, A.K. Greaves, L.T. Gauthier, R.J. Letcher. 2014. Liquid chromatography-electrospraytandem mass spectrometry method for determination of organophosphate diesters in biotic samples including Great Lakes herring gull plasma. Journal of Chromatography A, 1374, 8592. (Chapters 2 and 5)

A.K. Greaves, R.J. Letcher. 2014. Comparative body compartment composition and in ovo transfer of organophosphate flame retardants in North American Great Lakes herring gulls. Environmental Science \& Technology, 48, 7942-7950. (Chapter 4)

\section{Refereed Conference Abstracts and Proceedings:}

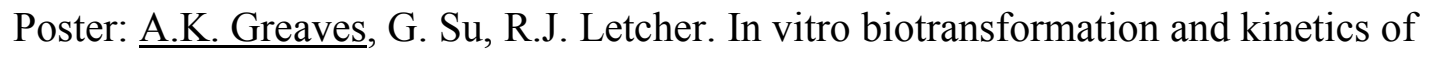
organophosphate triesters and diester metabolite formation using a model avian hepatic microsomal assay. DIOXIN Meeting; $36^{\text {th }}$ International Symposium on Halogenated Persistent Organic Pollutants. Aug 28 - Sept 2, 2016, Florence, Italy.

Platform: A.K. Greaves, G. Su, R.J. Letcher. In vitro metabolism of organophosphate triester flame retardants in herring gulls (Larus argentatus). International Association for Great Lakes Research (IAGLR) Annual Meeting. June 6 - 10, 2016, Guelph, Ontario.

Platform: A.K. Greaves, G. Su, R.J. Letcher. In vitro biotransformation and kinetics of organophosphate triester flame retardants using herring gull liver microsomes. Ottawa Carleton Chemistry Institute Day. June 3, 2016, Ottawa, Ontario. 
Poster: A.K. Greaves, G. Su, R.J. Letcher. Understanding organophosphate flame retardant in vitro metabolism in herring gulls (Larus argentatus) using Michaelis-Menton enzyme kinetic parameters. $36^{\text {th }}$ Annual SETAC North America Meeting, November 1-5, 2015, Salt Lake City, Utah.

Poster: A.K. Greaves, G. Su, R.J. Letcher. Metabolites of organophosphate flame retardants in the blood plasma of herring gulls (Larus argentatus) from the North American Great Lakes. $35^{\text {th }}$ Annual SETAC North America Meeting, November $9-13$, 2014, Vancouver, British Columbia.

Platform: A.K. Greaves, R.J. Letcher. Does the egg represent the bird? Tissue distribution and in ovo transfer of bioaccumulative organophosphate flame retardants in herring gulls from the Great Lakes. Ottawa Carleton Chemistry Institute Day, May 2014, Carleton University, Ottawa, Ontario.

Poster: A.K. Greaves, G. Su, R.J. Letcher. Metabolites of organophosphate flame retardants are detected in blood plasma of herring gulls (Larus argentatus) from the North American Great Lakes. Ottawa Carleton Chemistry Institute Day, May 2014, Carleton University, Ottawa, Ontario.

Platform: A.K. Greaves, R.J. Letcher. Tissue distribution and in ovo transfer of bioaccumulative organophosphate flame retardants in Great Lakes herring gulls (Larus argentatus). $34^{\text {th }}$ Annual SETAC North America Meeting, November 17 - 21, 2013, Nashville, Tennessee.

Platform: A.K. Greaves, R.J. Letcher. Organophosphate flame retardants are maternally transferred in ovo in herring gulls (Larus argentatus). International Association for Great Lakes Research (IAGLR) Annual Meeting, June 2 - 6, 2013, West Lafayette, Indiana. 


\section{ACKNOWLEDGEMENTS}

There are many people I would like to expressly thank for the success of this project. I would like to begin by thanking my supervisor, Rob Letcher. He has been a constant source of encouragement and positive feedback throughout the years I have spent in the Organic Contaminants Research Lab (OCRL), and made it easy and enjoyable to come into the office every day. I could not have asked for a better supervisor. I am now a much stronger researcher than when I started with Rob, and can only aspire to make a fraction of the impact he has made in the environmental toxicology community. Thank you.

This project would not have been possible without other key individuals. I wish to thank Shaogang Chu for always being available to troubleshoot with me in the lab, and always managing to pull the LC-MS away from the brink of failure. Guanyong Su has been of invaluable help during this project. I thank him for analyzing the herring gull plasma samples for OP diesters (Chapter 5), assisting with herring gull microsome preparation (Chapter 6), and performing the in-lab work regarding the enzyme kinetic constants for the six OP triesters (Chapter 6). I would also like to thank Lewis Gauthier for performing the in-lab analysis of all Lake Ontario and Lake Erie samples (Chapter 3), as well as Da Chen for performing the in-lab

analysis of all herring gull eggs (Chapter 3). I would also like to thank Craig Hebert for performing the stable isotope analysis of the food web samples (Chapter 3).

A large thank you goes out to Craig, Doug Crump, and Kim Williams for herring gull tissue and egg collection (Chapter 4, and throughout). Michael Keir, Mandi Clark and Mary Malecki are thanked for sampling the Lake Ontario and Lake Erie food webs, as well as the NWRC's specimen bank staff for processing and storing the samples. I would like to thank 
Heather Stapleton for donating the V6 standard. I would also like to thank Da, Guanyong, Daryl McGoldrick, and Sean Backus for providing valuable suggestions and comments during the revision of various manuscripts.

A large thank you goes out to Daryl, Michael, and Mandi for taking me under their wings during Lake Ontario field sampling on board the CCGS Kelso. (Next time I will bring Gravol.) I would also like to thank all of the members of the OCRL, past and present (David Blair, Shaogang Chu, Luke Periard, Guanyong Su, Lisa Mattioli, Katie Wooding, Gabriel Boisvert, Adelle Strobel, Adam Morris, Lewis Gauthier, Eric Pelletier, and Lennart Troubourst), as well as many other students and staff at the NWRC for making my time at Carleton truly enjoyable.

I would like to thank my husband, David, for being my biggest supporter, both in my personal and professional endeavours. His support is what has allowed me to follow my aspirations, and for that I am truly grateful. I can honestly say that without him, I would not be where I am today. Thank you. I would also like to thank my mom, Tammy, for always being there as a sounding board and providing good advice, and to my dad, Rob, for being my biggest fan. Finally, I would like to thank the rest of my family (William, Baby Boy Fortin (sorry hon, we don't know what your name will be yet!), David, Lauren, Brian, Kaylie, Ryan, Kyle, Laura, Kait, Linda, Patrick, Audrey, André, Maxime and Nicholas). What a large family, and I couldn't be more grateful for it.

This project was funded by Environment and Climate Change Canada's Chemical Management Plan (CMP) (to R.J.L.), as well as by the Natural Science and Engineering Research Council (NSERC) of Canada (to R.J.L.). Doctoral support was in part from NSERC (to R.J.L.) as well as an Ontario Graduate Scholarship (to A.K.G.). 
TABLE OF CONTENTS

ABSTRACT
LIST OF WORKS ASSOCIATED WITH THESIS
ACKNOWLEDGEMENTS
LIST OF TABLES
LIST OF FIGURES
LIST OF ABBREVIATIONS
LIST OF APPENDICES

\section{Chapter 1}

General Introduction

1.1 Organophosphate Esters

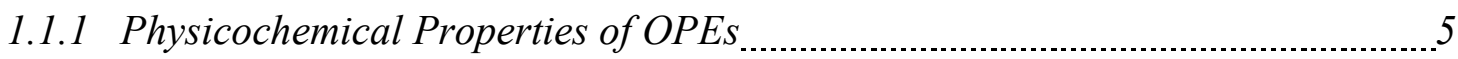

1.1.2 Qualitative and Quantitative Analytical Determination of OPEs _................. 5

1.2 Global Distribution of OPEs

1.2.1 Distribution of OPEs in the Environment ……....................................... 7

1.2.2 Distribution of OPEs in Biota with an Emphasis on Birds ….......................... 9

1.2.3 Distribution of OPEs in the Great Lakes of North America ........................... 11

1.3 OPEs in the Body: Absorption, Distribution, Metabolism, and Excretion _......................13

1.3.1 Absorption, Distribution and Excretion ………............................... 13

1.3.2 Metabolism

1.4 Toxicity of OPEs

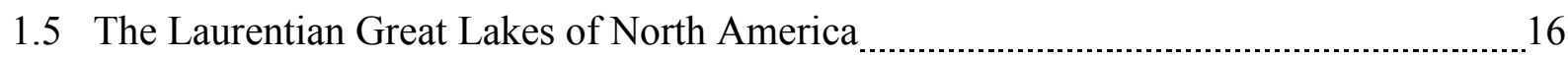

1.5.1 Herring Gulls and the Great Lakes Aquatic Food Web _...............................17

1.6 Thesis Objectives 20

\section{Chapter 2}

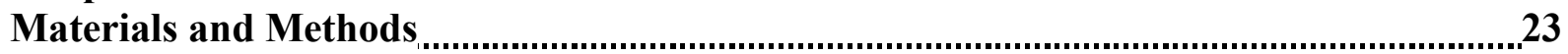

2.1 Sampling Details

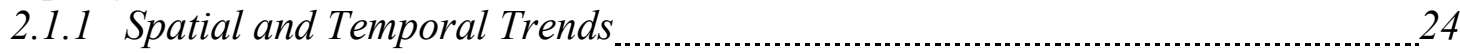

2.1.2 Lake Ontario and Lake Erie Food Webs _.............................................22 27

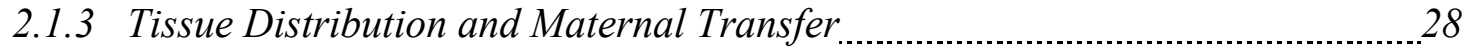

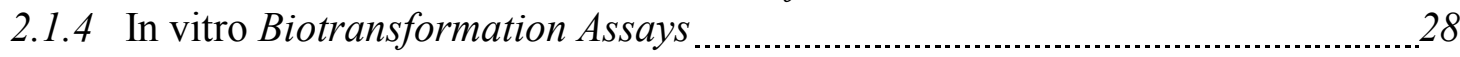

2.2 Contaminant Analysis _.............- 28

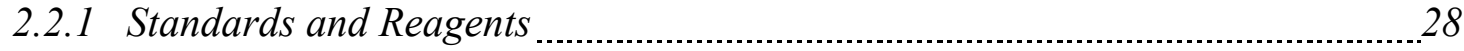

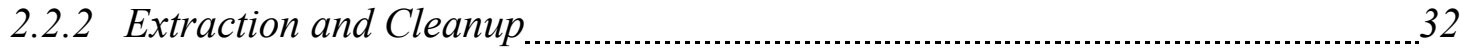

2.2.2.1 Organophosphate Triesters ………………………………………..... 32

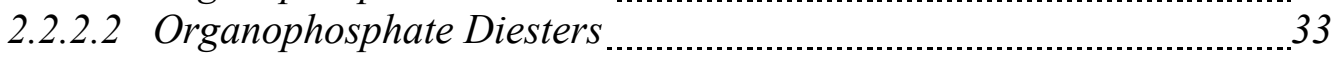

2.2.3 Measurement 34 
2.2.4 Quality Control

2.3 Stable Isotope Analysis and Trophic Level Determination ……................................. 39

2.3.1 Stable Isotope Extraction

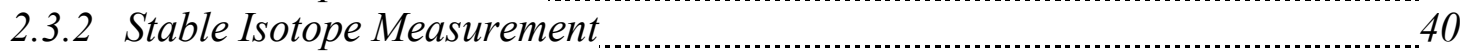

2.3.3 Trophic Level Determination _.............................................................4 41

2.4 Total Burden Estimates of OP Triesters in Herring Gull Tissues and Eggs _.................... 42

2.5 In vitro Biotransformation Assays $\ldots$

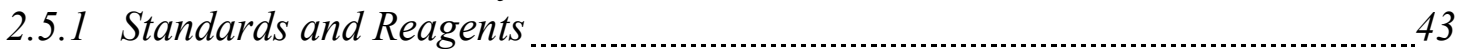

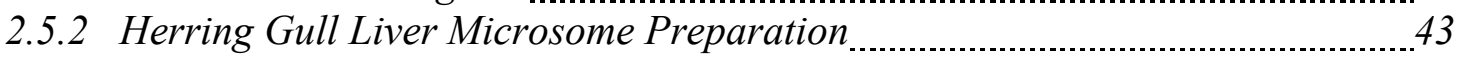

2.5.3 Microsome Protein Content and Catalytic Activity Determination _.................46

2.5.4 In vitro Biotransformation Assay Procedure ……....................................4 47

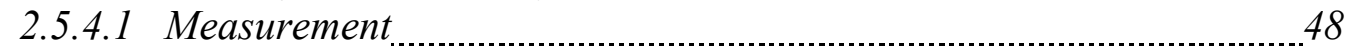

2.5.5 Quality Control

2.6 Data Analysis

2.6.1 Great Lakes Spatial Trends, Temporal Trends, and Food Web Analysis .........52

2.6.2 Tissue Distribution and Maternal Transfer …….................................... 53

2.6.3 Enzyme Kinetic Parameter Determination and In vitro Biotransformation of

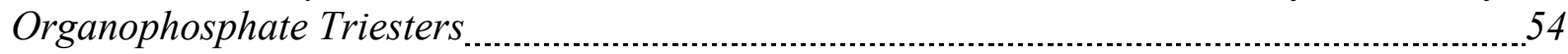

\section{Chapter 3}

Retrospective Analysis of Organophosphate Ester Flame Retardants in Herring Gull Eggs and Relation to the Aquatic Food Web in the Great Lakes .............................................55

3.1 Introduction $\ldots$

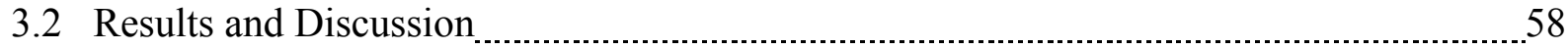

3.2.1 Spatial Distributions and Temporal Trends of OPEs in Herring Gull Eggs .....60

3.2.2 Dietary Shift Influences on OPE Exposure in Herring Gulls _.........................62 62

3.2.3 Herring Gull-Aquatic Food Web Relationships and OPE Concentrations _.......65

3.3 Conclusions

\section{Chapter 4}

Tissue Distribution and In Ovo Transfer of Organophosphate Ester Flame Retardants in Herring Gulls from the Great Lakes ...........................................................................74

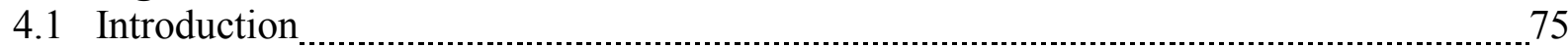

4.2 Results and Discussion

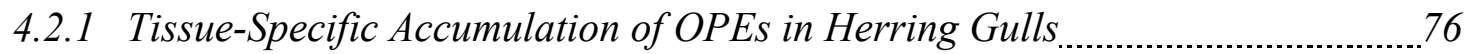

4.2.2 Burden Estimate of Organophosphate Ester Flame Retardants _....................... 86

4.3 Conclusions $\ldots$

\section{Chapter 5}

Metabolites of Organophosphate Ester Flame Retardants in the Blood Plasma of Herring Gulls from the North American Great Lakes

5.1 Introduction 91

5.2 Results and Discussion 


\section{Chapter 6}

Enzyme Kinetic Determination for the Metabolism of Organophosphate Triester Flame

Retardants in Herring Gull Liver Microsomes ...........................................................99

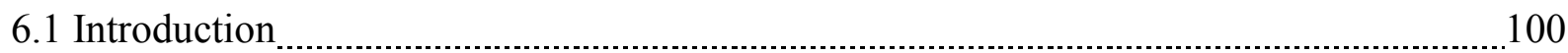

6.2 Results and Discussion ........................................................................................... 101

6.2.1 Microsomal Protein Content and Enzyme Catalytic Activity..........................101

6.2.2 Enzyme Kinetic Parameters $\left(V_{\max }\right.$ and $K_{M}$ ) for OP triesters in Gull Liver

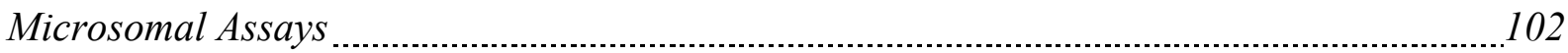

6.2.3 In Vitro OP Triester Metabolism and OP Diester Formation _....................... 106

6.3 Conclusions

\section{Chapter 7}

Conclusions, Implications and Future Directions,

7.1 Conclusions and Implications

7.2 Future Directions 


\section{LIST OF TABLES}

Table 2.1 Complete sampling list of all herring gull eggs $(n=10$ to 13 per site per year) collected from 5 colony nesting sites around the Great Lakes. All eggs at a given site for each collection year were combined into a pooled egg homogenate. For each year, $\square$ denotes the analysis of organophosphate flame retardants, and $\bullet$ denotes the analysis of stable isotopes 26

Table 2.2 Octanol-water partition coefficients $\left(\log \mathrm{K}_{\mathrm{OW}}\right)$ for all target organophosphate triesters in this thesis

Table 2.3 List of monitored ion transitions, retention times, and other operational details for all analyses performed via HPLC-ESI(+)-MS/MS, used in Chapters 3 and 4

Table 2.4 List of monitored ion transitions, retention times, and other operational details for all analyses performed via UPLC-ESI(+)-MS/MS, used in Chapter 6

Table 3.1: Mean organophosphate triester flame retardant (OPE) concentrations $(\mathrm{ng} / \mathrm{g} w w)$ in 2010-collected food web samples from western Lake Ontario and Lake Erie (see Figure 2.1 for sampling locations). Concentration ranges are given in parentheses. Whole body homogenates were analyzed, unless otherwise indicated 67

Table 3.2: Estimated trophic magnification factors (TMFs) of OPEs with $95 \%$ confidence intervals for Lake Ontario and Lake Erie food webs

Table 4.1 Mean ( \pm standard error) OPE concentrations across all herring gull tissues. For compounds detected in less than half of samples for a given tissue, concentration ranges are shown (min - max), with detection frequency $(\%)$ in brackets. All concentrations are given in ng/g wet weigh. 77

Table 4.2 Mean ( \pm standard error) OPE mass burdens across all herring gull tissues. All burdens are given in $\mathrm{ng}$ 
Table 5.1 Complete list of organophosphate (OP) flame retardant triester and OP diester concentrations (ng/g wet weight) in herring gull plasma samples $(n=6)$, collected from Chantry Island, Lake Huron, in April 2010

Table 6.1 Calculated Michaelis-Menton enzyme kinetic parameters for the metabolism of six organophosphate (OP) triesters in the herring gull liver microsomal assay. $\mathrm{V}_{\max }$ represents the maximal rate of OP triester metabolism for a saturated enzyme system. $\mathrm{K}_{\mathrm{M}}$ represents the OP triester concentration corresponding to $1 / 2$ of the $V_{\max }$ value. Triethyl phosphate (TEP) was not found to degrade. All errors are standard error.

Table 6.2 Summary of organophosphate ester (OPE) metabolism assays based on herring gull liver microsomes. Administered concentrations for each OP triester are given. All OP triester and diester concentrations are given at the 100 minute time points, and are an average of $\mathrm{n}=5$ replicate samples. All errors are given as standard errors. 107 


\section{LIST OF FIGURES}

Figure 1.1 General structures of an organophosphate (OP) triester and an OP diester. Hydrogens have been removed for clarity. $\mathrm{R}$ represents any hydrocarbon substituent.

Figure 1.2 Simplified schematic of the Great Lakes food web. Modified from NOAA (2015)

Figure 2.1 Herring gull colony sampling sites throughout the Great Lakes of North America. Colony names are as follows: 1, Agawa Rock (Lake Superior); 2, Gull Island (Lake Michigan); 3, Chantry Island (Lake Huron); 4, Fighting Island (mouth of Detroit River, Lake Erie); 5, Toronto Harbour (Lake Ontario). Aquatic food web sampling locations are also shown $(\bullet)$, namely Port Hope, Port Credit, and Niagara-on-the-Lake (Lake Ontario), and Dunkirk and the Western Basin (Lake Erie)

Figure 2.2 Chemical structures of all target organophosphate flame retardants (triesters and diesters) in this thesis. Compounds are as follows: (A) tris(2-chloroethyl) phosphate (TCEP); (B) tris(2-butoxyethyl) phosphate (TBOEP); (C) tris(2-chloroisopropyl) phosphate (TCIPP); (D) tris(1,3-dichloro-2-propyl) phosphate (TDCIPP); (E) triphenyl phosphate (TPHP); (F) tris(2,3dibromopropyl) phosphate (TDBPP); (G) tri-n-butyl phosphate (TNBP); (H) trimethylphenyl phosphate (TMPP); (I) 2-ethylhexyl-diphenyl phosphate (EHDPP); (J) tris(2-bromo-4methylphenyl) phosphate (T2B4MPP) / tris(4-bromo-3-methylphenyl) phosphate (T4B3MPP) / tris(3-bromo-4-methylphenyl) phosphate (T3B4MPP); (K) tripropyl phosphate (TPP); (L) tris(2ethylhexyl) phosphate (TEHP); (M) triethyl phosphate (TEP); (N) 2,2-bis(chloromethyl)propane1,3-diyltetrakis(2-chloroethyl) bisphosphate (V6); (O) bis(1-chloro-2-propyl) phosphate (BCIPP); (P) bis(2-butoxyethyl) phosphate (BBOEP); (Q) di(2-ethylhexyl) phosphate (DEHP); (R) diphenyl phosphate (DPHP); (S) di-n-butyl phosphate (DNBP); (T) bis(1,3-dichloro-2propyl) phosphate (BDCIPP). Hydrogen atoms have been omitted for clarity. 31

Figure 2.3 Schematic flow diagram of the sample extraction, clean-up and instrumental analysis of organophosphate (OP) diesters. 34

Figure 2.4 Schematic for the preparation of herring gull liver microsomes 45 
Figure 3.1: Temporal changes of $\Sigma \mathrm{OPE}$ concentrations (ng/g ww) in herring gull egg pool homogenates from five colony sites in the Laurentian Great Lakes of North America

Figure 3.2: Temporal changes of $\delta^{13} \mathrm{C}$ (circles) and $\delta^{15} \mathrm{~N}$ (squares) from 1981 to 2008 across five colony sites from the Great Lakes. The left axes represent $\delta^{15} \mathrm{~N}$ levels, and the right axes represent $\delta^{13} \mathrm{C}$ levels

Figure 3.3 Principal component analysis (PCA) showing variation of OPE concentrations and stable isotope levels among biota and plankton from the Lake Ontario food webs. Top: loading plot showing the relationship between variables and the two principal components. Bottom: score plot showing species differences among the two principle components: (1) plankton; (2) mysis; (3) herring gull egg; (4) round goby; (5) rainbow smelt; (6) slimy sculpin; (7) lake trout; (8) deepwater sculpin; (9) alewife. All variables have been autoscaled to ensure normalization. Error bars represent standard error 70

Figure 3.4 Principal component analysis showing variation of OPE concentrations and stable isotope levels among the Lake Erie food web. Top: loading plots showing the relationship between variables and the two principal components. Bottom: Score plots showing species differences among the two principal components. All variables have been autoscaled to ensure normalization. Error bars represent standard errors

Figure 4.1 Percent proportions of the arithmetic mean $\Sigma$ OPE concentrations for each tissue $(\mathrm{n}=$ 16 for yolk and albumen, $\mathrm{n}=8$ for all other tissues)

Figure 4.2 Principle Components Analysis (PCA) of the ratios of individual OPE to $\Sigma$ OPE concentrations and showing the first and second principle components; PC 1 and PC 2 (top). Mean ( \pm standard error) factor scores for all tissues are shown in the bottom plot. Variability associated with PC 1 and PC 2 are given

Figure 4.3 Example correlations between the bioconcentration factors (BCFs) of detected OPEs and their concentrations in a given herring gull tissue. The example provided is in yolk. Statistically significant relationships were observed in yolk and albumen, but not in any other tissue 
Figure 4.4 Combined arithmetic mean ( \pm standard error) OPE burdens for the egg (yolk and albumen), and maternal body (fat, muscle, red blood cells, plasma, liver and brain)

Figure 5.1 Extracted ion chromatograms of the detected BBOEP in plasma of Herring Gull \#2 (Table 5.1) by use of LC-ESI(+)-MS/MS (A), LC-ESI(-)-MS/MS (B) and LC-ESI(-)-Q-ToF-MS (C). The concentration of the spiked internal standard in A and $\mathrm{B}, \mathrm{d}_{4}-\mathrm{BBOEP}$, was $20 \mathrm{ng} / \mathrm{mL}$. For comparison, the concentration of BBOEP in $\mathrm{C}$ was $500 \mathrm{ng} / \mathrm{mL}$. The structures of TBOEP and BBOEP are provided, and where the hydrogen atoms are omitted for clarity. 95

Figure 6.1 Lineweaver-Burk plots generated for all enzyme kinetic 2-minute incubation assays 104

Figure 6.2 Depletion of OP triesters (blue) and formation of OP diesters (red) over a 100 minute assay with herring gull liver microsomes. Error bars represent the standard error of 5 replicate assays. 108

Figure 6.3 Specific rates of enzyme-mediated depletion of organophosphate (OP) triesters. The upper and lower bounds of the boxes represent the 75 th and 25 th percentiles, respectively. The middle line in the box represents the median, and the error bars represent the minimum and maximum values. 109

Figure 6.4 In vitro organophosphate (OP) triester metabolism in herring gull liver microsomes over a $100 \mathrm{~min}$ incubation period. Error bars represent standard error. 110 


\section{LIST OF ABBREVIATIONS:}

\begin{tabular}{|c|c|}
\hline ANOVA & Analysis of Variance \\
\hline ASE & Accelerated solvent extraction \\
\hline BBOEP & Bis(2-butoxyethyl) phosphate \\
\hline BCEP & Bis(2-chloroethyl) phosphate \\
\hline BCIPP & Bis(1-chloro-2-propyl) phosphate \\
\hline BDCIPP & Bis(1,3-dichloro-2-propyl) phosphate \\
\hline BSA & Bovine serum albumin \\
\hline $\mathrm{CEH}$ & Chicken embryonic hepatocyte \\
\hline CYP & Cytochrome P450 \\
\hline$\delta^{15} \mathrm{~N}$ & Ratio of stable isotopes ${ }^{15} \mathrm{~N}:{ }^{14} \mathrm{~N}$ \\
\hline$\delta^{13} \mathrm{C}$ & Ratio of stable isotopes ${ }^{13} \mathrm{C}:{ }^{12} \mathrm{C}$ \\
\hline DCM & Dichloromethane \\
\hline DEHP & Di(2-ethylhexyl) phosphate \\
\hline DNBP & Di-n-butyl phosphate \\
\hline DPHP & Diphenyl phosphate \\
\hline $\mathrm{ECCC}$ & Environment and Climate Change Canada \\
\hline EHDPP & 2-ethylhexyl-diphenyl phosphate \\
\hline EIL & Environmental Isotope Laboratory \\
\hline EROD & Ethoxyresorufin-O-deethylase \\
\hline ESI & Electrospray Ionization \\
\hline FR & Flame retardant \\
\hline GLHGMP & Great Lakes Herring Gull Monitoring Program \\
\hline HBCDD & Hexabromocyclododecane \\
\hline HPLC & High-performance liquid chromatography \\
\hline IS & Internal standard \\
\hline $\mathrm{K}_{\mathrm{M}}$ & Michaelis constant \\
\hline$K_{O W}$ & Octanol-water partition coefficient \\
\hline lw & Lipid weight \\
\hline $\mathrm{MeOH}$ & Methanol \\
\hline MLOQ & Method limit of quantification \\
\hline $\mathrm{MS} / \mathrm{MS}$ & Tandem mass spectrometry \\
\hline NADPH & Nicotinamide adenine dinucleotide phosphate \\
\hline NWRC & National Wildlife Research Centre \\
\hline OCRL & Organic Contaminants Research Laboratory \\
\hline OPE & Organophosphate ester \\
\hline$p$-value & Statistical significance level \\
\hline PBDE & Polybrominated diphenyl ether \\
\hline $\mathrm{PC}(\mathrm{A})$ & Principle component (analysis) \\
\hline PCB & Polychlorinated biphenyls \\
\hline
\end{tabular}




\begin{tabular}{ll} 
QA/QC & Quality Assurance/Quality Control \\
$r$-value & Pearsons' product-moment correlation coefficient \\
S9 & Cellular fraction containing Phase I and Phase II enzymes \\
SD & Standard deviation \\
SE & Standard error \\
SI & Stable isotope \\
SPE & Solid-phase extraction \\
T2B4MP & Tris(2-bromo-4-methylphenyl) phosphate \\
T $_{3}$ & Triiodothyronine \\
T3B4MP & Tris(3-bromo-4-methylphenyl) phosphate \\
T $_{4}$ & Thyroxine \\
T4B3MP & Tris(4-bromo-3-methylphenyl) phosphate \\
TBOEP & Tris(2-butoxyethyl) phosphate \\
TCEP & Tris(2-chloroethyl) phosphate \\
TCIPP & Tris(2-chloroisopropyl) phosphate \\
TDBPP & Tris(2,3-dibromopropyl) phosphate \\
TDCIPP & Tris(1,3-dichloro-2-propyl) phosphate \\
TEHP & Tris(2-ethylhexyl) phosphate \\
TEP & Triethyl phosphate \\
TMPP & Trimethylphenyl phosphate \\
TNBP & Tri-n-butyl phosphate \\
TPHP & Triphenyl phosphate \\
TPP & Tripropyl phosphate \\
UPLC & Ultra-performance liquid chromatography \\
V6 & 2,2 -bis(chloromethylpropane-1,3-diyl tetrakis(2- \\
chloroethyl)bis(phosphate) & \\
$V_{\text {max }}$ & Maximal biotransformation rate for a saturated system \\
$v_{0}$ & Initial rate of reaction \\
ww & Wet weight \\
\hline
\end{tabular}




\section{LIST OF APPENDICES}

Appendix 1 OPE concentrations (ng/g ww) among all herring gull pooled egg homogenates from five colonial nesting sites in the Laurentian Great Lakes between 1990 and 2010. 138

Appendix 2 Stable isotope analysis data for herring gull pooled egg homogenates from five colonial nesting sites in the Laurentian Great Lakes between 1981 and 2008

Appendix 3 OPE concentrations (ng/g ww) in food webs from Lake Erie and Lake Ontario collected in 2010 


\section{CHAPTER 1 \\ General Introduction ${ }^{1}$}

\footnotetext{
${ }^{1}$ Publication Associated with this Thesis Chapter:

A.K. Greaves, R.J. Letcher. 2016. Bulletin of Environmental and Chemical Toxicology, Accepted.
} 
In Canada alone, 42,753 residential and commercial fires were reported in 2007, causing 224 civilian deaths, two firefighter deaths, and $\$ 1,551,657,179$ in direct property damage (CFMFC, 2011). Furniture, clothing and bedding are often the three materials reported to catch fire first, which has been made worse in recent years due to the use of more combustible synthetic fibers and fabric blends. Over the last 40 years, the average escape time has decreased from 17 minutes (in 1975) to as little as 3 minutes (CEFIC, 2012). Efforts have been made to reduce the spread of fires over the last few decades and increase the average escape time. In 1975, California implemented Technical Bulletin 117, which required furniture filled with polyurethane foam to be able to withstand small flames for up to 12 seconds (Shaw et al., 2010). Since then, the use of flame retardants has become common practice to meet flammability standards in textiles, furniture, electronics, and insulation.

Organophosphate esters (OPEs) are a large group of chemicals that have been used for decades as flame retardants (FRs) and plasticizers in various consumer products, such as plastics, textiles, electronics and many others materials (van der Veen and de Boer, 2012). Furthermore, non-halogenated OPEs are additionally used as plasticizers and lubricants (Andersen et al., 2004). Although mainly halogenated OPEs have been used as FRs in modest amounts as far back as the 1960 s, it has primarily been the phase-out of the more popular polybrominated diphenyl ethers (PBDEs) that has caused the production volumes and usage of OPEs to increase substantially in the last 15 years. Worldwide OPE production volumes increased from approximately 100,000 tonnes per year in 1992 to 341,000 tonnes per year in 2007. Furthermore, North American annual production of tris(2-chloroisopropyl) phosphate (TCIPP), tris(1,3dichloro-2-propyl) phosphate (TDCIPP), and tris(2-chloroethyl) phosphate (TCEP) increased from less than 14,000 tonnes per year in 1986 to 38,000 tonnes per year in 2012 (Schreder et al., 
2016). Multiple government agencies and regulatory bodies expressed the benefits of using OPEs over PBDEs, since initial testing found that OPEs are much less persistent in the environment than PBDEs, and produce less noxious gases during a fire. As a result, OPEs are now currently found in a wide variety of applications, including as plasticizers, as antifoaming agents in floor polishes, glue, lubricants, lacquers, and hydraulic fluids, and as FRs in plastics,

electronic equipment, furniture, textiles, and building materials (Salamova et al., 2014).

\subsection{Organophosphate Esters}

OPEs have a central phosphate molecular group. In the case of organophosphate (OP) triesters, these are three ester bonds with alkyl or aromatic substituents. Often the three substituents are identical, though not always. OP diesters differ from triesters in that one of the alkyl ester groups is replaced by a hydroxyl group and thus OP diesters are phosphoric acids. A generic structure of an OP triester and an OP diester is provided in Figure 1.1. 


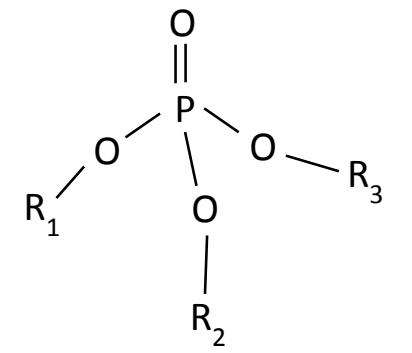

Native OPE (i.e., OP Triester)

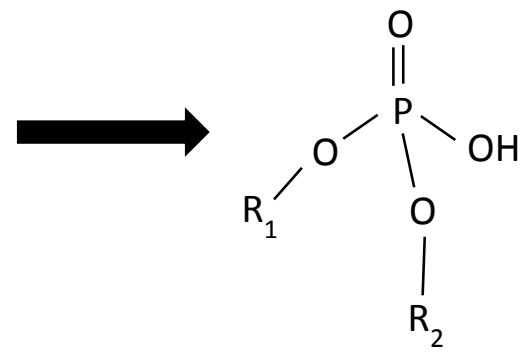

OPE Metabolite (i.e., OP Diester)

Figure 1.1 General structures of an organophosphate (OP) triester and an OP diester. R represents a given hydrocarbon substituent.

When used as a flame retardant, OPEs are used as additive flame retardants, meaning that they are not chemically bound to their products. In the event of a fire, solid materials are decomposed into flammable gases, which ignite. OPEs decompose via the heat in one of two ways. Non-halogenated OPEs react mainly in the solid phase of burning materials. The phosphorous compounds, when heated, react to form a polymeric form of phosphorous acid. This acid causes a char layer, shielding the burning material from oxygen, and thus slowing the reaction (van der Veen and de Boer, 2012). Halogenated OPEs will also cause a char layer on the burning materials, but will additionally decompose to react in the gas phase. Liberated bromine and chlorine atoms react with hydrogen $\left(\mathrm{H}^{*}\right)$ and hydroxide $\left({ }^{\circ} \mathrm{OH}\right)$ radicals to further slow the burning process, reducing the spread of the fire (van der Veen and de Boer, 2012). The effectiveness of the OPE increases with increasing numbers of halogen atoms in the molecule. 


\subsubsection{Physicochemical Properties of OPEs}

Due to the varying nature of the substituents, OPEs have a wide range of physical and chemical properties, ranging from very polar to very hydrophobic. For example, octanol-water partition coefficients ( $\log K_{\mathrm{OW}}$ ) range from -9.8 to 10.6 (van der Veen and de Boer, 2012). However, most popular-use OPEs have $\log K_{\mathrm{OW}}$ values between 1 and 5, indicating that they are more lipophilic than hydrophilic (Chu and Letcher 2015; Eulaers et al., 2014).

Differences in size and polarity of OPEs have large influences on their physicochemical properties. In general, $\log K_{\mathrm{OW}}$ values increase with increasing molecular weight, as do bioconcentration factors (i.e., the ratio of a chemical's concentration in biota to its concentration in water). Inversely, solubility decreases with increasing molecular weight, with the exception of halogenated OPEs, for which no relationship has been observed (van der Veen and de Boer 2012). OPEs are generally quite stable in water, though susceptible to microbial degradation. Saeger et al. (1979) showed a complete lack of OPE degradation in heat-sterilized water samples from the Mississippi river, while complete primary degradation of tri-n-butyl phosphate (TNBP),

trimethylphenyl phosphate (TMPP), and triphenyl phosphate (TPHP) was observed within 7 days in non-treated water samples (Sundkvist et al., 2010).

\subsubsection{Qualitative and Quantitative Analytical Determination of OPEs}

Multiple analytical methods for the determination of OP triesters, OP diesters, and other OPE metabolites have emerged over the last 10 years, particularly pertaining to the analysis of 
biological samples. Early methods quantified OP triester concentrations in human plasma, human urine, and biota samples including muscle and liver from fish and birds (Shah et al., 2006; Schindler et al., 2009; Green et al., 2008; Evenset et al., 2009). These methods often relied on quantification via gas chromatography-mass spectrometry (GC-MS) analysis, which resulted in fairly high limits of detection (LOD), particularly for biota samples. For example, LODs of OP triesters ranged from $5-40 \mathrm{ng} / \mathrm{g}$ ww in blue mussel and cod liver samples from Norway (Green et al., 2008). Recently, more sensitive analytical methods involving liquid chromatography-tandem mass spectrometry (LC-MS/MS) have been developed and applied primarily to fish, bird, and mammal samples (Chu et al., 2011; Su et al., 2014; Chu and Letcher, 2015; van den Eede et al., 2013a,b; Ma et al., 2013; Chen et al., 2012). For example, Chen et al. (2012) developed a method for the quantification of 12 OPEs in chicken and herring gull egg homogenate using accelerated solvent extraction (extraction), followed by solid phase extraction (cleanup), and finally HPLC-MS/MS analysis (quantification). Method limits of quantification (MLOQs) for all OPEs were quite low, ranging from $0.06 \mathrm{ng} / \mathrm{g}$ ww (TDCIPP) to $0.20 \mathrm{ng} / \mathrm{g}$ ww (TCIPP).

Although the quantification of OP triesters has been somewhat common over the last 10 years, it is only in the last few years that methods have been developed to qualify and quantify OPE metabolites in biological samples. Chu et al. (2011) developed a method for the quantification of five OP diesters via LC-MS/MS, and applied the method to analyze the in vitro biotransformation of TDCIPP to its diester bis(1,3-dichloro-2-propyl) phosphate (BDCIPP) in Wistar-Han rat liver micrsomes. van den Eede et al. (2013b) qualitatively identified the metabolites of five OPEs through LC-quadrupole-time-of-flight-MS/MS after an in vitro incubation with human liver S9 and microsomal fractions. Very recently, Su et al. (2014) 
developed a method for the quantification of six OP diesters in biota samples using accelerated solvent extraction (extraction), followed by weak anion exchange solid phase extraction (cleanup), and finally HPLC-MS/MS analysis (quantification). This method was the first method to successfully quantify OP diester concentrations in biota tissue samples, and was proven effective for analyzing bovine serum, chicken egg homogenate, and pork liver.

\subsection{Global Distribution of OPEs}

\subsubsection{Distribution of OPEs in the Environment}

Studies characterizing OPE concentrations in abiotic compartments are growing in number. Salamova et al. (2014) recently measured OPE atmospheric concentrations in the particle phase for air samples taken from the Laurentian Great Lakes. Total OPE atmospheric concentrations ranged from 120 to $2100 \mathrm{pg} / \mathrm{m}^{3}$ at the five sites sampled, with higher OPE concentrations at urban sites (i.e., Cleveland and Chicago). Concentrations at these urban sites were dominated by chlorinated OPEs (i.e., tris(2-chloroethyl) phosphate (TCEP), TCIPP, TDCIPP), whereas concentrations at remote sites were dominated by non-halogenated OPEs. Green et al. (2008) similarly found chlorinated OPEs to be most present in urban air samples, when analyzing samples from Oslo, Norway. OPEs have been detected in air as far away as Antarctica, with concentrations around $1 \mathrm{ng} / \mathrm{m}^{3}$, indicating their persistence in air, and their potential for long-range transport (Ciccioli et al., 1994; Salamova et al., 2014).

OPEs appear to be ubiquitous in water samples across the Northern Hemisphere. OPEs were recently detected in water from the Laurentian Great Lakes (Venier et al., 2014). Samples were analyzed for TNBP, TCEP, TCIPP, TDCIPP, TPHP and tris(2-butoxyethyl) phosphate 
(TBOEP), and all six triesters were detected at all sampling sites. TBOEP and TCIPP were the most present at all sites, with $\Sigma$ OPE concentrations ranging from $7.3 \pm 4.5 \mathrm{ng} / \mathrm{L}$ (Lake Huron) to 95.9 $\pm 43.5 \mathrm{ng} / \mathrm{L}$ (Lake Erie). OPEs have also been detected in remote lakes in central Italy, with highest concentrations of TNBP and tripropyl phosphate (TPP) (annual peaks of 784 and 951 ng/L, respectively) (Bacaloni et al., 2008). River water from Germany, Austria, and Spain have been analyzed for OPEs, with TBOEP and TCIPP consistently being present at highest concentrations (Cristale et al., 2013; Martinez-Carballo et al., 2007; Andresen et al., 2004; Fries and Püttmann, 2003).

Similarly, TBOEP and TCIPP are consistently found at the highest concentrations in wastewater influent at wastewater treatment plants (WWTPs) across Europe, Australia, and the United States (Martinez-Carballo et al., 2007; Bester, 2005; Rodil et al., 2005; Green et al., 2008; Marklund et al., 2005; Meyer and Bester, 2004; O'Brien et al., 2015; Stackelberg et al., 2004). TBOEP concentrations at WWTPs ranged from $950 \mathrm{ng} / \mathrm{L}$ (Austria) to 12,800 ng/L (Sweeden), while TCIPP concentrations ranged from $520 \mathrm{ng} / \mathrm{L}$ (Germany) to 4,000 ng/L (Sweeden). In general, WWTPs tend to not remove chlorinated OPEs, while alkyl-OPEs such as TNBP are more successfully removed. It is estimated that $49 \%$ of the OPEs to reach WWTPs will get degraded, $50 \%$ of the OPEs gets emitted in wastewater effluent, and $1 \%$ ends up in sludge (Marklund et al., 2005). Therefore, although 50\% of OPEs are removed from wastewater via WWTP processing, it is clear that large quantities of OPEs enter the aquatic ecosystem via WWTPs, stemming from OPEs found in indoor environments.

Since OPEs are added to consumer products to reduce flammability, it is logical that OPE concentrations in indoor environments are quite high. A number of studies have emerged in recent years documenting OPE concentrations in house dust from North America and Europe 
(Stapleton et al., 2009; Ingerowski et al., 2001; van den Eede et al., 2011; Meeker and Stapleton 2010). TDCIPP, TCIPP, TBOEP, and TPHP were the major OPEs detected, with maximal mean concentrations of $1890,4820,6580$, and $7360 \mathrm{ng} / \mathrm{g}$, respectively. TDCIPP was the most commonly detected flame retardant found in polyurethane foam collected from American baby products (Stapleton et al., 2011). Similarly, 26 foam samples from American furniture were analyzed for OPEs, with TDCIPP being found in 15 of the samples (1-5\% by weight) and TCIPP being found in four of the samples $(0.5-2.2 \%$ by weight) (Stapleton et al., 2009).

\subsubsection{Distribution of OPEs in Biota With an Emphasis on Birds}

Although a great number of studies have explored OPE concentrations in abiotic compartments, studies examining OPE concentrations in biota have only started emerging in the last few years. One of the earliest wildlife studies to examine OPE concentrations in an avian species was done by Evenset et al. (2009) who examined kittiwake and common eider livers from Svalbard. Concentrations were generally low, with 2-ethylhexyl-diphenyl phosphate (EHDPP; 6 to $28 \mathrm{ng} / \mathrm{g}$ ww), TPHP (0.9 to $3.3 \mathrm{ng} / \mathrm{g} \mathrm{ww}$ ), and TCEP and TCIPP (n.d. to $4.7 \mathrm{ng} / \mathrm{g}$ ww) being the only OPEs detected. Additional avian studies have emerged from Norway, examining blood plasma and feathers from white-tailed eagle nestlings, and eggs from great black-backed gulls, shags, common eiders, and white-tailed eagles (Eulaers et al., 2014; Leonards et al., 2011). Six OPEs were detected in feathers from white-tailed eagle nestlings, although only TCIPP and TDCIPP were detected in blood plasma $(0.2 \mathrm{ng} / \mathrm{g}$ ww), suggesting atmospheric deposition of OPEs onto their feathers (Eulaers et al., 2014). In general, OPE concentrations in Norwegian avian eggs were below the limit of detection (Leonards et al., 
2011). Similarly, common tern eggs from the Western Scheldt (Netherlands) also contained no quantifiable amounts of OPEs (Brandsma et al., 2015). In North America, herring gull eggs have been analyzed recently from various locations among the Great Lakes. TCIPP, TBOEP, and TCEP were typically found at highest concentrations, and $\Sigma$ OPE concentrations ranged from 0.31 to $2.14 \mathrm{ng} / \mathrm{g}$ ww (Chen et al., 2012; Su et al., 2015a). From these studies, it is clear that OPE accumulation in avian species is quite low. The pharmacokinetic behaviour of OPEs in the (avian) body is still poorly understood. Studying the behaviour of OPEs in an avian species is highly warranted to properly assess accumulation potential and toxicity concerns.

Most studies to have analyzed OPE concentrations in biota have analyzed fish. Kim et al. (2011) analyzed OPE concentrations in 19 species of fish from Manila Bay, Philippines. $\Sigma$ OPE concentrations were much higher for benthic fish (1900 ng/g lw) than for pelagic fish (100 ng/g lw), suggesting that the biomagnification potential of OPEs is quite low. In Norway (including Svalbard), liver samples from cod, burbot, and trout primarily contained TCEP, TCIPP, TPHP, and EHDPP (Leonards et al., 2011; Green et al., 2008; Evenset et al., 2009). In Canada, whole body homogenates of lake trout and walleye were collected from multiple lakes including Lake Ontario and Lake Erie (McGoldrick et al., 2014a), and found to consistently contain TCEP and TBOEP ( $\Sigma$ OPEs n.d. to $9.8 \mathrm{ng} / \mathrm{g} \mathrm{ww}$ ). Levels of TBOEP were highest in fish from the Great Lakes region, while TCEP was only detected in fish from northern Saskatchewan, Northwest Territories, and Yukon.

A handful of studies have also emerged examining OPE concentrations in human fluids including urine, breast milk, and blood. In general, OPEs were not detected in blood samples, while TCIPP (22 to $82 \mathrm{ng} / \mathrm{g} \mathrm{lw}$ ) and TNBP (10 to $57 \mathrm{ng} / \mathrm{g}$ lw) were present at highest concentrations in breast milk samples (Shah et al., 2006; Sundkvist et al., 2010). OP triesters 
were not detected in human urine samples, although OP diesters including bis(1,3-dichloro-2propyl) phosphate (BDCIPP), bis(2-chloroethyl) phosphate (BCEP), and diphenyl phosphate (DPHP) were detected (Cooper et al., 2011; van den Eede et al., 2013a; Schindler et al., 2009; Meeker et al., 2013).

\subsubsection{Distribution of OPEs in the Great Lakes of North America}

A limited number of studies have emerged in recent years detailing OPE levels in the Great Lakes of North America. Salamova et al. (2014) recently analyzed air particle phase samples for 12 OPEs at 5 different sites along the Great Lakes. Higher $\Sigma$ OPE concentrations

were seen at urban sites ( $\mathrm{COPE}$ range 1500 to $2100 \mathrm{pg} / \mathrm{m}^{3}$ ), and were more heavily dominated by chlorinated OPEs such as TCEP, TCIPP, and TDCIPP, compared to rural sites ( $\Sigma$ OPE range 120 to $340 \mathrm{pg} / \mathrm{m}^{3}$ ). On average, the $\Sigma \mathrm{OPE}$ concentrations were $2-3$ orders of magnitude higher than concentrations of brominated flame retardants measured in similar air particle phase samples (Salamova et al., 2014). Similarly, water samples from the Great Lakes showed higher $\Sigma$ OPE concentrations at urban sites compared to remote sites $(93.9 \pm 43.5 \mathrm{ng} / \mathrm{L}$ vs. $7.3 \pm 4.5 \mathrm{ng} / \mathrm{L}$, respectively) (Venier et al., 2014). Furthermore, $\Sigma$ OPE concentrations in water samples were on average $2-4$ orders of magnitude higher than concentrations of brominated flame retardants such as PBDEs and hexabromocyclododecane (HBCDD). From these studies, it is clear that OPE concentrations in both air and water samples from the Great Lakes are often orders of magnitude higher than other flame retardants, and that concentrations are largely dependent on sampling location, with higher concentrations in more urban, polluted locations. 
Limited studies have been published concerning OPE concentrations in wildlife and fish from the Great Lakes. Chen et al. (2012) quantified OPE concentrations in herring gull eggs from a colonial nesting site from Lake Huron. In general, only TCIPP, TCEP, and TBOEP were quantified, and at levels at or close to the method limit of quantification $(<\mathrm{MLOQ}-4.1 \mathrm{ng} / \mathrm{g} \mathrm{ww}$, $<$ MLOQ $-0.6 \mathrm{ng} / \mathrm{g} \mathrm{ww}$, and $<\mathrm{MLOQ}-2.2 \mathrm{ng} / \mathrm{g} \mathrm{ww}$, respectively). Similarly, Su et al. (2015a) recently analyzed herring gull eggs from five colonial nesting sites across the Great Lakes for a large suite of OPEs, as well as other classes of legacy and replacement flame retardants. In general, nine OPEs were detected in at least one sample, although TCEP and TNBP were the only OPEs to be quantified in more than $45 \%$ of samples. $\Sigma$ OPE concentrations were generally low across all sites, ranging from $0.31-2.14 \mathrm{ng} / \mathrm{g}$ ww. Unlike trends in air and water samples, $\Sigma$ OPE concentrations in herring gull eggs were determined to be 2 to 3 orders of magnitude lower than $\Sigma$ PBDE concentrations, likely indicating that OPEs have a much lower potential for bioaccumulation compared to PBDEs. Finally, in the only reported study on OPE levels in fish from the Great Lakes, McGoldrick et al. (2014a) analyzed lake trout and walleye whole body homogenates from five sampling locations throughout Lake Ontario and Lake Erie. In general, only TBOEP (n.d. $-4.2 \mathrm{ng} / \mathrm{g} \mathrm{ww}$ ) and TCEP (n.d. $-1.4 \mathrm{ng} / \mathrm{g} \mathrm{ww}$ ) were consistently detected. From these limited studies, it is clear that despite high concentrations in water and air samples from the Great Lakes, wildlife and fish contain surprisingly low concentrations of OPEs. It was hypothesized by McGoldrick et al. (2014a) that the low OPE concentrations were the result of rapid metabolism in vivo. 


\subsection{OPEs in the Body: Absorption, Distribution, Metabolism, and Excretion}

\subsubsection{Absorption, Distribution and Excretion}

Absorption of OPEs into the body from the environment has been shown to occur through the skin, as well as through the intestine (Kurebayashi et al., 1985; Nomeir et al., 1981). Nomeir et al. (1981) exposed male Sprague-Dawley rats to ${ }^{14} \mathrm{C}$-TDCIPP via oral administration. The ${ }^{14} \mathrm{C}$-TDCIPP was rapidly distributed to the kidneys, liver, and lungs. Within 24 hours, more than $80 \%$ of the ${ }^{14} \mathrm{C}$ was excreted either in urine, feces, or expired air. Similarly, Kurebayashi et al. (1985) exposed male Wistar rats to ${ }^{14} \mathrm{C}$-TMPP via oral administration. The ${ }^{14} \mathrm{C}$-TMPP was rapidly distributed to fatty tissues including adipose, kidneys and liver. The majority of the ${ }^{14} \mathrm{C}$ was excreted within 7 days in urine or feces $(85 \%)$, although some ${ }^{14} \mathrm{C}$ was also excreted via exhaled air and bile. Apart from limited rodent studies, general information on OPE distribution and accumulation in the body is lacking.

\subsubsection{Metabolism}

The metabolism of OPEs, both in vivo and in vitro, has been loosely investigated both in the 1980s and in recent years. In the 1980s, it was generally found that OPEs are subject to rapid metabolism, with NADPH being crucial to the reaction. Sasaki et al. (1984) investigated in vitro OP triester metabolism in rat liver microsomes, and found that TNBP was the most rapidly metabolized, followed by TPHP and TDCIPP. TCEP showed minimal degradation in rat liver microsomes. Recently, rapid degradation of TPHP $(10 \mu \mathrm{M})$ was observed in chicken embryonic hepatocytes, with only $0.2 \%$ of the original administered dose remaining after 36 hours (Su et al., 2014a). Similarly, chemical analysis of chicken egg contents after injection of TCIPP (51 600 
$\mathrm{ng} / \mathrm{g}$ ) or TDCIPP (50 $200 \mathrm{ng} / \mathrm{g}$ ) showed that more than $92 \%$ of the administered dose was detectable at day 5 of incubation, but less than 1\% was detectable by day 19 (Farhat et al., 2013). In all of these cases, the enzyme kinetics of these reactions, including quantifiable reaction rates, were not investigated, nor were the enzymes responsible for the metabolism identified.

The detection of OP triester metabolites has been investigated, with increasing success in recent years. OP triester metabolites have been majorly identified as a combination of their respective diesters and a variety of hydroxylated products. TNBP has been found to get majorly metabolized to TNBP-OH, which is then further metabolized into TNBP-(OH $)_{2}$, or di-n-butyl phosphate (DNBP; Sasaki et al., 1984). Su et al. (2014a) recently found that diphenyl phosphate (DPHP) accounted for 17\% of the TPHP metabolized in dosed chicken embryonic hepatocytes, whereas OH-TPHP accounted for another 20\%. van den Eede et al. (2013b) investigated the metabolites of TPHP, TDCIPP, TCEP and TCIPP in human liver S9 fraction and microsomes and found that TPHP was mainly transformed to DPHP, TDCIPP was majorly transformed to BDCIPP and a glutathione S-conjugate, TCEP was poorly metabolized to bis(2-chloroethyl) phosphate (BCEP), and TCIPP primarily underwent oxidative dehalogenation.

\subsection{Toxicity of OPEs}

Differences in size and polarity of OPEs can have a large influence on physical and biochemical toxicity (Schindler et al., 2009). The chemical structures of OP triesters used as flame retardants and plasticizers are inherently similar to those of OP insecticides, which are designed to affect the nervous system of insects (Sundkvist et al., 2010). TCEP, TPHP and TDCIPP have been shown to cause deformation of the spine in killifish and zebrafish larvae 
(Sasaki et al., 1981; Wang et al., 2013). TDCIPP has been shown to cause decreased fecundity in Daphnia magna, as well as dose-dependent developmental toxicity in zebrafish embryos and larvae, including decreased body weight, reduced hatching and survival rates, and reduced heartbeat rates (Li et al., 2015; Wang et al., 2013; Liu et al., 2013; Zhu et al., 2015). TMPP decreased sperm density and sperm motility in both rats and mice, and TCEP decreased sperm motility in rats, and testis weight in mice (Morrissey et al., 1988). TBOEP, TNBP, TCIPP, and TDCIPP have all been shown to be skin irritants, and TPHP has been shown to cause contact dermatitis (Sundkvist et al., 2010; Camarasa et al., 1992; van der Veen and de Boer, 2012).

A multitude of studies have shown the wide ranging biochemical effects of OPEs. TCEP, TDCIPP, and TCIPP are all suspected carcinogens (van den Eede et al., 2013a; Ni et al., 2007; Chapin et al., 1997), while TDCIPP, ortho-containing TMPP isomers, TPHP, and TNBP have all been shown to be, or suspected of being neurotoxic (Martinez-Carballo et al., 2007; Ni et al., 2007; Pakalin et al., 2007, Dishaw et al., 2011; van der Veen and de Boer, 2012; Flaskos et al., 1998). Disturbance of thyroid hormone signaling is a common adverse outcome for both avian and piscivorous species following exposure to OPEs. TDCIPP exposure significantly decreased whole-body concentrations of the thyroid hormone thyroxine $\left(\mathrm{T}_{4}\right)$, and increased whole-body triiodothyronine $\left(\mathrm{T}_{3}\right)$ levels in zebrafish embryos (Wang et al., 2013). Additionally, treatment with TDCIPP significantly increased the transcription of genes involved in thyroid hormone synthesis and thyroid development. Similarly, TDCIPP significantly reduced plasma $\mathrm{T}_{4}$ levels in chicken embryos, while TCIPP downregulated the genes responsible for the $\mathrm{T}_{4}$ carrier, transthyretin (Farhat et al., 2013; Crump et al., 2012). Finally, OPEs have been shown to alter mRNA levels for multiple cytochrome (CYP) P450 genes associated with phase I and phase II 
metabolism, lipid regulation, and growth in avian hepatocytes (Crump et al., 2012; Porter et al., 2014; Su et al., 2014a).

\subsection{The Laurentian Great Lakes of North America}

The Laurentian Great Lakes of North America is a network of five interconnected freshwater lakes in northeastern North America, along the border between Canada and the United States. The Great Lakes (consisting of Lake Ontario, Lake Erie, Lake Michigan, Lake Huron and Lake Superior) form the largest group of freshwater lakes in the world, spanning

close to $250000 \mathrm{~km}^{2}$, and containing 84\% of North America's surface fresh water (EPA, 2015).

The Lakes' fauna is quite diverse. Mammals include gray wolf, Canada lynx, moose, beaver, river otter and coyote, among others. Birds include herring gull, common loon, bald eagle, double-crested cormorant and common tern. The Great Lakes are also home to a wide range of fish, some native to the area (e.g., brook trout, burbot, deepwater sculpin, slimy sculpin, emerald shiner, lake trout, freshwater drum, lake whitefish, largemouth bass, walleye, yellow perch), and others introduced as a result of trading (e.g., alewife, white perch, brown trout, carp, rainbow smelt, pacific salmon, round goby) (NOAA, 2016). Hebert et al. (2008) showed that between 1980 and 2005, annual indices of prey fish abundance declined significantly. It was thought that the decline in annual indices was the result of many contributing factors, with a major factor being the predation by larger piscivorous fish, namely exotic salmon and trout that were introduced into the Great Lakes to reduce populations of exotic prey fish and to create recreational fisheries. Fish have historically been an early indicator of the condition of the Lakes, and are still used today to that end. 
The Great Lakes basin is home to 30 million people, and includes the cities of (among others) Toronto (ON), Hamilton (ON), Chicago (IL), Milwaukee (WI), Detroit (MI), Buffalo $(\mathrm{NY})$, and Cleveland $(\mathrm{OH})$. As a result of large human populations, pollution in the Great Lakes basin is an ongoing concern. The volume of water entering and leaving the Great Lakes each year accounts for less than $1 \%$ of the total volume of the lakes (NWF, 2016). As a result, contaminants entering the Great Lakes ecosystem are subject to very limited dispersion, and if not easily degradable, can persist in the region for very long times.

\subsubsection{Herring Gulls and the Great Lakes Aquatic Food Web}

The herring gull (Larus argentatus) is a colonially breeding bird occurring throughout most of the northern hemisphere. They occupy a variety of habitats, including coasts, lakes, rivers, and even garbage dumps. They can be found year-round in the Great Lakes, although

during the winter months, some birds venture to the southern United States and northern Mexico. As adults, herring gulls have white heads, grey back and wings, and black wingtips with white spots. Breeding season typically lasts from March to April. Female herring gulls will lay anywhere from one to three eggs in a clutch, followed by a 27 to 30 day incubation period (Parsons, 1976).

Herring gulls from the Great Lakes have been routinely monitored since 1974 through the Great Lakes Herring Gull Monitoring Program (GLHGMP) at Canadian Wildlife Services (Environment and Climate Change Canada, Ottawa, ON). The program was originally developed in response to observed breeding failure in colonial fish-eating birds in the region (Hebert et al., 1999b). Herring gulls have since been monitored annually as a means of assessing reproductive 
success, the role of toxic contaminants and other stressors on gull and overall Great Lakes ecosystem health. Herring gull eggs are collected each spring, between late April and early May. Egg collection and analysis allows researchers to monitor changes in herring gull populations while being minimally invasive to the colonies. Today, the GLHGMP annually collects 10 to 13 eggs for contaminant analysis from each of the 15 monitored colonial nesting sites throughout the Great Lakes. As such, the GLHGMP is one of the oldest on-going contaminant monitoring programs in the world.

With over 250 fish species in the area, the Great Lakes aquatic food web is quite diverse. Major forage fish species include yellow perch, lake whitefish, rainbow smelt, deepwater sculpin, alewife, and round goby, whereas major piscivores (e.g., fish eaters) include Chinook salmon, Coho salmon, lake trout, rainbow trout, smallmouth bass, walleye and burbot. Bird species feeding within the aquatic food web include herring gull, double-crested cormorant, common tern and common loon. A simplified diagram of the Great Lakes aquatic food web is provided in Figure 1.2. It has been observed that herring gulls will feed preferentially on fish (e.g., alewife, rainbow smelt) although they will also feed on invertebrates (e.g., mussels, crabs, sea urchins, and insects), other bird eggs and chicks, and human refuse (Hebert et al., 1999a). Although herring gulls usually have an aquatic diet, it has been shown that over the last few decades herring gulls from the Great Lakes have been shifting their diets to more terrestrialbased food sources (Hebert et al., 1999a). It is assumed that the aquatic-to-terrestrial shift is a result of reduced prey fish abundances that has been observed in the Great Lakes over the same time period. As a result, herring gulls are now foraging more frequently on human refuse, exposing themselves to higher amounts of anthropogenic persistent contaminants. 


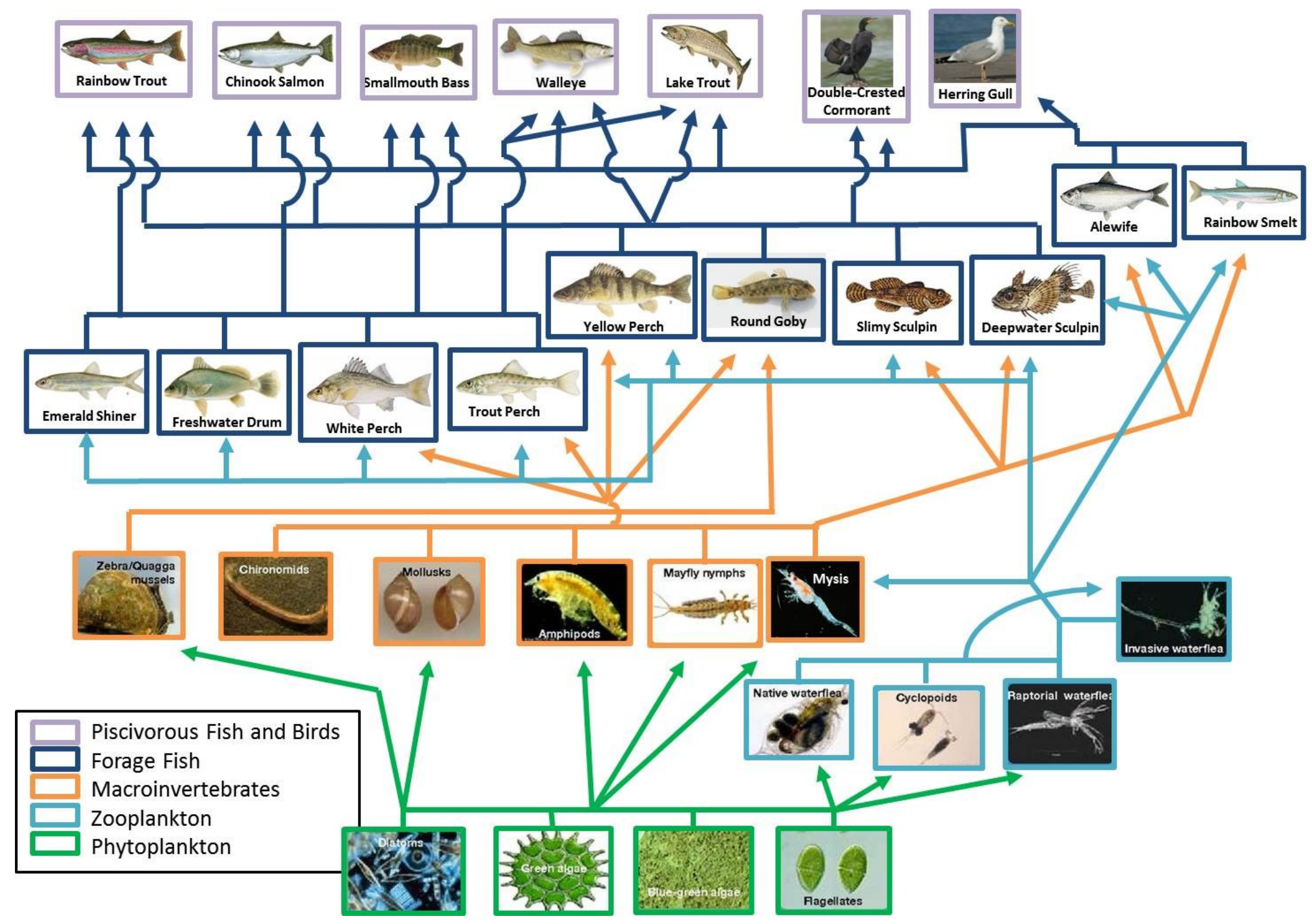

Figure 1.2 Simplified schematic of the Great Lakes food web. Modified from NOAA (2015) 


\subsection{Thesis Objectives}

The pharmacokinetics of OPE accumulation and metabolism in any wildlife species is extremely limited, even though OPEs are being manufactured and used in products at recordhigh levels, and have been shown to cause numerous deleterious effects. There is a dearth of information regarding the biomagnification potential of OPEs in a food web, as well as a lack of information regarding both spatial distribution patterns of OPEs in North America, as well as temporal trends. This thesis aims to understand the pharmacokinetics of OPEs in an avian model, the herring gull, with an emphasis placed on elucidating OPE persistence vs. metabolism in the body. To that end, this thesis has been subdivided into five main objectives:

Objective 1. Production levels of OPEs have increased substantially over the last few decades. New research is starting to investigate OPE concentrations in wildlife tissues, although this research is quite limited, particularly for avian species. Furthermore, there is a lack of information regarding the spatial distribution patterns of OPEs throughout North America. Through the Great Lakes Herring Gull Monitoring Program, the NWRC's specimen bank contains herring gull egg samples from multiple nesting sites among the Great Lakes collected over the last 40 years. In Chapter 3, the spatial and temporal trends of OPEs among herring gull egg samples from the Great Lakes are assessed. Herring gull eggs were collected at five different nesting sites around the Great Lakes between 1990 and 2010, and analyzed for OPEs. Due to recent increases in OPE consumption, it is hypothesized that OPE concentrations in herring gull eggs generally increase over the 20-year span. Furthermore, as OPEs are anthropogenic and found in human-made materials, it is further hypothesized that herring gull eggs from urban nesting sites contain higher OPE concentrations than eggs from remote nesting sites. 
Objective 2. Many OP triesters are predicted to have low biomagnification potential in biota. Regardless, there is a dearth of information regarding the biomagnification potential of OPEs in a food web. To further understand the pharmacokinetics and biomagnification of OPEs in biota, the predator-prey relationships of OPEs among food webs from Lake Ontario and Lake Erie are examined in Chapter 3. OPEs were analyzed in a total of 14 species (invertebrates, fishes, and herring gull), sampled from Lake Ontario and Lake Erie. It is hypothesized that predator-prey differences will be quite small, if not non-existent, due to the predicted low biomagnification of OPEs. Furthermore, it is hypothesized that invertebrates will contain different OPE patterns than fishes/birds due to the different metabolic pathways in invertebrates vs. fishes/birds.

Objective 3. There is generally a dearth of reports on OPEs in wildlife and fish, and to my knowledge there are no published reports on OPE body compartment composition and in ovo or in utero transfer for any given wildlife species. As a result, in Chapter 4 the distribution of OPE triesters within multiple tissues of female herring gulls from the Great Lakes is investigated, and in ovo transfer of OPEs from mother to egg is examined. Eight different tissues are analyzed for OPEs: liver, fat, muscle, brain, red blood cells, blood plasma, egg yolk, and egg albumen. Due to the different physiology and function of these eight tissues, it is hypothesized that there are tissue-specific differences in OPE accumulation. OPEs will be preferentially distributed to fatty tissues (i.e., fat), as a result of low metabolism in these tissues. It is further hypothesized that in ovo transfer of OPEs does not occur in a structure-dependent fashion, and it is generally found that OPE patterns in the egg reflect OPE patterns in the mother. 
Objective 4. Multiple reports have been published which show that select OPE triesters are metabolized in vivo and in vitro. Although the exact metabolic products for many of the OP triesters remains to be analytically and quantitatively determined, OP diesters have been found in many cases to be either a major or minor metabolic product of OP triester metabolism. In Chapter 5, using a novel method for the determination of OP diesters in biological tissues, herring gull blood plasma samples are analyzed to determine the presence of OP diesters. Due to the rapid metabolism of some OP triesters that has been previously observed in avian and mammalian liver tissues, it is hypothesized that OP diesters will be detected in blood plasma samples, although at very low levels.

Objective 5. As previously mentioned, OP triesters have been shown in multiple reports to rapidly metabolize in vivo and in vitro. However, these reports have only focused on a few select OP triesters, do not quantify the metabolism in terms of specific activities, and do not investigate metabolite formation. Therefore, in Chapter 6 the Michaelis-Menton enzyme kinetic parameters responsible for the metabolism of six OP triesters are determined using prepared herring gull liver microsomes. Then, using the newly established kinetic parameters, the metabolism of the five OP triesters is investigated. The depletion of the OP triesters and the formation of the OP diesters are measured and specific activities are calculated. It is hypothesized that structurerelated differences will be observed for both the enzyme kinetic parameters, as well as the specific activities. 
CHAPTER 2

Materials and Methods ${ }^{1}$

${ }^{1}$ Publication Associated with this Thesis Chapter:

G. Su, A.K. Greaves, L.T. Gauthier, R.J. Letcher. 2014. Journal of Chromatography A 1374, 85-92. 


\subsection{Sampling Details}

\subsubsection{Spatial and Temporal Trends}

Herring gull (Larus argentatus) eggs ( $\mathrm{n}=10-13$ per site per year) were collected in multiple years from Agawa Rock (Lake Superior), Gull Island (Lake Michigan), Chantry Island (Lake Huron), Fighting Island (Lake Erie) and Toronto Harbour (Lake Ontario) (Figure 2.1) for the purposes of OPE analysis. The selection of these five colonies was based in part on the availability of historical egg samples, but also considering potential OPE point sources, and breeding colonies in urban and more remote sites. For all colonies, the available gull eggs were collected in the spring for all even years (and thus 11 year in total) spanning the period of 1990 to 2010 . The $\mathrm{n}=10-13$ eggs per colony site per year were transported to the NWRC in padded cases designed for herring gull eggs. Eggs were kept at ambient temperature (between 2 and $10^{\circ} \mathrm{C}$ ) for 24 to 48 hours until their arrival at the National Wildlife Research Centre (NWRC; Environment and Climate Change Canada). Eggs were subsequently pooled on an equal wet weight basis and the pooled homogenates were stored at $-40{ }^{\circ} \mathrm{C}$ prior to chemical analysis.

Herring gull eggs $(n=10-13$ per site per year) were additionally collected from the same five colony nesting sites for most years between 1981 and 2008 for the purposes of stable isotope analysis (Figure 2.1). Same as above, the $\mathrm{n}=10-13$ eggs per colony site per year were transported to the NWRC in padded cases designed for herring gull eggs. Eggs were kept at ambient temperature (between 2 and $10^{\circ} \mathrm{C}$ ) for 24 to 48 hours until their arrival at the NWRC.

Eggs were subsequently pooled on an equal wet weight basis and the pooled homogenates were stored at $-40{ }^{\circ} \mathrm{C}$ prior to chemical analysis. A table of all herring gull eggs collected for this thesis can be found in Table 2.1 . 


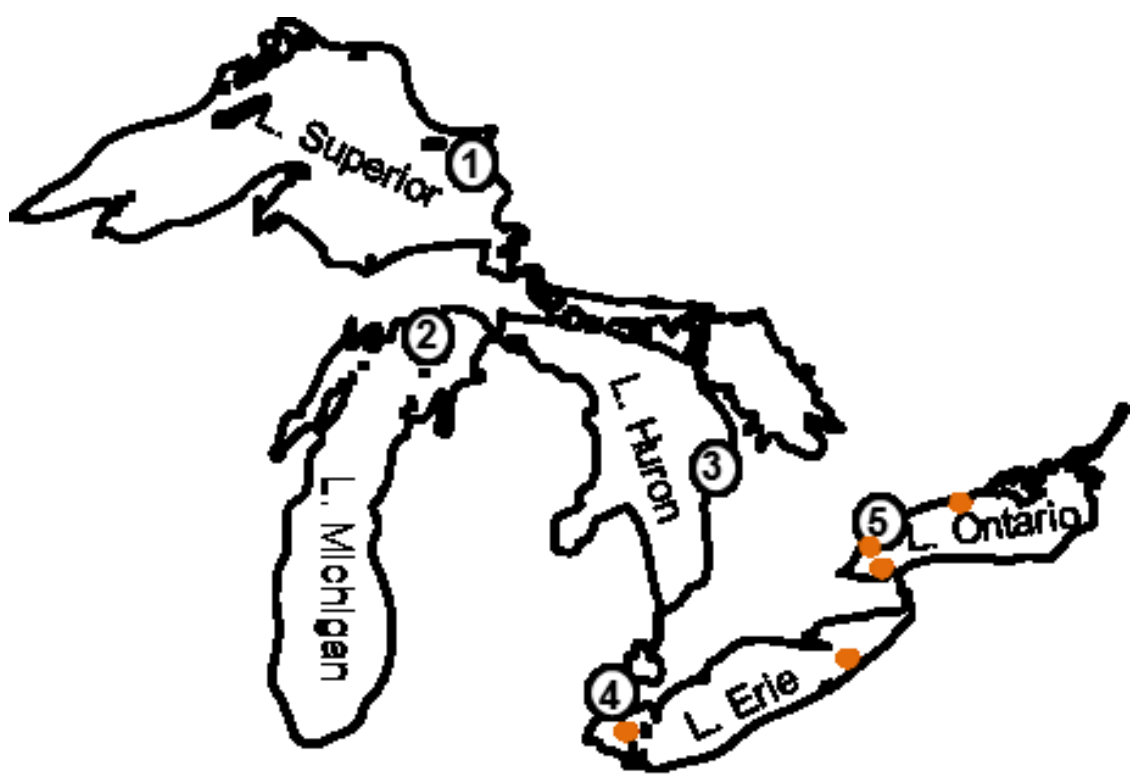

Figure 2.1 Herring gull colony sampling sites throughout the Great Lakes of North America. Colony names are as follows: 1, Agawa Rock (Lake Superior); 2, Gull Island (Lake Michigan); 3, Chantry Island (Lake Huron); 4, Fighting Island (mouth of Detroit River, Lake Erie); 5, Toronto Harbour (Lake Ontario). Aquatic food web sampling locations are also shown (•), namely Port Hope, Port Credit, and Niagara-on-the-Lake (Lake Ontario), and Dunkirk and the Western Basin (Lake Erie). 
Table 2.1 Complete sampling list of all herring gull eggs $(n=10$ to 13 per site per year) collected from 5 colony nesting sites around the Great Lakes. All eggs at a given site for each collection year were combined into a pooled egg homogenate. For each year, $\square$ denotes the analysis of organophosphate ester flame retardants, and $\bullet$ denotes the analysis of stable isotopes.

\begin{tabular}{|c|c|c|c|c|c|}
\hline Year & Agawa Rock & Gull Is. & Chantry Is. & Fighting Is. & Toronto Harbour \\
\hline 1981 & $\bullet$ & $\bullet$ & $\bullet$ & $\bullet$ & $\bullet$ \\
\hline 1982 & $\bullet$ & $\bullet$ & $\bullet$ & $\bullet$ & $\bullet$ \\
\hline 1983 & $\bullet$ & $\bullet$ & $\bullet$ & $\bullet$ & • \\
\hline 1984 & $\bullet$ & $\bullet$ & $\bullet$ & $\bullet$ & $\bullet$ \\
\hline 1985 & $\bullet$ & $\bullet$ & $\bullet$ & $\bullet$ & $\bullet$ \\
\hline 1986 & $\bullet$ & $\bullet$ & $\bullet$ & $\bullet$ & $\bullet$ \\
\hline 1987 & $\bullet$ & $\bullet$ & $\bullet$ & $\bullet$ & $\bullet$ \\
\hline 1988 & $\bullet$ & $\bullet$ & $\bullet$ & $\bullet$ & $\bullet$ \\
\hline 1989 & $\bullet$ & $\bullet$ & $\bullet$ & $\bullet$ & $\bullet$ \\
\hline 1990 & व・ & 口・ & व・ & $\square \bullet$ & 口・ \\
\hline 1991 & $\bullet$ & $\bullet$ & $\bullet$ & $\bullet$ & $\bullet$ \\
\hline 1992 & $\square \bullet$ & $\square \bullet$ & $\square \bullet$ & $\square \bullet$ & 口・ \\
\hline 1993 & $\bullet$ & $\bullet$ & $\bullet$ & $\bullet$ & $\bullet$ \\
\hline 1994 & 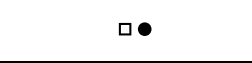 & 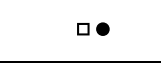 & 口・ & $\square \bullet$ & 口・ \\
\hline 1995 & $\bullet$ & $\bullet$ & $\bullet$ & $\bullet$ & $\bullet$ \\
\hline 1996 & $\square \bullet$ & $\square \bullet$ & $\square \bullet$ & $\square \bullet$ & $\square \bullet$ \\
\hline 1997 & $\bullet$ & $\bullet$ & $\bullet$ & $\bullet$ & $\bullet$ \\
\hline 1998 & $\square \bullet$ & 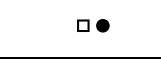 & $\square \bullet$ & $\square \bullet$ & $\square \bullet$ \\
\hline 1999 & $\bullet$ & $\bullet$ & $\bullet$ & $\bullet$ & \\
\hline 2000 & $\square \bullet$ & 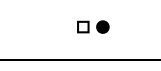 & $\square \bullet$ & 口・ & 口・ \\
\hline 2001 & $\bullet$ & $\bullet$ & $\bullet$ & $\bullet$ & $\bullet$ \\
\hline 2002 & $\square \bullet$ & 口・ & 口・ & 口・ & 口・ \\
\hline 2003 & $\bullet$ & $\bullet$ & $\bullet$ & $\bullet$ & $\bullet$ \\
\hline 2004 & $\square \bullet$ & व・ & व・ & व・ & व・ \\
\hline 2005 & $\bullet$ & $\bullet$ & $\bullet$ & $\bullet$ & $\bullet$ \\
\hline 2006 & 口・ & $\square \bullet$ & व・ & व・ & 口・ \\
\hline 2007 & $\bullet$ & $\bullet$ & $\bullet$ & $\bullet$ & $\bullet$ \\
\hline 2008 & $\square \bullet$ & 口・ & 口・ & 口・ & 口・ \\
\hline 2010 & 口・ & 口・ & 口• & 口• & 口• \\
\hline
\end{tabular}




\subsubsection{Lake Ontario and Lake Erie Food Webs}

A total of 67 aquatic samples were collected in 2010 from Lake Ontario and Lake Erie for the analysis of OPEs. Sampling locations in Lake Ontario included Port Hope, Port Credit, and Niagara-on-the-Lake. Sampling locations in Lake Erie included Dunkirk, and the Western Basin (Figure 2.1). Samples consisted of net plankton $(\mathrm{n}=1)$, mysis (Mysis diluviana; $\mathrm{n}=1$ ), and multiple fishes: alewife (Alosa pseudoharengus; $\mathrm{n}=2$ ), deepwater sculpin (Myoxocephalus thompsonii; $\mathrm{n}=2$ ), slimy sculpin (Cottus cognatus; $\mathrm{n}=2$ ), emerald shiner (Notropis atherinoides; $\mathrm{n}=3$ ), freshwater drum (Aplodinotus grunniens; $\mathrm{n}=3$ ), rainbow smelt (Osmerus mordax; $\mathrm{n}=5$ ), round goby (Neogobius melanostomus; $\mathrm{n}=5)$, trout perch (Percopsis omiscomaycus; $\mathrm{n}=3$ ), white perch (Morone americana; $\mathrm{n}=3$ ), yellow perch (Perca flavescens; $\mathrm{n}=3$ ), walleye (Sander vitreus; $\mathrm{n}=10$ ), and lake trout (Salvelinus namaycush; $\mathrm{n}=24)$. Lake trout and walleye were collected via stationary bottom set gillnets, while smaller fish were collected via midwater and bottom trawling. All carcasses were placed in polyethylene bags, previously determined to be free of OP triester contamination, and put on ice within $1 \mathrm{hr}$ post mortem. Whole carcasses were homogenized upon return to NWRC and all samples were stored at $-40^{\circ} \mathrm{C}$ prior to analysis. Additional food web sampling details can be found in McGoldrick et al. (2010).

\subsubsection{Tissue Distribution and Maternal Transfer}

Female herring gulls $(n=8)$, and their eggs $(n=16 ; 2$ eggs total in each clutch per female), were collected from Chantry Island, Lake Huron in April 2010. See Figure 2.1 for a map of all sampling locations. Four tissues (liver, brain, fat and muscle), red blood cells and 
plasma, and egg yolk and albumen were collected. All samples were collected within $1 \mathrm{hr}$ post mortem using (chemically cleaned) scalpels and scissors. Collected blood was separated into plasma and red blood cells on-site via a portable centrifuge. All tissues, with the exception of the eggs, were stored in (chemically cleaned) $2 \mathrm{~mL}$ cryovials, and placed in liquid nitrogen dryshippers until their arrival at the NWRC for long-term storage at $-40^{\circ} \mathrm{C}$ until the time of analysis. Eggs were carefully removed from nests and placed in padded cases designed for herring gull eggs. Eggs were kept at ambient temperature (between 2 and $10^{\circ} \mathrm{C}$ ) for 24 to 48 hours until their arrival at the NWRC. After separation of yolk and albumen, samples were stored at $-40^{\circ} \mathrm{C}$ until the time of analysis.

\subsubsection{In Vitro Biotransformation Assays}

Biotransformation assays employed herring gull liver microsomes, prepared from the liver samples detailed in section 2.1.1. In brief, eight female herring gull livers were collected within $1 \mathrm{hr}$ post mortem using (chemically cleaned) scalpels and scissors. Liver samples were placed in (chemically cleaned) $2 \mathrm{~mL}$ cryovials, and snap-frozen in liquid nitrogen dry-shippers to preserve enzymatic activity in the tissue. Samples were kept in the dry shippers until their arrival at the NWRC, where they were stored at $-80^{\circ} \mathrm{C}$ until the time of analysis.

\subsection{Contaminant Analysis}

\subsubsection{Standards and Reagents}

For spatial and temporal trends, as well as food web analysis (Chapter 3), tris(2chloroethyl) phosphate (TCEP), tripropyl phosphate (TPP), tris(2-chloroisopropyl) phosphate (TCIPP), tris(1,3-dichloro-2-propyl) phosphate (TDCIPP), triphenyl phosphate (TPHP), tributyl 
phosphate (TNBP), trimethylphenyl phosphate (TMPP), 2-ethylhexyl-diphenyl phosphate (EHDPP), tris(2-butoxyethyl) phosphate (TBOEP), and tris(2-ethylhexyl) phosphate (TEHP) were purchased from Sigma-Aldrich (Oakville, ON, Canada). Tris(2,4-dibromopropyl) phosphate (TDBPP) was purchased from AccuStandard, (New Haven, CT, USA). Finally, tris(2bromo-4-methylphenyl) phosphate (T2B4MP), tris(4-bromo-3-methylphenyl) phosphate (T4B3MPP) and tris(3-bromo-4-methylphenyl) phosphate (T3B4MPP) were synthesized by GL Chemtec International, (Oakville, ON, Canada). The deuterated tributyl phosphate ( $\left.\mathrm{d}_{27}-\mathrm{TNBP}\right)$, purchased from Cambridge Isotope Laboratories (Andover, MA, USA), was used as the internal standard (I.S.) for quantification of OPEs. A complete list of all target compounds can be found in Figure 2.2, while their $\log \mathrm{K}_{\mathrm{OW}}$ values can be found in Table 2.2 .

For the tissue distribution and maternal transfer analysis (Chapter 4), all of the above standards were used, plus the addition two newly acquired standards and 4 additional internal standards. Triethyl phosphate (TEP) was purchased from Sigma-Aldrich, and 2,2bis(chloromethyl)propane-1,3-diyltetrakis(2-chloroethyl) bisphosphate (V6) was donated by Dr. H. Stapleton (Duke University, USA). Additionally, 4 newly available internal standards were added to the method to aid in the quantification of OPEs: $\mathrm{d}_{15}$-TEP (Cambridge Isotope Laboratories, Tewksbury, USA), $\mathrm{d}_{15}$-TPHP (Wellington Laboratories, Guelph, Canada), and $\mathrm{d}_{12^{-}}$ TCEP and $\mathrm{d}_{15}$-TDCIPP (Dr. V. Belov, Max Planck Institute for Biophysical Chemistry, Germany).

When developing a method for the determination and quantification of OP diesters in biological matrices, and its application to herring gull blood plasma samples (Chapter 5), diester standards included di-n-butyl phosphate (DNBP), di(2-ethylhexyl) phosphate (DEHP) and diphenyl phosphate (DPHP) (Sigma-Aldrich), as well as bis(1-chloro-2-propyl) phosphate 
(BCIPP), bis(2-butoxyethyl) phosphate (BBOEP) and bis(1,3-dichloro-2-propyl) phosphate

(BDCIPP) (Dr. Belov). Internal standards were also purchased from Dr. Belov, and included $\mathrm{d}_{4}{ }^{-}$ BBOEP, $\mathrm{d}_{10}$-BDCIPP and $\mathrm{d}_{10}$-DPHP.

Table 2.2 Octanol-water partition coefficients $\left(\log \mathrm{K}_{\mathrm{OW}}\right)$ for all target organophosphate triesters in this thesis.

\begin{tabular}{lll}
\hline Compound Name & Abbreviation & Log K \\
\hline Tris(2-chloroethyl) phosphate & TCEP & 1.63 \\
Tris(2-butoxyethyl) phosphate & TBOEP & 3.00 \\
Tris(2-chloroisopropyl) phosphate & TCIPP & 2.89 \\
Tris(1,3-dichloro-2-propyl) phosphate & TDCIPP & 3.65 \\
Triphenyl phosphate & TPHP & 4.70 \\
Tris(2,3-dibromopropyl) phosphate & TDBPP & 4.29 \\
Tri-n-butyl phosphate & TNBP & 4.00 \\
Trimethylphenyl phosphate & TMPP & 5.48 \\
2-Ethylhexyl-diphenyl phosphate & EHDPP & 6.30 \\
Tripropyl phosphate & TPP & 2.67 \\
Tris(2-ethylhexyl) phosphate & TEHP & 9.49 \\
Triethyl phosphate & TEP & 0.87 \\
2,2-Bis(chloromethyl)propane-1,3-diyltetrakis(2-chloroethyl) & V6 & 1.90 \\
bisphosphate & & \\
\hline
\end{tabular}


<smiles>O=P(OCCl)(OCCl)OCCl</smiles>

(A)<smiles>O=[Po]([O-])([O-])[O-]</smiles>

(E)<smiles>CCOC(=O)OCCO</smiles>

(I)<smiles>CCOP(=O)(OC)OC</smiles>

(M)

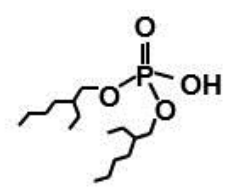

(Q)<smiles>[3H]OOP(=O)(OOCC)OOCC</smiles>

(B)<smiles>O=P(Br)(OCBr)OP(=O)(OCBr)OCBr</smiles>

(F)

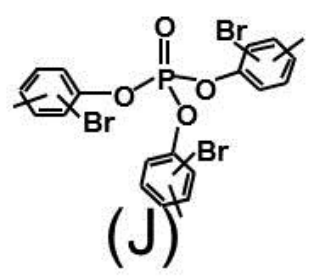<smiles>O=P(OCCl)(OOC(Cl)Cl)OC(Cl)Cl</smiles>

(C)<smiles>CCP(O)OP(=O)(OC)OC</smiles>

(G)

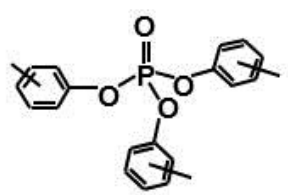

(H)<smiles>CC1OC2(C)OC(=O)OC1(C)O2</smiles><smiles>CCOOP(=O)(O)OOc1ccccc1</smiles><smiles>O=P(O)(OCCl)OC(Cl)Cl</smiles>

(S)<smiles>CCOP(=O)(O)OCI</smiles>

(R)<smiles>O=P(O)(Oc1ccccc1)Oc1ccccc1</smiles>

(R)<smiles>[O]</smiles>

(T)

Figure 2.2 Chemical structures of all target organophosphate flame retardants (triesters and diesters) in this thesis. Compounds are as follows: (A) tris(2-chloroethyl) phosphate (TCEP); (B) tris(2-butoxyethyl) phosphate (TBOEP); (C) tris(2-chloroisopropyl) phosphate (TCIPP); (D) tris(1,3-dichloro-2-propyl) phosphate (TDCIPP); (E) triphenyl phosphate (TPHP); (F) tris(2,3dibromopropyl) phosphate (TDBPP); (G) tri-n-butyl phosphate (TNBP); (H) trimethylphenyl phosphate (TMPP); (I) 2-ethylhexyl-diphenyl phosphate (EHDPP); (J) tris(2-bromo-4methylphenyl) phosphate (T2B4MPP) / tris(4-bromo-3-methylphenyl) phosphate (T4B3MPP) / tris(3-bromo-4-methylphenyl) phosphate (T3B4MPP); (K) tripropyl phosphate (TPP); (L) tris(2ethylhexyl) phosphate (TEHP); (M) triethyl phosphate (TEP); (N) 2,2-bis(chloromethyl)propane1,3-diyltetrakis(2-chloroethyl) bisphosphate (V6); (O) bis(1-chloro-2-propyl) phosphate (BCIPP); (P) bis(2-butoxyethyl) phosphate (BBOEP); (Q) di(2-ethylhexyl) phosphate (DEHP); (R) diphenyl phosphate (DPHP); (S) di-n-butyl phosphate (DNBP); (T) bis(1,3-dichloro-2propyl) phosphate (BDCIPP). Hydrogen atoms have been omitted for clarity. 


\subsubsection{Extraction and Cleanup}

\subsubsection{Organophosphate Triesters}

The OP triester extraction and cleanup procedure for the herring gull tissue distribution samples is given below. The extraction and cleanup procedure for all spatial and temporal trends samples, as well as food web samples follows an identical method, with the exception that only $\mathrm{d}_{27}$-TNBP was used as an internal standard, since the other four internal standards were not yet commercially available.

The extraction and cleanup method followed that of Chen et al. (2012) with minor modifications, including the use of additional deuterated OPE internal standards. Briefly, approximately $0.6 \mathrm{~g}$ of a given sample to be analyzed was ground with $3 \mathrm{~g}$ of diatomaceous earth, and loaded into a $15 \mathrm{~mL}$ stainless steel extraction cell. All five deuterated OPE internal standards $\left(\mathrm{d}_{12}\right.$-TCEP, $\mathrm{d}_{15}$-TDCIPP, $\mathrm{d}_{15}$-TPHP, $\mathrm{d}_{27}$-TNBP, and $\mathrm{d}_{15}$-TEP) were spiked at $5 \mathrm{ng}$ each to all samples. The spiked samples were extracted for OPEs using accelerated solvent extraction (Dionex ASE 200) operating at $100^{\circ} \mathrm{C}$ and $1500 \mathrm{psi}$, using a 1:1 mixture of dichloromethane (DCM) and hexane. Anhydrous sodium sulphate (1g) was added to the resulting samples to remove any water, and the solution was concentrated to $10 \mathrm{~mL}$. Ten percent was removed for gravimetric lipid determination, while the remaining $90 \%$ was concentrated to $0.5 \mathrm{~mL}$ and loaded onto a pre-conditioned solid-phase extraction (SPE) cartridge containing $1 \mathrm{~g}$ of ISOLUTE NH2® aminopropyl silica gel. After rinsing the cartridge with $3 \mathrm{~mL}$ of 20:80 DCM:hexane, OPEs were eluted using $3 \mathrm{~mL}$ of 20:80 DCM:hexane, followed by $8 \mathrm{~mL}$ of DCM, and finally 4 $\mathrm{mL}$ of 90:10 DCM:methanol. The eluate was evaporated to dryness, reconstituted in methanol, and analyzed via high performance liquid chromatography-electrospray (positive mode)-tandem quadrupole mass spectrometry (HPLC-ESI(+)-MS/MS). 


\subsubsection{Organophosphate Diesters}

The extraction and cleanup procedure for the determination of OP diesters in biological matrices followed that of Su et al. (2014), which was developed as part of the present thesis research. In brief, approximately $0.6 \mathrm{~g}$ of a given sample to be analyzed was ground with $3 \mathrm{~g}$ of diatomaceous earth, and loaded into a $15 \mathrm{~mL}$ stainless steel extraction cell. After spiking with the OP diester internal standards $\left(\mathrm{d}_{4}\right.$-BBOEP, $\mathrm{d}_{10}$-BDCIPP and $\mathrm{d}_{10}$-DPHP), OP triesters and diesters were extracted using accelerated solvent extraction, first with 1:1hexane/DCM (fraction 1) and then with $1: 1$ hexane/acetone with $1 \%$ acetic acid (fraction 2 ) at $100^{\circ} \mathrm{C}$ and $1500 \mathrm{psi}$. The OP triesters were eluted in the first fraction, and OP diesters were eluted in the second fraction.

The second fraction containing the OP diesters was reduced to $1 \mathrm{~mL}$ under gentle nitrogen flow. This concentrated fraction was then cleaned up on a pre-conditioned SPE cartridge containing $1 \mathrm{~g}$ of ISOLUTE NH2® aminopropyl silica gel. After loading the concentrated fraction onto the column with $3 \mathrm{~mL}$ acetone, the column was rinsed with $6 \mathrm{~mL}$ acetone, $3 \mathrm{~mL} \mathrm{MeOH}, 4 \mathrm{~mL}$ 5:95 water/MeOH containing 0.005 $\mathrm{M}$ ammonium acetate, and finally $1.5 \mathrm{~mL}$ 5:95 water/MeOH containing 0.1 M ammonium acetate. The target $\mathrm{OP}$ diesters were eluted in $4 \mathrm{~mL}$ of 5:95 water/MeOH containing $0.1 \mathrm{M}$ ammonium acetate. The methanol present in the eluate was evaporated using a constant nitrogen flow, and the remaining water was diluted with $4 \mathrm{~mL}$ acetone. $1.5 \mathrm{~g}$ of sodium sulfate was added to remove the moisture and ammonium acetate. The acetone portion of the solution was transferred into a new glass tube and evaporated to dryness under nitrogen flow. The residue was reconstituted in $\mathrm{MeOH}$, and filtered. The resulting filtrate was transferred to a vial for HPLC-ESI(+)-MS/MS analysis. A schematic of the extraction and clean-up is provided in Figure 2.3. 


\section{Accelerated Solvent Extraction}

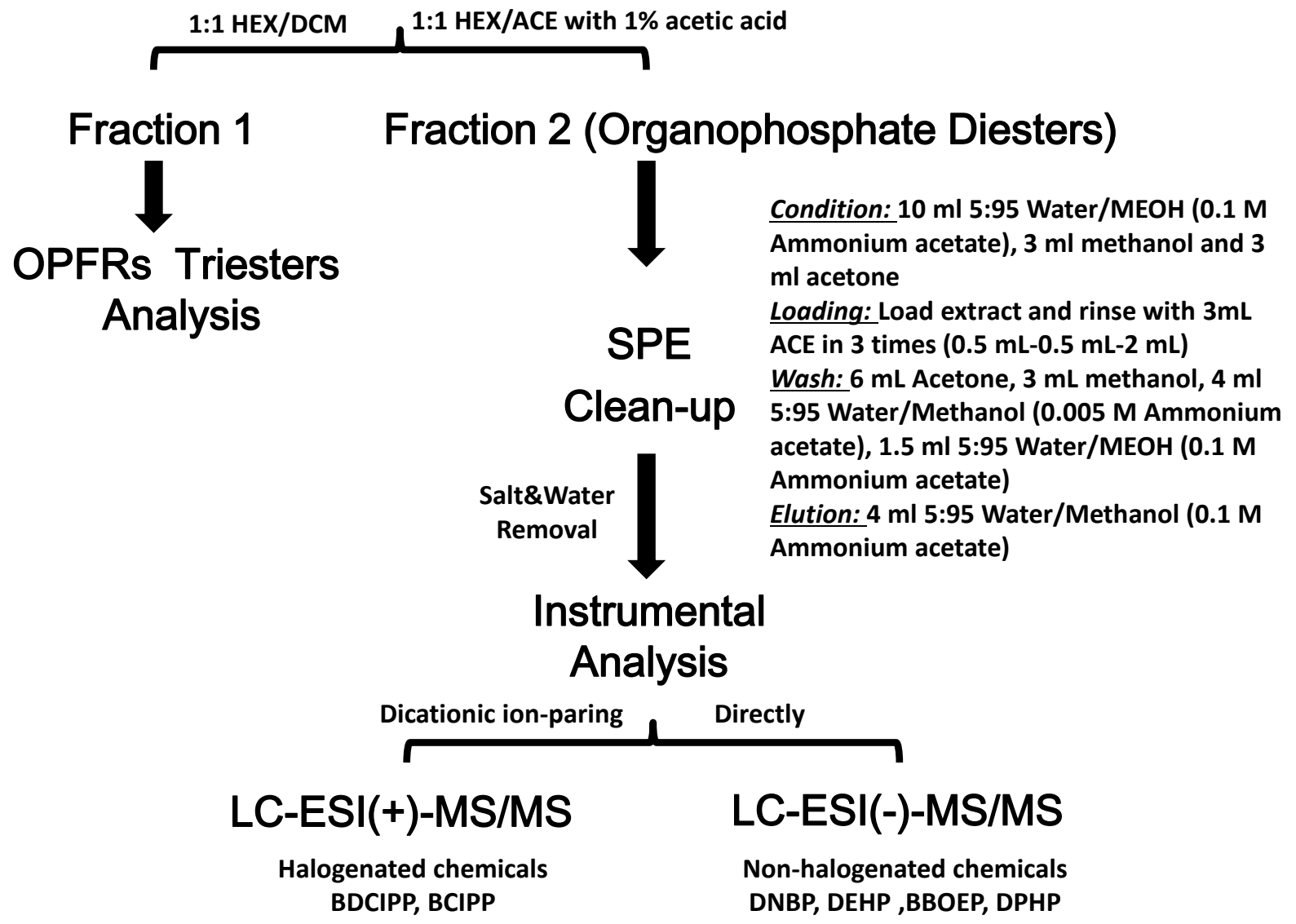

Figure 2.3 Schematic flow diagram of the sample extraction, clean-up and instrumental analysis of organophosphate (OP) diesters.

\subsubsection{Measurement}

All OP triester quantification was performed using HPLC-ESI(+)-MS/MS. Analysis was performed using a Waters 2695 HPLC coupled to a Waters Quatro Ultima triple quadrupole. All target compounds, with the exception of V6, were analyzed using a Waters Symmetry $\mathrm{C}_{18}$ 
column (100 mm L x $2.1 \mathrm{~mm}$ i.d., $3.5 \mu \mathrm{m}$ particle size). The column temperature was kept at $40^{\circ} \mathrm{C}$. The mobile phases consisted of water (A) and methanol (B), both containing $0.1 \%$ formic acid $(\mathrm{v} / \mathrm{v})$. The mobile phase flow rate was $0.2 \mathrm{~mL} / \mathrm{min}$, and the following gradient was employed: 5\% B ramped to 70\% B over 3 minutes (linear), ramped to $80 \%$ B over 12 minutes (linear), ramped to $95 \%$ B over 3 minutes, held for 12 minutes, dropped to 5\% B over 1 minute, and held for 15 minutes, for a total run time of 45 minutes. The injection volume was $10 \mu \mathrm{L}$. Instrument operation parameters for $\operatorname{ESI}(+)$ were optimized as follows: capillary voltage: 4.0 $\mathrm{kV}$; source temperature: $100^{\circ} \mathrm{C}$; desolvation temperature: $300^{\circ} \mathrm{C}$; desolvation gas flow rate: 700 $\mathrm{L} / \mathrm{hr}$; cone gas flow rate: $150 \mathrm{~L} / \mathrm{hr}$.

V6 was analyzed using a Phenomenex LUNA $\mathrm{C}_{18}$ column $(50 \mathrm{~mm} \mathrm{~L}$ x 2 mm i.d., $3 \mu \mathrm{m}$ particle size). The column temperature was kept at $40^{\circ} \mathrm{C}$. The mobile phases consisted of water (A) and methanol (B). The mobile phase flow rate was $0.2 \mathrm{~mL} / \mathrm{min}$, and the following gradient was employed: 5\% B was ramped to $95 \%$ B over 10 minutes (linear), held at $95 \%$ B for 10 minutes, dropped to 5\% B over 1 min (linear), and held at 5\% B for 14 minutes, for a total run time of 35 minutes. The injection volume was $10 \mu \mathrm{L}$. Instrument operation parameters for ESI(+) were optimized as follows: capillary voltage: $4.0 \mathrm{kV}$; source temperature: $100^{\circ} \mathrm{C}$; desolvation temperature: $350^{\circ} \mathrm{C}$; desolvation gas flow rate: $700 \mathrm{~L} / \mathrm{hr}$; cone gas flow rate: $150 \mathrm{~L} / \mathrm{hr}$.

All OP diester measurements were performed using HPLC-ESI(+)-MS/MS. Analysis was performed using a Waters 2695 HPLC coupled to a Waters Quattro Ultima triple quadrupole. The column temperature was kept at $40^{\circ} \mathrm{C}$. The mobile phases consisted of water (A) and $\mathrm{MeOH}$ (B), both with $0.2 \mathrm{mM}$ ammonium acetate. Ammonium acetate was employed instead of the previously employed formic acid due to its higher volatility, which helped ionize the phosphate diesters. The mobile phase flow rate was $0.2 \mathrm{~mL} / \mathrm{min}$ and the following gradient was employed: 
$5 \% \mathrm{~B}$ ramped to $95 \%$ over 10 minutes (linear), held for 10 minutes, ramped to $5 \% \mathrm{~B}$ over 1 minute, and held for 10 minutes, for a total run time of 31 minutes. The injection volume was 10 $\mu \mathrm{L}$. OP diesters were ion-paired using decamethonium hydroxide before reaching the triple quadrupole. The dicationic ion pairing reagent was prepared by using a column $(30 \mathrm{~cm} \mathrm{~L} \times$ $1.1 \mathrm{~cm}$ i.d.) packed with $5 \mathrm{ml}$ Amberlite IRA-400 (chloride form; Sigma-Aldrich). The column was then conditioned by eluting $50 \mathrm{~mL}$ of $1 \mathrm{M} \mathrm{NaOH}$ followed by $50 \mathrm{~mL}$ of ultrapure water. After $1 \mathrm{~mL}$ of a $0.1 \mathrm{M}$ aqueous solution of decamethonium bromide (Sigma-Aldrich) was loaded on the column, the hydroxide dication reagent was eluted with $80 \mathrm{~mL}$ of water. The total elution of the decamethonium hydroxide dicationic reagent was determined to be achieved when the eluant reached approximately $\mathrm{pH}$ 7. The eluate was collected and adjusted to a final volume to $100 \mathrm{~mL}$ in a volumetric flask. Finally, the decamethonium hydroxide dicationic reagent solution was diluted ten times with ultrapure water and used for OP diester ion-pairing prior to LC$\mathrm{ESI}(+)-\mathrm{MS} / \mathrm{MS}$ analysis. The dicationic reagent solution $(0.1 \mathrm{mM}$ in aqueous solution) was mixed with mobile phase post LC separation with a "T" connector. The flow rate was $5 \mu \mathrm{L} / \mathrm{min}$ by use of a constant syringe pump. Instrument operation parameters for $\operatorname{ESI}(+)$ were optimized as follows: capillary voltage: $1.0 \mathrm{kV}$; source temperature: $120^{\circ} \mathrm{C}$; desolvation temperature: $350^{\circ} \mathrm{C}$; desolvation gas flow rate: $600 \mathrm{~L} / \mathrm{hr}$; cone gas flow rate: $100 \mathrm{~L} / \mathrm{hr}$.

All compounds were identified based on their retention times compared to authenticated standards, and their characteristic mass transitions observed by multiple reaction monitoring. An eight-point calibration curve was performed daily to ensure linearity of response and to allow for quantification. Quantification was done using MassLynx 4.0 (Waters, 2002). Additional details regarding HPLC analysis including all monitored transitions can be found in Table 2.3. 
Table 2.3 List of monitored ion transitions, retention times, and other operational details for all analyses performed via HPLC-ESI(+)-MS/MS, used in Chapters 3 and 4.

\begin{tabular}{|c|c|c|c|c|c|c|}
\hline & $\begin{array}{c}\text { Retention } \\
\text { Time (min) }\end{array}$ & $\begin{array}{c}\text { Parent Ion } \\
\text { (Da) }\end{array}$ & $\begin{array}{c}\text { Daughter } \\
\text { Ion (Da) }\end{array}$ & $\begin{array}{c}\text { Cone } \\
\text { Voltage (V) } \\
\end{array}$ & $\begin{array}{c}\text { Collision } \\
\text { Energy } \\
(\mathrm{eV})\end{array}$ & $\begin{array}{r}M^{M L O Q}{ }^{a} \\
(n g / g ~ w w)\end{array}$ \\
\hline TEP & 8.50 & 183.0 & 98.7 & 35 & 17 & 0.4 \\
\hline TCEP & 9.00 & 284.9 & 63.0 & 35 & 25 & 0.1 \\
\hline TPP & 11.12 & 225.3 & 99.0 & 40 & 5 & 0.1 \\
\hline TCIPP & 11.20 & 329.1 & 99.0 & 35 & 20 & 0.2 \\
\hline V6 & 12.95 & 582.9 & 359.0 & 35 & 16 & 0.6 \\
\hline ТРНР & 13.74 & 327.1 & 77.1 & 100 & 40 & 0.1 \\
\hline TDCIPP & 13.77 & 430.9 & 99.0 & 60 & 25 & 0.06 \\
\hline TDBPP & 15.05 & 698.6 & 99.0 & 55 & 30 & 0.15 \\
\hline TNBP & 15.86 & 267.1 & 99.0 & 35 & 20 & 0.1 \\
\hline ТВОЕР & 17.25 & 399.0 & 199.0 & 35 & 15 & 0.15 \\
\hline TMPP & 19.68 & 369.1 & 91.0 & 90 & 40 & 0.12 \\
\hline EHDPP & 20.78 & 363.2 & 250.8 & 35 & 10 & 0.09 \\
\hline T2B4MP & 22.34 & 604.9 & 90.0 & 110 & 70 & 0.1 \\
\hline T4B3MP & 23.81 & 604.9 & 90.0 & 110 & 70 & 0.1 \\
\hline T3B4MP & 24.20 & 604.9 & 90.0 & 110 & 70 & 0.1 \\
\hline ТЕНР & 27.33 & 435.3 & 99.0 & 50 & 20 & 0.07 \\
\hline$d_{15}$-TEP & 8.50 & 198.2 & 101.7 & 35 & 17 & N/A \\
\hline $\mathrm{d}_{12}$-ТCEP & 9.00 & 297.0 & 67.0 & 35 & 25 & N/A \\
\hline $\mathrm{d}_{15}$-TDCIPP & 13.77 & 446.0 & 108.8 & 60 & 25 & N/A \\
\hline $\mathrm{d}_{15}$-TPHP & 13.74 & 342.0 & 82.0 & 100 & 40 & N/A \\
\hline$d_{27}$-TNBP & 15.86 & 294.3 & 102.0 & 35 & 20 & $\mathrm{~N} / \mathrm{A}$ \\
\hline
\end{tabular}




\subsubsection{Quality Control}

Three replicate procedural blanks were run with every batch of eight samples to determine any background OPE contamination. Procedural blanks were treated identical to all samples, with the exception that blanks did not contain sample tissue, but rather $0.25 \mathrm{~g}$ of chicken egg homogenate, previously determined to contain non-detectable levels of all target OPEs. Chicken egg homogenate was added to the blanks since percent recoveries were quite low without it $(28 \% \pm 12$, compared to $100 \% \pm 8$ with the chicken egg homogenate acting as a keeper). All solvents used during this experiment, including dichloromethane, hexane, and especially methanol, contained quantifiable levels of multiple OPEs. Procedural blanks $(n=30)$ contained TBOEP $(15.0 \pm 1.1 \mathrm{ng} / \mathrm{g}$ wet weight; ww $)$, TCIPP $(12.4 \pm 7.6 \mathrm{ng} / \mathrm{g} \mathrm{ww}), \mathrm{TNBP}(5.6 \pm$ $0.5 \mathrm{ng} / \mathrm{g} \mathrm{ww})$, TCEP $(2.2 \pm 0.2 \mathrm{ng} / \mathrm{g} \mathrm{ww})$, TEP $(2.0 \pm 0.4 \mathrm{ng} / \mathrm{g} \mathrm{ww})$, TPHP $(1.5 \pm 0.1 \mathrm{ng} / \mathrm{g} \mathrm{ww})$, EHDPP $(1.2 \pm 0.1 \mathrm{ng} / \mathrm{g} \mathrm{ww})$, TDCIPP $(1.0 \pm 0.09 \mathrm{ng} / \mathrm{g} w w)$, and TEHP $(0.4 \pm 0.04 \mathrm{ng} / \mathrm{g} w w)$ in over $90 \%$ of the procedural blanks. All sample concentrations were therefore blank-corrected on a batch-by-batch basis using the average of the three procedural blanks in each batch. A control was also run with every batch of eight samples to ensure reproducibility across all batches. To our knowledge, a biological standard reference material is not yet commercially available for OPE analysis. Therefore, an in-house standard reference material was created for the purposes of this project: chicken egg homogenate, pre-determined to be free of OPE contamination, was spiked with a cocktail of all OPE target compounds assessed in this study, such that the concentration of each OPE in the tissue was $10 \mathrm{ng} / \mathrm{g}$ wet weight. Controls were reproducible, with a mean relative standard deviation of $20 \%$ across all target compounds. The Letcher LabOCRL (Carleton University) participated in 2012 in the first international NORMAN PFR (OPE- 
FR) Inter-laboratory Study. For this QA/QC exercise, the OPE results from the OCRL complied within $10 \%$ of the NORMAN PFR certified data.

The five deuterated internal standards spiked at the start of the sample extraction accounted for matrix effects and sample-to-sample variations. Mean percent recoveries ( \pm standard error; SE) of higher molecular weight ISs ( $\mathrm{d}_{12}$-TCEP, $\mathrm{d}_{15}$-TDCIPP, $\mathrm{d}_{15}-\mathrm{TPHP}, \mathrm{d}_{27}-$ TNBP) were highly quantitative and very similar $(89 \% \pm 1,88 \% \pm 2,93 \% \pm 1$, and $91 \% \pm 1$, respectively), whereas the more volatile $\mathrm{d}_{15}$-TEP had an overall lower mean recovery but with very good replicate precision $(40 \% \pm 2)$. All target OPE concentrations were inherently corrected for any recovery inefficiencies as the internal standard quantification approach was used. Target compounds for which there was not a matched isotopically-enriched internal standard available, were assigned one of the five ISs as a surrogate IS. Surrogate ISs were chosen based on similarity of chemical structure to the target compound: $\mathrm{d}_{15}$-TDCIPP was chosen as a surrogate IS for TCIPP and TDBPP; $\mathrm{d}_{15}$-TPHP was chosen as a surrogate for TMPP, EHDPP, and all three TBMPP isomers; and finally $\mathrm{d}_{27}$-TNBP was chosen as a surrogate for TPP, TBOEP, and TEHP.

\subsection{Stable Isotope Analysis and Trophic Level Determination}

\subsubsection{Stable Isotope Extraction}

For the herring gull spatial and temporal trends dataset, along with the Lake Ontario and Lake Erie food web dataset, all samples were analyzed for nitrogen $\left(\delta^{15} \mathrm{~N}\right)$ and carbon $\left(\delta^{13} \mathrm{C}\right)$ stable isotope ratios. Stable isotope extraction was performed by Craig Hebert (NWRC), and followed Hebert et al. (2006). Approximately $1 \mathrm{~g}$ of homogenized material from each of the samples was dried overnight at $80^{\circ} \mathrm{C}$. After dried samples were ground to a powder, they were 
spiked with $20 \mathrm{~mL}$ chloroform/methanol (2:1), and then vortexed, sonicated, and let stand overnight. Subsequently the samples were centrifuged at $3000 \mathrm{rpm}$ for 20 minutes and the supernatant was discarded. $20 \mathrm{~mL}$ of water was added, and the samples were vortexed, sonicated and centrifuged. The supernatant was discarded; the lipid-extracted samples were dried overnight at $80^{\circ} \mathrm{C}$, and then sent to the Environmental Isotope Laboratory (EIL) at the University of Waterloo (ON, Canada) for stable isotope analysis.

\subsubsection{Stable Isotope Analysis}

Samples were analyzed for nitrogen $\left({ }^{15} \mathrm{~N}:{ }^{14} \mathrm{~N}\right.$; herein referred to as $\left.\delta^{15} \mathrm{~N}\right)$ and carbon $\left({ }^{13} \mathrm{C}:{ }^{12} \mathrm{C}\right.$; herein referred to as $\left.\delta^{13} \mathrm{C}\right)$ isotope ratios at the EIL (University of Waterloo, Canada). Stable isotope ratios are the ratio of stable isotopes found in the sample relative to the ratio of stable isotopes found in a standard. The $\delta^{15} \mathrm{~N}$ and $\delta^{13} \mathrm{C}$ for a sample is given by the following equations:

$$
\begin{aligned}
\delta^{15} N & =\left[\left(\frac{{ }^{15} N /{ }^{14} N_{\text {sample }}}{{ }^{15} N /{ }^{14} N_{\text {standard }}}\right)-1\right] \times 1000 \% \\
\delta^{13} C & =\left[\left(\frac{{ }^{13} C /{ }^{12} C_{\text {sample }}}{{ }^{13} C / /^{12} C_{\text {standard }}}\right)-1\right] \times 1000 \%
\end{aligned}
$$

The nitrogen and carbon standards referred to in the above equations are ambient air and Vienna Pee Dee Belemnite limestone, respectively. The lipid-free samples were analyzed on one 
of two machines at the EIL: (1) a Carlo Erba Elemental Analyzer coupled to a Delta Plus Continuous Flow Stable Isotope Ratio Mass Spectrometer, or (2) a Carlo Erba Elemental Analyzer coupled to a Micromass VG Isochrom Continuous Flow Stable Isotope Ratio Mass Spectrometer, with analytical precisions of $\pm 0.2 \%\left(\delta^{13} \mathrm{C}\right)$ and $\pm 0.3 \%\left(\delta^{15} \mathrm{~N}\right)$. Precision was established through repeat analysis of International Atomic Energy Agency (IAEA) standards IAEA-N1 and IAEA-N2 (both ammonium sulphate) for $\delta^{15} \mathrm{~N}$, and IAEA-CH6 (sugar) as well as two in-house standards, EIL-72 (cellulose) and EIL-32 (graphite) for $\delta^{13} \mathrm{C}$. Standards were run at the beginning and end of each sample run to monitor machine drift. Sample replicates were run every eight samples, and duplicates were run from previous groups to ensure reproducibility and inter-day variability.

\subsubsection{Trophic Level Determination}

Trophic levels were assigned relative to plankton, which was assumed to occupy trophic level 2. Trophic levels (TL) for each individual sample were determined as follows:

$$
\mathrm{TL}_{\text {consumer }}=2+\left(\delta^{15} \mathrm{~N}_{\text {consumer }}-\delta^{15} \mathrm{~N}_{\text {plankton }}\right) / \Delta \mathrm{N}
$$

where $\Delta \mathrm{N}$ is the trophic enrichment factor, estimated to be 3.4\% (McGoldrick et al., 2014b; Jardine et al., 2006). Trophic magnification factors (TMFs) for OPEs were determined by plotting the logarithmic concentration of residual OPE concentrations as a function of trophic 
level (Borgå et al., 2011). OPEs with TMFs above 1 were considered to biomagnify, whereas those with TMFs under 1 were considered to biodilute.

\subsection{Total Burden Estimates of OP Triesters in Herring Gull Tissues and Eggs}

The mass burdens of all detected OPEs were estimated based on empirical data collected during collection and sample processing, as well as previously documented data. Mean masses $( \pm \mathrm{SE})$ for whole body $(946 \mathrm{~g} \pm 15)$, brain $(5.7 \mathrm{~g} \pm 0.1)$ and $\mathrm{egg}(82 \mathrm{~g} \pm 2 ; 29 \%$ yolk, $71 \%$ albumen) were recorded for all samples. The total mass of fat was not recorded, although Norstrom et al. (1986) found that body fat accounts for approximately $8.2 \%$ of the total body weight of a herring gull. Therefore, the average mass of body fat in our bird samples was $78 \mathrm{~g} \pm$ 1. The total mass of muscle was also not recorded. To our knowledge, there has not been a study to determine the total muscle mass in herring gulls. However, the largest muscle in herring gulls, and the muscle from which our samples were taken, is the pectoralis muscle. In the California Gull (Larus californicus), the pectoralis muscle accounts for approximately $10.8 \%$ of total body weight (Carrier et al., 1990). Using this figure as an estimate, the mean pectoralis muscle mass was found to be $102 \mathrm{~g} \pm 2$, which acts as a lower bound muscle mass estimate in herring gulls. Gebbink et al. (2012) estimated the liver of herring gulls to account for approximately $2.7 \%$ of body mass. As such, liver weights averaged $25.3 \mathrm{~g} \pm 0.5$. Finally, whole blood volume in herring gulls has been estimated at $60 \mathrm{~mL} / \mathrm{kg}$ body weight (Gebbink et al., 2012). As such, whole blood volumes averaged $56.8 \mathrm{~mL} \pm 0.9(\sim 60 \% \mathrm{v} / \mathrm{v}$ red blood cells, $\sim 40 \% \mathrm{v} / \mathrm{v}$ plasma $)$. The total burdens of OP triesters were calculated by multiplying their concentration (ng/g ww) by the estimated weight of the tissue (g). 


\subsection{In Vitro Biotransformation Assays}

\subsubsection{Standards and Reagents}

For the herring gull liver microsome preparation, sodium phosphate dibasic $\left(\mathrm{Na}_{2} \mathrm{HPO}_{4}\right)$, and potassium phosphate monobasic $\left(\mathrm{KH}_{2} \mathrm{PO}_{4}\right)$ were purchased from Fisher Scientific (Ottawa, ON, Canada). For the total protein content and catalytic activity determination of the microsomes, sodium phosphate monobasic $\left(\mathrm{NaH}_{2} \mathrm{PO}_{4} \bullet \mathrm{H}_{2} \mathrm{O}\right)$ was purchased from Fisher Scientific. Resorufin sodium salt, 7-ethoxyresorufin, nicotinamide adenine dinucleotide phosphate (NADPH), bovine serum albumin (BSA) and fluorescamine were all purchased from Sigma-Adrich (Oakville, ON, Canada).

For the in vitro biotransformation assays, Wistar Han rat liver microsomes (20 mg microsomal protein/mL), NADPH regenerating system solution A, NADPH regenerating system

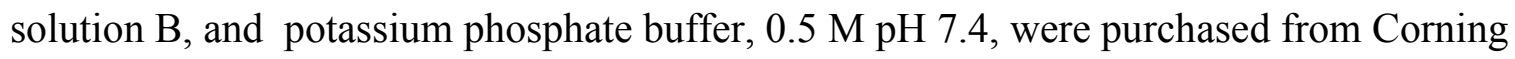
(Corning, NY, USA). OP triester and diester standards included TDCIPP, TPHP, TBOEP, TNBP, TCIPP, TEP, DNBP, and DPHP were purchased from Sigma-Aldrich. BDCIPP, BBOEP, BCIPP, $\mathrm{d}_{15}$-TDCIPP, $\mathrm{d}_{15}$-TPHP, $\mathrm{d}_{10}$-BDCIPP, $\mathrm{d}_{4}$-BBOEP, and $\mathrm{d}_{10}$-DPHP were purchased from Dr. Belov (Max Planck Institute for Biophysical Chemistry, Germany). $d_{27}$-TNBP and $d_{15}$-TEP were purchased from Cambridge Isotope Laboratories (Andover, MA, USA).

\subsubsection{Herring Gull Liver Microsome Preparation}

The preparation of liver microsomes has been described before (Verreault et al., 2009). A 0.1 M phosphate buffer, $\mathrm{pH} 7.4$, was prepared by mixing $200 \mathrm{~mL}$ of a $0.1 \mathrm{M}$ potassium phosphate solution with $800 \mathrm{~mL}$ of a $0.1 \mathrm{M}$ sodium phosphate solution. Briefly, liver samples to be processed were thawed on ice. In order to reduce enzyme degradation, all operations were 
done on ice, and performed as quickly as possible. After rinsing approximately $500 \mathrm{mg}$ of tissue with a phosphate buffer ( $0.1 \mathrm{M}, \mathrm{pH}$ 7.4; prepared at the NWRC), the liver tissue was minced into small pieces with scalpels over ice, and transferred to a $5 \mathrm{~mL}$ plastic centrifuge tube. $800 \mu \mathrm{L}$ of cold phosphate buffer was added, and the sample was homogenized using an IKA Ultra Turrax homogenizer (Wilmington, NC, USA). Contents were quantitatively transferred into a previously cooled microcentrifuge tube. The tube was equilibrated and centrifuged at $9000 \times \mathrm{g}$ at $4^{\circ} \mathrm{C}$ for 15 minutes using a Beckman-Coulter Optima TLX Ultracentrifuge (Mississauga, ON, Canada). The supernatant was decanted and re-centrifuged at $100000 \times \mathrm{g}$ at $4^{\circ} \mathrm{C}$ for 60 minutes. The pellet (containing the microsomes) was weighed, gently re-suspended in $125 \mu \mathrm{L}$ of cold phosphate buffer, transferred to a cryovial, and snap-frozen in liquid nitrogen. A schematic of microsome preparation is provided in Figure 2.4. There was not a sufficient amount of liver microsomes from each individual gull to allow for a meaningful inter-individual metabolism study. Therefore, all microsomes were pooled together and subsequently the protein content and general enzyme catalytic activity was determined. Once all liver tissue was processed, all cryovials were thawed on ice. All microsomal suspensions were combined together to form one large batch, and then re-frozen in liquid nitrogen. All microsomes were stored at $-80^{\circ} \mathrm{C}$ until the time of analysis. 


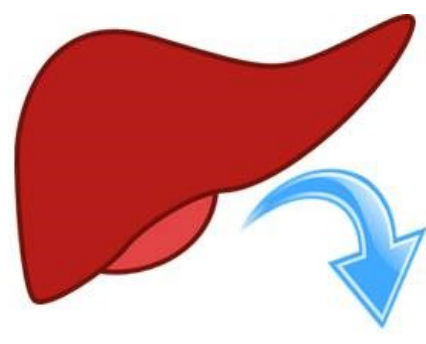

Thaw $0.5 \mathrm{~g}$ liver on ice. Mince liver, and homogenize with $800 \mu \mathrm{L}$ phosphate buffer, $0.1 \mathrm{M}, \mathrm{pH} 7.4$ on ice.

Homogenized Liver

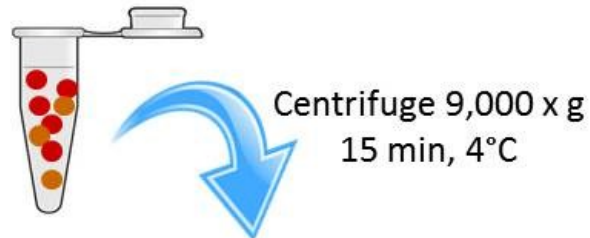

Supernatant: Cytosol + Microsomes

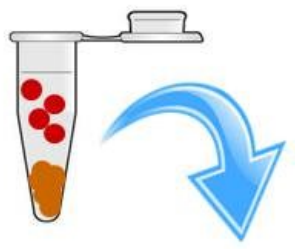

Centrifuge Supernantant

Pellet: Cellular Debris $100,000 \times \mathrm{g}, 60 \mathrm{~min}, 4^{\circ} \mathrm{C}$

Redo for total of $35 \mathrm{~g}$ of GULL liver samples (or desired mass). Combine all microsomal solutions.
Microsomal solution

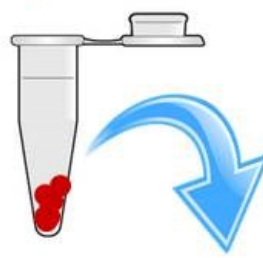

Suspend pellet in
$125 \mu \mathrm{L}$ buffer on ice.
Pellet: Microsomal Fraction

\section{Determine total protein content and enzyme (CYP 1A) activity via a combined Bradford Assay / ethoxyresorufin- O-deethylase (EROD) Assay. \\ Dilute microsomes to $20 \mathrm{mg}$ microsomal protein $/ \mathrm{mL}$.}

Figure 2.4 Schematic for the preparation of herring gull liver microsomes. 


\subsubsection{Microsome Protein Content and Catalytic Activity Determination}

Total protein content and cytochrome P450IA enzyme activity was determined using the well-established ethoxyresorufin-O-deethylase (EROD) assay, following the methods in Kennedy and Jones (1994). Total protein content was quantified against a concentrationdependent standard curve based on bovine serum albumin (BSA). EROD activity, which catalyzes the reaction of 7-ethoxyresorufin to resorufin in the presence of NADPH, was quantified against a concentration-dependent standard curve based on resorufin. A sodium phosphate buffer $(0.05 \mathrm{M}, \mathrm{pH} 8.0)$ was prepared by combining $100 \mathrm{~mL}$ of a $0.05 \mathrm{M}$ sodium phosphate monobasic $\left(\mathrm{NaH}_{2} \mathrm{PO}_{4} \cdot \mathrm{H}_{2} \mathrm{O}\right)$ solution with $1 \mathrm{~L}$ of a $0.05 \mathrm{M}$ sodium phosphate dibasic $\left(\mathrm{NaHPO}_{4}\right)$ solution. Herring gull liver microsomes (prepared in Section 2.5.2) were thawed on ice. Herring gull microsomal suspensions, as well as a 5-point standard calibration curve of BSA and resorufin were prepared in triplicate in a 48-well plate. Each standard and sample well contained sodium phosphate buffer and 7-ethoxyresorufin $(2 \mu \mathrm{M})$, while sample wells also contained herring gull liver microsomes. The plate was then incubated on a block heater at $37^{\circ} \mathrm{C}$ for 5 minutes. NADPH was added to each well, and incubated at $37^{\circ} \mathrm{C}$ for 2 minutes. Acetonitrile containing $2.16 \mathrm{mM}$ fluorescamine was added to each well to stop the catalytic enzyme reaction. The 48-well plate was placed into a Cytofluor 2350 fluorescence multiwell plate reader (Millipore Ltd., Etobicoke, ON, Canada) and scanned for resorufin with a $530 \mathrm{~nm}$ excitation filter and a $590 \mathrm{~nm}$ emission filter, and scanned for proteins with a $400 \mathrm{~nm}$ excitation filter and a $460 \mathrm{~nm}$ emission filter. Once the total protein concentration had been determined, the herring gull liver microsomes were diluted to $20 \mathrm{mg}$ protein $/ \mathrm{mL}$, and were frozen at $-80^{\circ} \mathrm{C}$ until further use. 


\subsubsection{In Vitro Biotransformation Assay Procedure}

Enzyme kinetics were assumed to follow the Michaelis-Menton enzyme kinetics model, where $V_{\max }$ is the maximal biotransformation rate for a saturated system, and $\mathrm{K}_{\mathrm{M}}$ is the Michaelis constant (representing the substrate concentration at one half of the $V_{\max }$ ). The enzyme kinetic parameters $\mathrm{V}_{\max }$ and $\mathrm{K}_{\mathrm{M}}$ were determined by quantifying the initial depletion of all 6 OP triesters at 8 different concentrations ranging from 0.01 to $10 \mu \mathrm{M}$ over a 2 minute incubation period. Only the administrated concentrations that resulted in significant and quantifiable concentration depletion over the two minutes (determined via a Student's t-test) were used to calculate $V_{\max }$ and $\mathrm{K}_{\mathrm{M}}$ values.

All in vitro assays followed the procedure given by Chu et al. (2011). In brief, $3 \mu \mathrm{L}$ of OP triester (final dosing concentration range 0.01 to $10 \mu \mathrm{M}$ ) was spiked in potassium phosphate buffer $(0.5 \mathrm{M})$, along with $50 \mu \mathrm{L}$ of NADPH solution $\mathrm{A}, 10 \mu \mathrm{L}$ of NADPH solution $\mathrm{B}$, and 50 $\mu \mathrm{L}$ microsomes (20 mg microsomal protein $/ \mathrm{mL}$ ). The final reaction mixture volume was $1 \mathrm{~mL}$. The system was left to incubate at $37^{\circ} \mathrm{C}$ in a water bath with gentle shaking. After 0 and 2 minutes, $100 \mu \mathrm{L}$ aliquots were removed from the reaction mixture, and were added to $400 \mu \mathrm{L}$ of methanol containing $\mathrm{d}_{15}$-TDCIPP and $\mathrm{d}_{10}$-BDCIPP internal standards (20 $\mathrm{ng} / \mathrm{g}$ each) to terminate all enzymatic activity. The sample was vortexed and filtered through a microcentrifugal filter (nylon $0.2 \mu \mathrm{m}$ pore size, $500 \mu \mathrm{L}$ capacity; VWR, Mississauga, ON, Canada), and subsequently analyzed via UPLC-ESI(+)-MS/MS. All assays were run a total of four times over the course of two days (i.e., $\mathrm{n}=2+\mathrm{n}=2$ ) to ensure low inter- and intra-day variability.

Once the $\mathrm{V}_{\max }$ and $\mathrm{K}_{\mathrm{M}}$ values were determined for all $\mathrm{OP}$ triesters, all subsequent in vitro biotransformation assays were designed such that the initial OP triester dose saturated the metabolic enzyme system (i.e., a zero-order metabolic reaction, with the dosing concentration $>>$ 
$2 \times \mathrm{K}_{\mathrm{M}}$ ). Biotransformation assay procedures were identical to the procedure described above, with the exception that $100 \mu \mathrm{L}$ aliquots were collected at $0,1,2,5,10,40,70$, and 100 minutes. All assays were run five times over the course of three days (i.e., $n=2, n=2, n=1$ ) to ensure low inter- and intra-day variability.

\subsubsection{Measurement}

All in vitro biotransformation assay samples were analyzed for OP triesters and their respective diesters using ultra performance liquid chromatography, UPLC-ESI(+)-MS/MS. Analysis was performed using a Waters Acquity UPLC coupled to a Waters Xevo TQ-S triple quadrupole mass spectrometer. All target compounds were separated using a Waters Aquity UPLC BEH $\mathrm{C}_{18}$ column ( $50 \mathrm{~mm} \mathrm{~L} \mathrm{x} 2.1 \mathrm{~mm}$ i.d., $1.7 \mu \mathrm{m}$ particle size). The column temperature was kept at $40^{\circ} \mathrm{C}$. The mobile phases consisted of water (A) and methanol (B), both containing 2 $\mathrm{mM}$ ammonium acetate. The mobile phase flow rate was $0.5 \mathrm{~mL} / \mathrm{min}$, and the following gradient was employed: 5\% B ramped to $95 \%$ B over 5 minutes (linear), held for 1 minute, dropped to $5 \%$ $\mathrm{B}$, and held for 4 minutes, for a total run time of 10 minutes. The injection volume was $5 \mu \mathrm{L}$. As in section 2.2.3, a dicationic reagent (decamethonium hydroxide; $0.1 \mathrm{mM}$ in aqueous solution) was mixed with mobile phase post LC separation with a "T" connector. The flow rate was 10 $\mu \mathrm{L} /$ min by use of a constant syringe pump. Instrument operation parameters for ESI $(+)$ were as follows: capillary voltage: $0.5 \mathrm{kV}$; desolvation temperature: $600^{\circ} \mathrm{C}$; desolvation gas flow rate: $800 \mathrm{~L} / \mathrm{hr}$; cone gas flow rate: $150 \mathrm{~L} / \mathrm{hr}$.

All compounds were identified based on their retention times compared to authenticated standards, and their characteristic mass transitions observed by multiple reaction monitoring. A seven-point calibration curve was performed daily to ensure linearity of response and to allow 
for quantification. Quantification was done using MassLynx 4.1 (Waters, 2014). Additional details regarding UPLC analysis including all monitored transitions can be found in Table 2.4. 
Table 2.4 List of monitored ion transitions, retention times, and other operational details for all analyses performed via UPLC-ESI(+)-MS/MS, used in Chapters 6 and 7.

\begin{tabular}{|c|c|c|c|c|c|c|}
\hline & $\begin{array}{c}\text { Retention } \\
\text { Time (min) }\end{array}$ & $\begin{array}{c}\text { Parent Ion } \\
\text { (Da) }\end{array}$ & $\begin{array}{l}\text { Daughter } \\
\text { Ion (Da) }\end{array}$ & $\begin{array}{c}\text { Cone } \\
\text { Voltage (V) } \\
\end{array}$ & $\begin{array}{c}\text { Collision } \\
\text { Energy } \\
(\mathrm{eV}) \\
\end{array}$ & $\begin{array}{c}\mathrm{MLOQ}^{\mathrm{a}} \\
(\mathrm{ng} / \mathrm{g} \text { ww) }\end{array}$ \\
\hline TEP & 2.01 & 183.0 & 98.7 & 35 & 17 & 0.06 \\
\hline BCIPP & 2.35 & 507.3 & 243.3 & 42 & 28 & 0.31 \\
\hline DPHP & 2.99 & 507.3 & 243.3 & 42 & 28 & 0.19 \\
\hline DNBP & 3.22 & 467.4 & 243.3 & 40 & 26 & 0.06 \\
\hline BDCIPP & 3.33 & 577.2 & 243.3 & 53 & 30 & 0.18 \\
\hline ВBОЕР & 3.73 & 555.5 & 243.3 & 43 & 25 & 0.10 \\
\hline TCIPP & 4.22 & 329.1 & 99.0 & 35 & 20 & 0.19 \\
\hline TDCIPP & 4.69 & 430.9 & 99.0 & 42 & 26 & 0.11 \\
\hline ТРНР & 4.74 & 327.1 & 77.1 & 100 & 40 & 0.09 \\
\hline TNBP & 4.96 & 267.1 & 99.0 & 35 & 20 & 0.08 \\
\hline ТВОЕР & 5.09 & 399.0 & 199.0 & 35 & 15 & 0.29 \\
\hline$d_{15}-$ TEP & 2.01 & 198.2 & 101.7 & 35 & 17 & N/A \\
\hline $\mathrm{d}_{10}-\mathrm{DPHP}$ & 2.99 & 517.4 & 243.3 & 42 & 28 & N/A \\
\hline $\mathrm{d}_{10}$-BDCIPP & 3.33 & 587.3 & 243.3 & 53 & 30 & N/A \\
\hline $\mathbf{d}_{4}$-ВBOEP & 3.73 & 559.5 & 243.3 & 43 & 25 & N/A \\
\hline $\mathrm{d}_{15}$-TDCIPP & 4.69 & 446.0 & 102.0 & 42 & 26 & N/A \\
\hline $\mathrm{d}_{15}$-TPHP & 4.74 & 342.2 & 82.0 & 100 & 40 & N/A \\
\hline$d_{27}$-TNBP & 4.96 & 294.3 & 102.0 & 35 & 20 & N/A \\
\hline
\end{tabular}




\subsubsection{Quality Control}

When determining the total protein content and catalytic activity of the prepared herring gull microsomes, all standards and samples were run in triplicate. This assay proved highly reproducible, with mean relative standard deviations of protein and resorufin concentrations among triplicates averaging $\pm 2 \%$ and $3 \%$, respectively. A sample blank containing all reagents with the exception of NADPH was run for every sample run in triplicate to asses any background levels of fluoresence in samples at 530/590 nm that would interfere with resorufin readings. Overall, blanks contained minimal background fluorescence levels (equating to a resorufin concentration of approximately $0.01 \mu \mathrm{M}$ ). All spectrofluorometry readings were corrected for background fluorescence prior to data analysis. A negative control containing all reagents with the exception of microsomes was run in triplicate to asses any background levels of protein in the reagents. Overall, negative controls contained no quantifiable levels of protein. Wistar Han rat liver microsomes were used as a positive control and were run in triplicate with each batch. Total protein content was determined to be within $2 \%$ of certified values (i.e., 20.3 vs $20.0 \mathrm{mg} / \mathrm{mL}$ ), while EROD/CYP 1A activity was determined to be within $55 \%$ of certified values (i.e., 124 vs. $\left.280 \mathrm{pmol} \cdot \mathrm{min}^{-1} \cdot \mathrm{mg}^{-1}\right)$. It was later determined that the lower-than-predicted enzymatic activity observed in the rat microsomes was likely the result of adding an NADPH solution to the wells, as opposed to a regenerative NADPH solution. Regardless, the positive controls indicate that the determination of protein content is extremely accurate (i.e., within $2 \%$ of accepted values) and that the microsomes are enzymatically active.

For the in vitro biotransformation assays, a sample blank, positive control, and negative control were run with each batch of samples. Sample blanks contained all reagents with the exception of the OP triester of interest. In its place, $3 \mu \mathrm{L}$ of methanol was added. Overall, sample 
blanks did not contain any quantifiable levels of any OP triester studied. Positive controls were the same as reported in Chu et al. (2011), where they showed a complete depletion of TDCIPP in a Wistar-Han rat liver microsomal assay. As such, positive controls contained rat liver microsomes (as opposed to herring gull microsomes), and consistently were spiked with $3 \mu \mathrm{L}$ of a $100 \mathrm{ppm}$ solution of TDCIPP (final administered concentration of $0.7 \mu \mathrm{M}$ ). Overall, positive controls showed good reproducibility, with a mean relative standard deviation of $\pm 21 \%$. Negative controls were treated identically to positive controls, with the exception that the rat microsomes that were added had previously been denatured by treating at $100^{\circ} \mathrm{C}$ for 5 minutes, and showed that OP triesters were not degraded in the absence of enzymatically viable microsomes. Two internal standards were added to each sample, $\mathrm{d}_{15}$-TDCIPP, and $\mathrm{d}_{10}$-BDCIPP, and showed great recoveries $(100 \% \pm 1$ and $114 \% \pm 1$, respectively). Inter-day triplicate variability averaged $28 \%(\mathrm{RSD})$ across all compounds while intra-day duplicate variability averaged $21 \%$ (RSD).

\subsection{Data Analysis}

\subsubsection{Great Lakes Spatial Trends, Temporal Trends, and Food Web Analysis}

All statistical analysis was done using Statistica 12 (Dell, 2015). Shapiro-Wilk's normality tests were performed among egg clutches for each sampling location. In general, OPE concentrations were normally distributed ( $p \geq 0.05)$, and thus data were not transformed before statistical analysis. For OP triester concentrations measuring below the MLOQs, concentrations were randomly assigned between zero and one third of the MLOQ for statistical analysis. Correlations were evaluated using Pearson product-moment correlations. Differences between groups of data (including temporal and spatial trends) were evaluated using one-way ANOVA, 
followed by a Tukey honest significant difference test. The level of significance for all statistical analyses was set at $\alpha=0.05$. Finally, principal component (PC) analysis was used to determine potential trends in the food web dataset. All variables were first autoscaled to ensure a normalized dataset for PC analyses.

\subsubsection{Tissue Distribution and Maternal Transfer}

All statistical analysis was performed using Statistica 8.0 (StatSoft, 2008). Normality of the data was tested using a Shapiro-Wilk test, with $\alpha$ set to 0.05 . Initial testing found that the majority of OPEs were not normally distributed; however after log-transformation, all compounds were normally distributed $(p \geq 0.05)$. Statistical analysis was only performed for compounds where concentrations were above the method limit of quantification (MLOQ) in at least half of the samples. A full list of MLOQs can be found in Table 2.3. For compounds where at least half of the samples had quantifiable concentrations, any individual sample below the MLOQ was randomly assigned a concentration between zero and the MLOQ for statistical purposes. All correlations, including correlations between OPE concentrations and tissue lipid content, were evaluated using a Pearson product-moment correlation, with $p \leq 0.05$ indicating statistical significance, and a Pearson product-moment correlation coefficient, $r \geq 0.5$ indicating a strong correlation. The influence of laying order on egg OPE concentrations were examined using one-way ANOVA, followed by a Tukey honest significant difference test, with $p \leq 0.05$ indicating statistical significance. Finally, principle component (PC) analysis was used to determine potential patterns and trends in the dataset, such as co-variation of compounds among tissues. To ensure a normalized data set, all PC analyses were done using percent composition data. 


\subsubsection{Enzyme Kinetic Parameter Determination and In Vitro Biotransformation of}

\section{Organophosphate Triesters}

All statistical analysis was done using Statistica 12 (Dell, 2015). Initial reaction rates $\left(v_{\mathrm{o}}\right)$ between 0 and 2 minutes were calculated for eight different administered concentrations ranging from 0.01 and $10 \mu \mathrm{M}$, and defined as the difference in OP triester concentration at $\mathrm{t}=0$ and its concentration at $\mathrm{t}=2$ divided by 2 minutes. The kinetic parameters for a given OP triester were determined using only the administered OP triester concentrations which showed a significant decline (Student's $t$-test) between $t=0$ and $t=2$. The kinetic parameters $V_{\max }$ (the maximal biotransformation rate for a saturated system) and $\mathrm{K}_{\mathrm{M}}$ (the Michaelis constant representing the substrate concentration at one half of the $\mathrm{V}_{\max }$ ) were determined by the use of a LineweaverBurk plot. Briefly, the inverse of the initial reaction rate $\left(1 / v_{0}\right)$ was plotted as a function of the inverse of the substrate concentration $(1 /[\mathrm{S}])$. Through linear regression, a line of best fit was established with an $\mathrm{x}$-intercept equal to $-1 / \mathrm{K}_{\mathrm{M}}$ and a $\mathrm{y}$-intercept equal to $1 / \mathrm{V}_{\max }$.

In the biotransformation assays, multiple administered concentrations were assessed for TDCIPP, TCIPP, TNBP, TBOEP and TPHP. The final dosing concentrations (range 2 to $5 \mu \mathrm{M}$ ) were chosen to fit two criteria: 1) that the administrated OP triester concentration was significantly higher than 2 times the calculated $\mathrm{K}_{\mathrm{M}}$ for that compound, and 2) between 40 and $99 \%$ of a given OP triester concentration was depleted in 100 minutes.

Specific rates of OP triester metabolic depletion were calculated between 1 and 40 minutes due to the observed linear depletion of all OP triesters within that assay incubation time window. Differences between the specific activities for the five OP triesters were analyzed via a student's t-test, with the level of significance set at $\alpha=0.05$. 


\section{CHAPTER 3}

Retrospective Analysis of Organophosphate Ester Flame Retardants in Herring Gull Eggs and Relation to the Aquatic Food Web in the Great Lakes ${ }^{1}$

\footnotetext{
${ }^{1}$ Publication Associated with this Thesis Chapter:

A.K. Greaves, R.J. Letcher, D. Chen, D.J. McGoldrick, L.T. Gauthier, S.M. Backus. 2016. Environmental Research, $150,255-263$.
} 


\subsection{Introduction}

With the phase-out and subsequent regulation of brominated flame retardants (BFRs), e.g. polybrominated diphenyl ethers (PBDEs) and hexbromocyclododecane, (added to Annex A of the Stockholm Convention on POPs in 2009 and 2011, respectively) (van der Veen and de Boer, 2012), the production and usage of organophosphate ester flame retardants (OPE-FRs) has increased. Consumption of OPEs in North America was approximately 75,000 tonnes in 2007 (CEFIC, 2012). Worldwide flame retardant sales are expected to reach 2.6 million tonnes in 2016, up from 1.8 million tonnes in 2008 (CEFIC, 2015).

OPEs are being detected with increasing frequency in abiotic compartments such as air and water. Detection is mainly limited to TCIPP and TDCIPP but also includes triphenyl phosphate (TPHP), trimethylphenyl phosphate (TMPP) and tris(2-chloroethyl) phosphate (TCEP) (van der Veen and de Boer, 2012; European Union, 2008a, 2008b). OPEs possess positive $\log K_{\mathrm{OW}}$ values of up to 7 , which is indicative of their potential for bioaccumulation in environmental biota (van der Veen and de Boer, 2012). Up until recently, there have been few scientific literature reports on OPEs in wildlife, particularly in birds. Scandinavian aquatic wildlife, including mussels and fishes, had concentrations of TCIPP and TDCIPP up to 1300 and 140 ng/g lipid weight (lw), respectively (Sunkdvist et al., 2010; Campone et al., 2010). TCIPP and TDCIPP were measured at concentrations of 3.9 and $1.5 \mathrm{ng} / \mathrm{g}$ wet weight (ww), respectively, in Norwegian great black-backed gull eggs (Leonards et al., 2010). Ma et al. (2013) found that tri-n-butyl phosphate (TNBP), TCEP, TCIPP and TBOEP were present in fish and bird muscle samples collected in Guandong, China, with concentrations reaching as high as $4692 \mathrm{ng} / \mathrm{g}$ lw. 
Recently, Chen et al. (2012) reported OPE concentrations in herring gull eggs collected in 2010 from a nesting colony in Lake Huron (Canada) contained quantifiable concentrations of TCIPP, TCEP and TBOEP, with maximum concentrations of 4.1, 0.6 and $2.2 \mathrm{ng} / \mathrm{g} \mathrm{ww}$, respectively. Also, McGoldrick et al. (2014a) recently reported on OPEs in whole Lake Trout collected in 2009-2010 from water bodies from across Canada including from Lakes Erie and Ontario. Similar to herring gull eggs, TCEP and TBOEP were the most frequently quantified OPEs and at similarly low concentrations. However, to our knowledge, for any wildlife or fish species (including within the Great Lakes), there have yet to be any reported studies on comparative trends over time and geographical distribution of OPE concentrations and profiles, to better understand OPE sources, exposure and fate. Furthermore, aquatic food web bioaccumulation studies are presently unknown for the Great Lakes.

We presently report on 14 non-halogenated, chlorinated or brominated triester OPEs, and 1) their occurrence, spatial distribution and retrospective temporal changes over two decades in herring gulls eggs from colony sites spanning the Laurentian Great Lakes of North America, 2) their influence of food web structure and diet sources in the gull eggs using nitrogen and carbon stable isotope ratios $\left(\delta^{15 / 14} \mathrm{~N}, \delta^{13 / 12} \mathrm{C}\right)$, and 3) a comparison of measured OPEs in eggs from gull colonies in western Lake Erie and Ontario to the top aquatic predators, lake trout (Salvelinus namaycush) and walleye (Sander vitreus), and forage species common to all three top predators in the aquatic food web. This is the first study to our knowledge that has investigated OPE trends in avian eggs over a 20 year span for any geographical location, and the first study to investigate OPE biomagnification within the Great Lakes food webs. 


\subsection{Results and Discussion}

Of the 14 OPEs screened for, only TCEP, TCIPP, TPHP and TBOEP were quantifiable in egg pools from all sites and collection years (Figure 3.1, Appendix 1). Overall, for egg pools collected between 1990 and 2010 from the five nesting colonies, $\Sigma$ OPE concentrations in the egg homogenates ranged from n.d. to $6.69 \mathrm{ng} / \mathrm{g} \mathrm{ww}$. The OPEs in the gull eggs are thus the result of in ovo transfer of the maternally accumulated OPEs from the diet, which could include via the aquatic food web (fish) or via terrestrial feeding sources (human refuse, etc.) as a consequence of opportunistic feeding. In the analysis of thirteen individual herring gull eggs from ChannelShelter Island (Lake Huron) collected in 2010, Chen et al. (2012) also reported that the eggs consistently contained TBOEP (0.16 to $2.2 \mathrm{ng} / \mathrm{g} \mathrm{ww})$, TCIPP ( $<$ MLOQ to $4.1 \mathrm{ng} / \mathrm{g} \mathrm{ww}$ ), and TCEP (<MLOQ to $0.55 \mathrm{ng} / \mathrm{g} \mathrm{ww})$. Recently, herring gull eggs collected from various Great Lakes sites in 2012 and 2013 were found to contain $\Sigma$ OPE concentrations ( 0.31 to $2.14 \mathrm{ng} / \mathrm{g} \mathrm{ww})$ that closely reflected what was detected in the present study (Su et al., 2015a). 


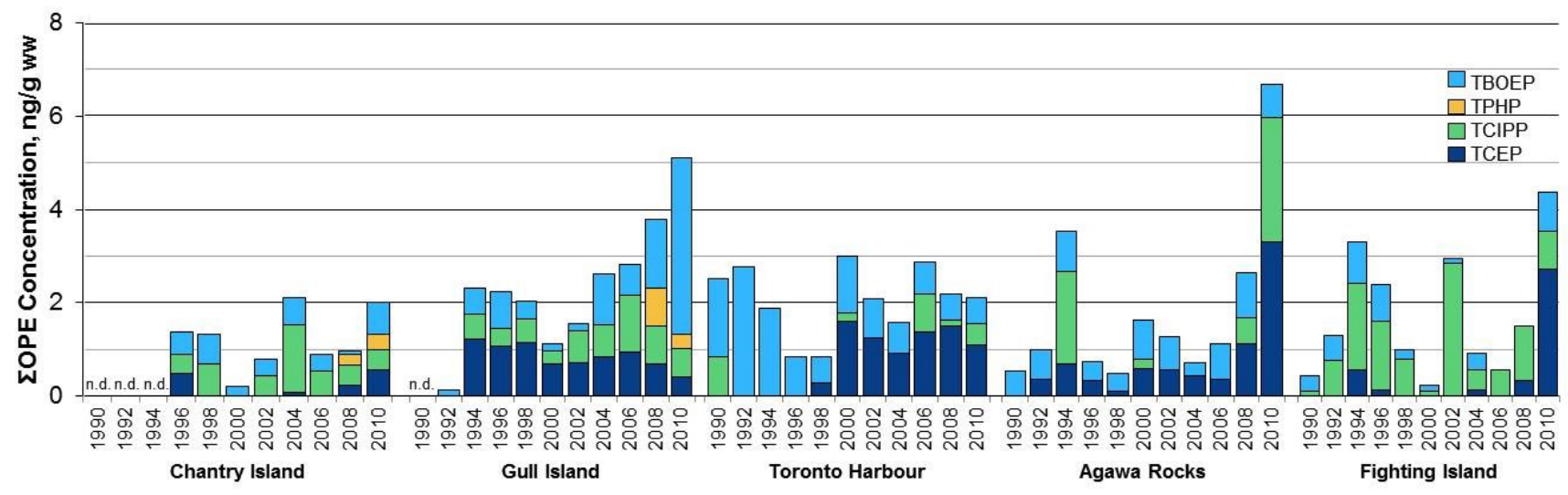

Figure 3.1: Temporal changes of $\Sigma \mathrm{OPE}$ concentrations (ng/g ww) in herring gull egg pool homogenates from five colony sites in the Laurentian Great Lakes of North America.

Zheng et al. (2015) recently reported that only TCIPP and TCEP were detected with regular frequency (i.e., $\geq 50 \%$ of samples) in chicken (Gallus gallus domesticus) eggs from an ewaste recycling region in China, with concentrations ranging from $0.33-0.56 \mathrm{ng} / \mathrm{g}$ ww (TCIPP), and $0.67-1.08 \mathrm{ng} / \mathrm{g}$ ww (TCEP). This suggests that lower OPE concentrations among the chicken eggs compared to the present herring gull eggs were likely a combination of differences in trophic position (i.e., herring gulls are top predators in their food web, and as such are more susceptible to contaminant biomagnification), as well as differences in their egg-laying patterns (i.e., herring gulls typically lay 2-3 eggs per year, whereas chickens lay one egg per day on average, resulting in large in-ovo transfer differences). 
Recent studies have also examined OPEs in air particulate phase and surface waters from the Great Lakes region. Salamova et al. (2014) analyzed air particulate phase samples collected from five sites around the Great Lakes. Of the twelve OPEs assessed, TCEP, TCIPP, and TDCIPP were dominant, and consistent with the OPEs found in the present gull eggs (i.e. TCEP and TCIPP). In surface water samples across Lake Erie, Huron, and Michigan TNBP, TCEP, TCIPP, TDCIPP, TPHP and TBOEP were quantifiable, while TCIPP and TBOEP were at the highest concentrations (Venier et al., 2014). Again, the dominance of TCIPP and TBOEP in Great Lakes water samples is consistent with the OPE profiles in the present gull eggs. These air particle and water data clearly indicate the present gulls (and eggs) have exposure sources to OPEs, including from their aquatic diet.

\subsubsection{Spatial Distributions and Temporal Trends of OPEs in Herring Gull Eggs}

Spatial distributions were not obvious regarding the concentrations of OPEs among the five colony sites, although the profiles did differ. For example, TPHP was only detected in 2008 - 2010 at Chantry and Gull Islands, and not detected at all at the other three sites. On average across all years, TCIPP concentrations at Toronto Harbour were lower than those at Fighting Island (0.22 vs. $1.00 \mathrm{ng} / \mathrm{g}$ ww, respectively), while TBOEP concentrations at Toronto Harbour were higher than those at Chantry Island (1.11 vs. $0.31 \mathrm{ng} / \mathrm{g} \mathrm{ww}$, respectively). Although some apparent region/colony-specific differences existed, overall the $\Sigma$ OPE concentrations were not statistically different between sites, indicating that the $\Sigma$ OPE concentrations in eggs were the same for rural sites (i.e., Chantry Island, Gull Island, Agawa Rocks) as for urban sites (Toronto Harbour and Fighting Island) over the 20 year period. Interestingly, air particulate phase samples 
from around the Great Lakes contained the highest $\Sigma \mathrm{OPE}$ concentrations at urban sites (i.e., Cleveland and Chicago) (Salamova et al., 2014), and in surface waters from Lake Huron, Michigan, and Erie, highest $\Sigma \mathrm{OPE}$ concentrations were also generally detected at more urban sites (i.e., Lake Erie and Michigan) (Venier et al., 2014).

Between 1998 and 2006, the European demand for chlorinated and non-halogenated OPEs increased from 58000 tonnes to 91000 tonnes (Kim et al., 2011). Similarly, American production volumes of TDCIPP, TPHP, and TCIPP in 2006 were between five and ten times higher than they were in the late 1980s (Chen et al., 2012). Nevertheless, temporal trends of $\Sigma \mathrm{OPE}$ concentrations were not obvious in gull egg pools spanning the period of 1990 to 2010 for all colony nesting sites. However, beginning in the early 2000s there was an increasing $\Sigma \mathrm{OPE}$ concentration trend over time at Gull Island. This increasing trend was mainly driven by increases in TBOEP and TCIPP at Gull Island. There was a small temporal increase of TCEP in egg pools from Agawa Rocks and Toronto Harbour. For Toronto Harbour there was an apparent TBOEP concentration decrease over time. Overall, across all five sites the TCEP concentrations in 2010 were significantly higher $(p=0.05)$ than they were between 1990 and 1998 (1.62 vs. $0.25 \mathrm{ng} / \mathrm{g} \mathrm{ww}$, respectively), and $\Sigma \mathrm{OPE}$ concentrations in 2010 were significantly higher ( $p=$ 0.02) than they were between 1990 and 2004 (4.06 vs. $1.55 \mathrm{ng} / \mathrm{g} \mathrm{ww}$, respectively).

The modest increasing trends observed in the present gull eggs over time are likely a direct result of increased concentrations in the environment due to increased production and use of OPEs over the last few decades and/or dietary exposure (Chen et al., 2012). However, it is highly likely that substantial metabolism in the maternal birds largely reduced the level of OPEs available for in ovo transfer. In vitro and in vivo metabolism studies have shown that some OPEs are rapidly metabolized. Rapid degradation of TPHP was recently observed in chicken 
embryonic hepatocytes exposed to a $10 \mu \mathrm{M}$ solution. After 36 hours, the remaining TPHP concentration only accounted for $0.2 \%$ of the original administered dose (Su et al., 2015b). In rat liver microsomes, TNBP, TPHP, and TDCIPP were rapidly metabolized in the presence of NADPH (Sasaki et al., 1984; Chu et al., 2011). The very low concentrations of TPHP, TDCIPP and TNBP in the present gull egg pools are consistent with the rapid in vivo and in vitro metabolism reported for these OPEs in other species.

\subsubsection{Dietary Shift Influences on OPE Exposure in Herring Gulls}

As reported for PCBs by Hebert et al. (2000), $\delta^{15} \mathrm{~N}$ and $\delta^{13} \mathrm{C}$ values have been used as dietary tracers to evaluate dietary influences on herring gull exposure to anthropogenic contaminants in the Great Lakes. The trophic position of an animal can be inferred by its $\delta^{15} \mathrm{~N}$ values since $\delta^{15} \mathrm{~N}$ increases by trophic level in a food chain (Kelly et al., 2000; Kelly et al., 2006). Similarly, the particular food chain can be inferred by the $\delta^{13} \mathrm{C}$ values since different photosynthesis mechanisms result in a typical $\delta^{13} \mathrm{C}$ pattern that remains largely unchanged throughout the food chain (Hebert et al., 1999a; 2008), differentiating between feeding strategies (e.g., nearshore/offshore, benthic/pelagic, freshwater/marine and terrestrial/aquatic). In the present study, we first evaluated dietary influence on the exposure in 13 individual eggs from the same colony (Channel-Shelter Island) and the same year (2010). Wide ranges of $\delta^{15} \mathrm{~N}$ (11 to $16 \%)$ and $\delta^{13} \mathrm{C}(-19$ to $-25 \%$ ) suggested varying trophic levels and primary food web carbon sources, respectively, for the maternal gulls of these individual Channel-Shelter eggs. A significant negative $\delta^{15} \mathrm{~N}$ to $\delta^{13} \mathrm{C}$ correlation $(p<0.001, r=-0.89)$ indicated that a greater reliance on terrestrial-based foods (resulting in elevated, less negative $\delta^{13} \mathrm{C}$ values) was 
associated with lesser $\delta^{15} \mathrm{~N}$ values in Channel-Shelter gull eggs. These results indicated that the pooled egg homogenates that were used for this study reflected the maternal gulls with differing trophic positions and diets, and would provide good average values for a given colony.

$\delta^{15} \mathrm{~N}$ and $\delta^{13} \mathrm{C}$ analysis was performed on herring gull eggs collected from all five colony nesting sites across the Great Lakes spanning 1981 to 2010 (Figure 3.2; Appendix 2). There were small decreases of egg $\delta^{15} \mathrm{~N}$ levels as a function of time (1981 to 2008) for all sites combined ( $p$ $<0.002, r=-0.26$ ), and for three of the five individual sites, with the exception of Gull Island and Fighting Island. These results indicate that herring gulls across most sites in the Great Lakes are occupying a lower trophic position now than they did 30 years ago. There was a significant correlation between $\delta^{15} \mathrm{~N}$ values and TBOEP concentrations in egg pools from all five colony nesting sites $(p=0.009, r=0.37)$. This weak correlation suggested that TBOEP weakly biomagnifies in the food web, since maternal gulls who occupied a higher trophic position passed on larger amounts of TBOEP to their eggs. 


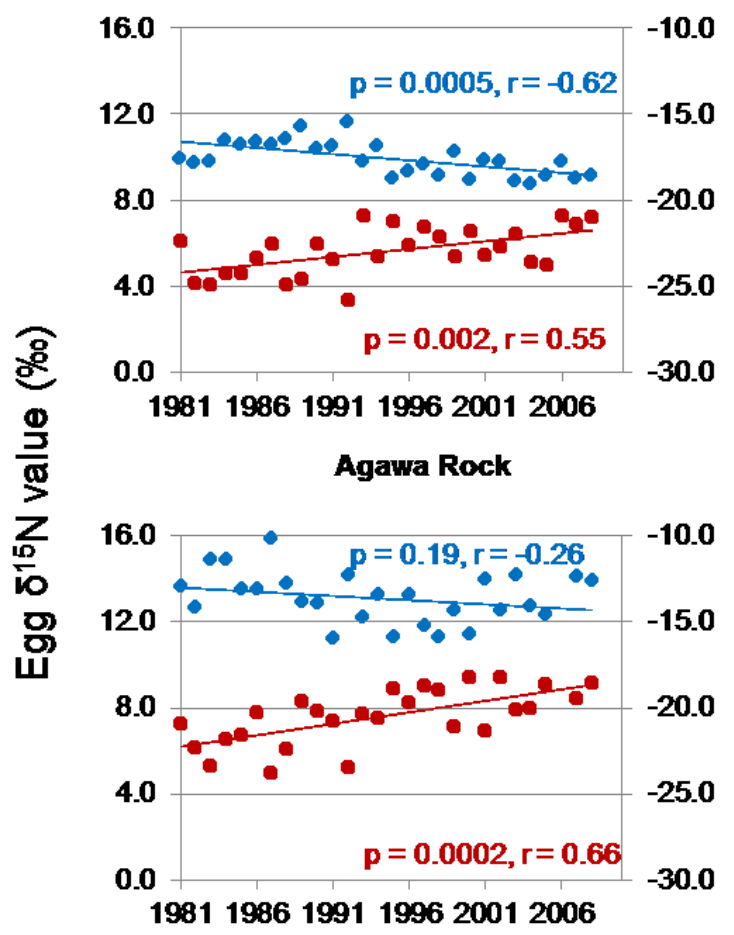

Fighting Island

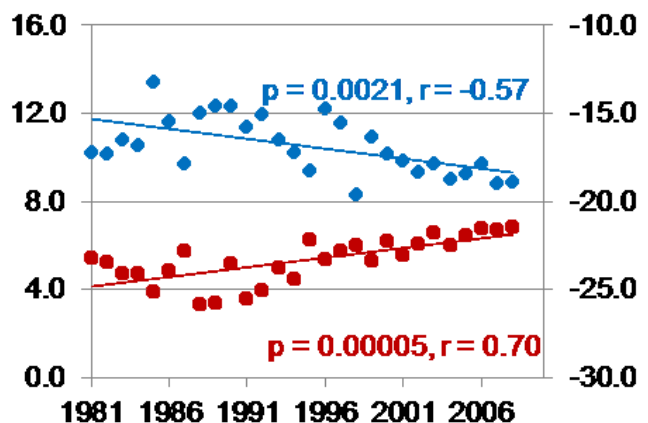

Chantry Island

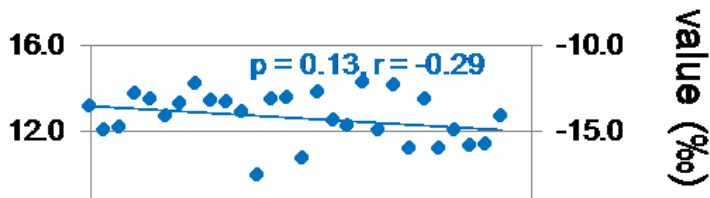

$\underset{\mathbf{0}}{\mathbf{0}}$

a

$\overrightarrow{\widetilde{\sigma}}$

品

के

$-20.0$

$-25.0$

$-30.0$

198119861991199620012006

\section{Gull Island}

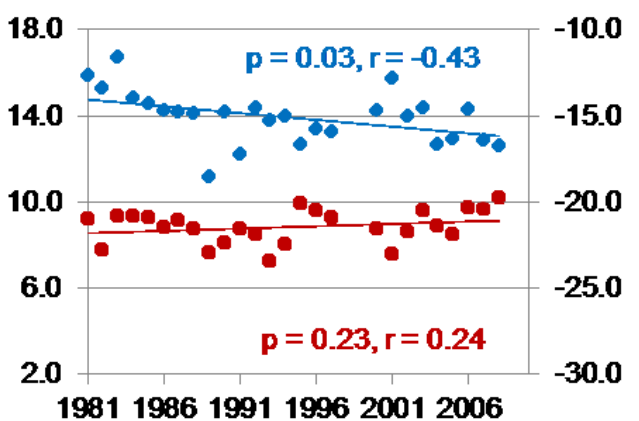

Toronto Harbor

Figure 3.2: Temporal changes of $\delta^{13} \mathrm{C}$ (circles) and $\delta^{15} \mathrm{~N}$ (squares) from 1981 to 2008 across five colony sites from the Great Lakes. The left axes represent $\delta^{15} \mathrm{~N}$ levels, and the right axes represent $\delta^{13} \mathrm{C}$ levels. 
Significant increases of egg $\delta^{13} \mathrm{C}$ values as a function of time (1981 to 2008) were found for all sites combined $(p<0.0001, r=0.42)$, and for four of the five individual sites, with the exception of Toronto Harbour, perhaps as a result of the introduction of invasive benthic species in the Great Lakes. Dreissenid mussels (Dreissena polymorpha and D. bugensis) has been shown to cause an overall benthification of the Great Lakes aquatic food web, as forage fish opportunistically feed on the increased number of benthic invertebrates (Rush et al., 2012;

Paterson et al., 2014). This in turn results in overall less negative (i.e., increased) $\delta^{13} \mathrm{C}$ values for the forage fish and their predators. Furthermore, as already mentioned, recent studies have demonstrated an overall aquatic to terrestrial shift in gull diet composition through time in some Great Lakes colonies (Hebert et al., 2008; Rush et al., 2012). The dietary shift was suggested as the result of reductions in pelagic prey fish abundances in the Great Lakes, where statistically significant temporal declines in annual indices of prey fish abundance were observed in past decades. Gulls have been consuming more food of terrestrial origins including human refuse. This enhances gulls' exposure to anthropogenic contaminants which are more enriched in a terrestrial versus aquatic environment.

\subsubsection{Herring Gull-Aquatic Food Web Relationships and OPE Concentrations}

In addition to the herring gull eggs collected from the Great Lakes, plankton, mysis, and multiple fish species were collected from sites in western Lake Ontario and Lake Erie (Figure 2.1) with the goal of better understanding OPE predator-prey relationships in the Great Lakes food web, which includes the herring gull. Most fish samples contained quantifiable levels of TBOEP (n.d. - 17.52 ng/g ww; Table 3.1). Mysis and plankton were the only samples to contain 
TPHP and TDCIPP, and were two of only four samples to contain TNBP. A complete list of all OPE concentrations, stable isotope values and calculated trophic positions for all individual samples can be found in Appendix 3. The presence of TPHP, TDCIPP and TNBP in plankton and mysis, while not present in prey fish or predators could be a result of differences in collection methods between both groups of samples. Plankton and mysis samples typically contain more water than fish samples, which may inadvertently increase the concentration of any water-soluble contaminants such as OPEs. It is equally likely, however, that OPEs have relatively low potential for bioconcentration or biomagnification, and again strongly suggests that the present aquatic biota have the ability to rapidly metabolize OPEs. TCIPP, TPHP, TDCIPP, and TNBP were all negatively correlated with $\delta^{15} \mathrm{~N}$ levels for Lake Ontario species $(p$ $\leq 0.009)$; these correlations were almost entirely driven by mysis and plankton. Correlations did not exist between any OPE concentration and $\delta^{15} \mathrm{~N}$ levels for Lake Erie species, indicating a lack of trophic magnification in these Great Lakes food webs. 
Table 3.1: Mean organophosphate ester (OPE) concentrations (ng/g ww) in 2010-collected food web samples from western Lake Ontario and Lake Erie (see Figure 2.1 for sampling locations). Concentration ranges are given in parentheses. Whole body homogenates were analyzed, unless otherwise indicated.

\begin{tabular}{|c|c|c|c|c|c|c|c|c|}
\hline Common Name & Lake & $\mathbf{n}$ & TBOEP & TCIPP & TPHP & TDCIPP & TNBP & $\Sigma_{14}$ OPE \\
\hline Herring Gull (Egg) & Ontario & 13 (1 pool) & 0.55 & 0.45 & n.d. & n.d. & n.d. & 2.10 \\
\hline Lake Trout & Ontario & 16 & 1.34 (n.d. - 9.81) & 0.02 (n.d. - 0.26) & n.d. & n.d. & 0.01 (n.d. -0.20$)$ & 1.37 (n.d. - 9.81) \\
\hline Rainbow Smelt & Ontario & 2 & $3.82(0.64-7.00)$ & n.d. & n.d. & n.d. & n.d. & $3.82(0.64-7.00)$ \\
\hline Slimy Sculpin & Ontario & 2 & $3.52(2.94-4.10)$ & n.d. & n.d. & n.d. & n.d. & $3.52(2.94-4.10)$ \\
\hline Round Goby & Ontario & 2 & $3.88(1.68-6.08)$ & n.d. & n.d. & n.d. & n.d. & $3.88(1.68-6.08)$ \\
\hline Deepwater Sculpin & Ontario & 2 & $3.65(3.29-4.00)$ & n.d. & n.d. & n.d. & n.d. & $3.65(3.29-4.00)$ \\
\hline Alewife & Ontario & 2 & $1.49(0.18-2.81)$ & n.d. & n.d. & n.d. & 0.03 (n.d. -0.06 ) & $1.52(0.24-2.81)$ \\
\hline Mysis & Ontario & 1 & 0.71 & 2.35 & 0.95 & n.d. & 1.12 & 5.13 \\
\hline Net Plankton & Ontario & 1 & 1.08 & n.d. & 0.67 & 0.63 & 0.63 & 3.01 \\
\hline Herring Gull (Egg) & Erie & 13 (1 pool) & 0.83 & 0.83 & n.d. & n.d. & n.d. & 4.37 \\
\hline Lake Trout & Erie & 8 & 1.29 (n.d. - 4.57) & n.d. & n.d. & n.d. & n.d. & 1.29 (n.d. - 4.57) \\
\hline Walleye & Erie & 10 & 3.17 (n.d. - 6.02) & 0.95 (n.d. - 3.12) & n.d. & n.d. & n.d. & $4.12(1.30-8.30)$ \\
\hline Rainbow Smelt & Erie & 3 & $2.64(1.72-3.75)$ & n.d. & n.d. & n.d. & n.d. & $2.64(1.72-3.75)$ \\
\hline Emerald Shiner & Erie & 3 & 3.20 (n.d. - 9.60) & 1.47 (n.d. - 4.42) & n.d. & n.d. & n.d. & 4.67 (n.d. - 9.60) \\
\hline Trout Perch & Erie & 3 & $1.92(0.10-3.92)$ & $2.15(1.01-4.31)$ & n.d. & n.d. & n.d. & $4.07(1.11-8.23)$ \\
\hline Round Goby & Erie & 3 & 2.25 (n.d. - 6.76) & n.d. & n.d. & n.d. & n.d. & 2.25 (n.d. - 6.76) \\
\hline Yellow Perch & Erie & 3 & 2.22 (n.d. - 6.66) & n.d. & n.d. & n.d. & n.d. & 2.22 (n.d. - 6.66) \\
\hline White Perch & Erie & 3 & $9.40(2.57-13.53)$ & 0.34 (n.d. -0.68$)$ & n.d. & n.d. & n.d. & $9.73(2.57-14.21)$ \\
\hline Freshwater Drum & Erie & 3 & $2.84(1.51-4.77)$ & n.d. & n.d. & n.d. & n.d. & $2.84(1.51-4.77)$ \\
\hline
\end{tabular}

Preliminary TMF values were calculated for all OPEs detected in more than $40 \%$ of aquatic samples from Lake Ontario and Lake Erie (Table 3.2) in order to determine if the low OPE concentrations observed in the herring gull eggs were a result of biomagnified levels in the food web. TBOEP was found to weakly biomagnify in the Lake Ontario food web (TMF = 1.6), 
while it was found to biodilute in the Lake Erie food web $(\mathrm{TMF}=0.59)$. Overall, this data suggests that OPEs, in particular TBOEP, may weakly biomagnify in food webs, where extensive metabolism is a likely contributing factor. These results should be interpreted with caution due to the low OPE levels, as well as the limited sampling of invertebrates and other low-trophic species. Additional, more expansive food web sampling is required to confirm these findings. The limited OPE biomagnification found in this study is similar to recent studies investigating OPE concentrations among food webs in the Western Scheldt Estuary (The Netherlands) (Brandsma et al., 2015) and Svalbard (Hallanger et al., 2015). In general, OPE biomagnification was limited, although TBOEP, TCIPP and TCEP were found to weakly biomagnify in the Western Scheldt Estuary's benthic food web. By comparison, Kim et al. (2011) showed biomagnification of TPHP in demersal fish species in the Philippines, and Eulaers et al. (2014) showed positive correlations between $\delta^{15} \mathrm{~N}$ values in White-tailed eagle (Haliaeetus albicilla) nestlings in Norway and TCEP, TPHP, and TBOEP concentrations, suggesting biomagnification.

Table 3.2: Estimated trophic magnification factors (TMFs) of OPEs with $95 \%$ confidence intervals for Lake Ontario and Lake Erie food webs.

\begin{tabular}{ccc}
\hline & Lake Ontario & Lake Erie \\
\hline TBOEP & & \\
TMF & 1.6 & 0.59 \\
95\% C.I. & $0.83-3.39$ & $0.27-1.28$ \\
& & \\
エOPEs & & \\
TMF & 1.02 & 0.45 \\
95\% C.I. & $0.51-2.09$ & $0.24-0.81$ \\
\hline
\end{tabular}


In additional food web examinations, principal component analysis of all samples from the Lake Ontario food web (including gull eggs) show distinct OPE profiles in plankton (driven by TDCIPP) and mysis (driven by TNBP and TCIPP) (Figure 3.3). However, no distinct differences can be seen between bird and fish species, regardless of their position in the food web ( $\left({ }^{15} \mathrm{~N}\right.$ values) or food web origin $\left(\delta^{13} \mathrm{C}\right.$ values). Similar results were obtained for the Lake Erie food web (Figure 3.4). No distinct differences can be seen between benthic vs. pelagic fish species, in either Lake Ontario or Lake Erie, although walleye contained significantly higher ( $p=$ 0.02) $\Sigma$ OPE concentrations compared to lake trout in Lake Erie (4.12 ng/g ww vs. $1.29 \mathrm{ng} / \mathrm{g}$ ww, respectively). Although they are both top predators, the walleye diet typically contains a larger percentage of nearshore benthic food sources, whereas lake trout typically feed on more offshore pelagic food sources. As a result, walleye typically occupy a lower trophic position than lake trout, as indicated by lower $\delta^{15} \mathrm{~N}$ values $(15 \%$ vs. $17 \%$, respectively; $p=0.00002)$. The higher OPE concentrations in walleye therefore strengthen the argument that OPEs generally have low biomagnification in food webs. 

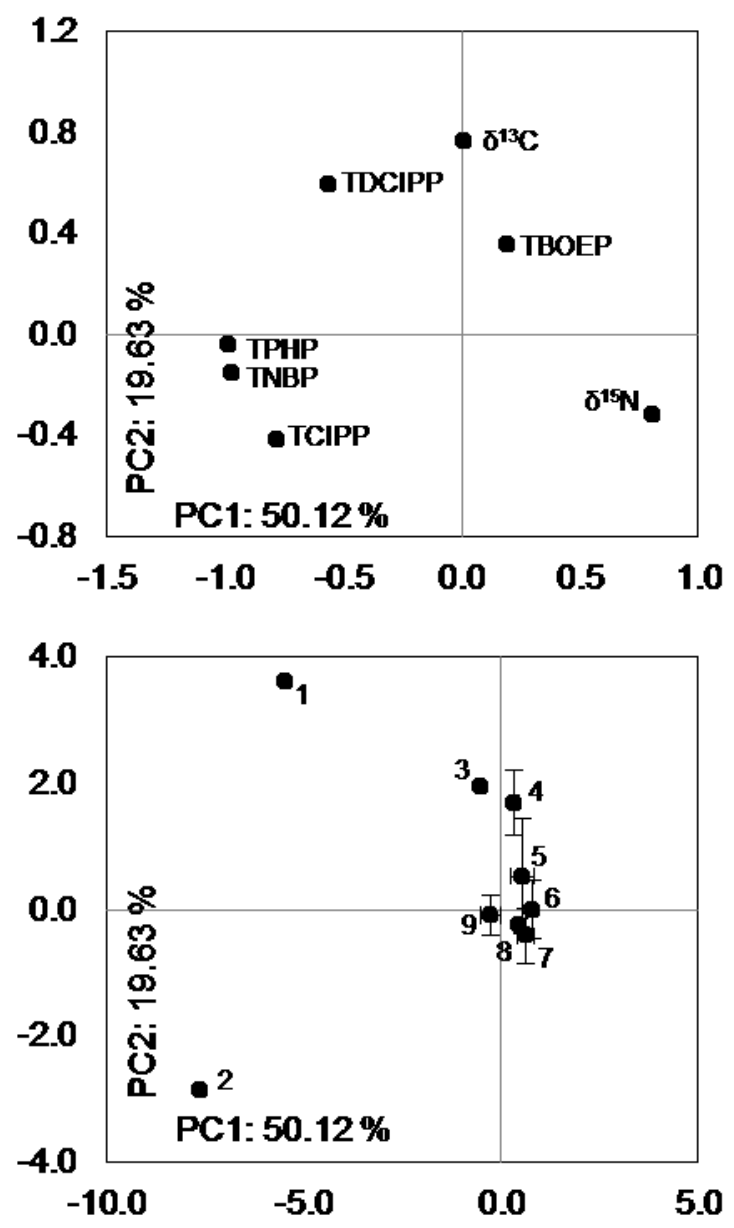

Figure 3.3 Principal component analysis (PCA) showing variation of OPE concentrations and stable isotope levels among biota and plankton from the Lake Ontario food webs. Top: loading plot showing the relationship between variables and the two principal components. Bottom: score plot showing species differences among the two principle components: (1) plankton; (2) mysis; (3) herring gull egg; (4) round goby; (5) rainbow smelt; (6) slimy sculpin; (7) lake trout; (8) deepwater sculpin; (9) alewife. All variables have been autoscaled to ensure normalization. Error bars represent standard error. 

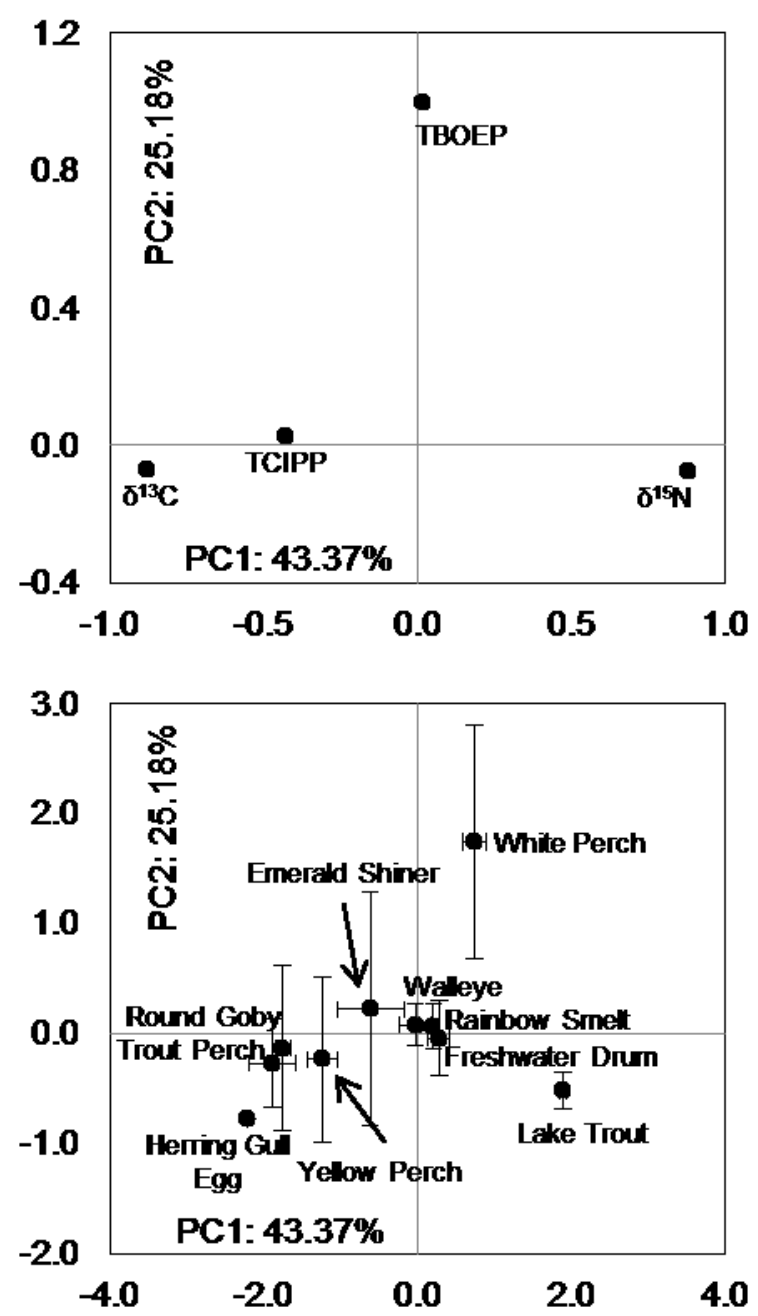

Figure 3.4 Principal component analysis showing variation of OPE concentrations and stable isotope levels among the Lake Erie food web. Top: loading plots showing the relationship between variables and the two principal components. Bottom: Score plots showing species differences among the two principal components. All variables have been autoscaled to ensure normalization. Error bars represent standard errors. 


\subsection{Conclusions}

It is important to reiterate that the OPE concentrations observed in the present Great Lakes herring gull eggs reflect OPE concentrations inherent to the maternal gull, but did not necessarily reflect the maternal dietary exposure, due to e.g. probable metabolism of OPEs by the maternal gull. To our knowledge, the present study is a rare examination of OPE concentrations in wildlife (e.g., birds) and fish, and the first study that has examined OPE concentrations in the Great Lakes food web and retrospectively over time in a wildlife species (the herring gull). Low OPE concentrations in herring gull eggs were clearly seen over 20 years despite large increases in OPE production and usage. The lack of correlation between OPE concentration and $\delta^{15} \mathrm{~N}$ values among species in the Lake Ontario and Lake Erie food webs further suggests that OPEs have low bioaccumulation and biomagnification potential as a likely result of rapid metabolism of OPEs in the gulls. In chicken eggs injected with either TCIPP or TDCIPP, less than $1 \%$ of either initial dose was detected by day 19 of incubation (Farhat et al., 2013). In chicken embryonic hepatocytes (CEH) injected with TPHP, only $0.2 \%$ of the initial TPHP dose remained after 36 hours, while 17\% of the initial TPHP dose was converted to DPHP (Su et al., 2014a). van den Eede et al. (2013b) and Su et al. (2014a) recently reported on the major metabolites of TPHP, TDCIPP, TBOEP, TCIPP and TCEP in human liver fractions and CEH. Major metabolites of these OP triesters often included their respective diester and/or various hydroxylated forms of the triesters. From these studies, it is clear that TCIPP, TDCIPP and TPHP are rapidly metabolized in developing chicken embryos and adult liver microsomes. Although OPE metabolism has yet to be demonstrated specifically in herring gulls, it is very likely that such biotransformation is occurring. As a result, in the present gull eggs as in other studies (Chen et al., 2012; Greaves and Letcher, 2014; Su et al., 2015a), the generally low OPE 
concentrations in gull eggs reflects in part their susceptibility to metabolism in the maternal gulls and are likely post-metabolic residue levels and not necessarily accurately reflective of the maternal dietary OPE exposure. Regardless, rates of OPE metabolism remain unknown for birds and wildlife in general. Furthermore, the pharmacokinetics of OPE accumulation (and potentially metabolism) remains largely unknown in wildlife. As such, in Chapter 4, the tissue distribution of OPEs among multiple tissues in herring gulls and their eggs is explored, with the goal of understanding the fate of OPEs in the body. 


\section{CHAPTER 4}

Tissue Distribution and In Ovo Transfer of Organophosphate Ester Flame Retardants in Herring Gulls from the Great Lakes ${ }^{1}$

\footnotetext{
${ }^{1}$ Publication Associated with this Thesis Chapter:

A.K. Greaves, R.J. Letcher. 2014. Environmental Science \& Technology 48, 7942-7950.
} 


\subsection{Introduction}

American production volumes of TDCIPP, TPHP, and TCIPP in 2006 were between five and ten times higher than they were in the late 1980s (Chen et al., 2012). That being said, it was found in Chapter 3 that $\Sigma$ OPE concentrations in herring gull eggs from 1990 to 2010 remained quite low (n.d. to $6.69 \mathrm{ng} / \mathrm{g} \mathrm{ww}$ ). Furthermore, OPE concentrations in air particulate and surface water samples from the Great Lakes are on average comparable to or exceed polybrominated diphenyl ether (PBDE) concentrations (Salamova et al., 2014; Venier et al., 2014), even though recently analyzed herring gull egg samples from the Great Lakes contained OPE concentrations 2 to 3 orders of magnitude lower than PBDEs ( $\mathrm{Su}$ et al., 2015a). It was concluded in Chapter 3 that OPE persistence in herring gulls is low, likely due to rapid metabolism of OPEs in maternal gulls. However, there is a dearth of information concerning OPE concentrations in maternal herring gulls and how that relates to concentrations in their eggs.

In fact, relatively few studies have investigated OPEs in wildlife, particularly in birds. Eulaers et al. (2014) very recently screened for six OPEs in feathers and blood plasma of whitetailed eagle nestlings from Norway. TCEP and TCIPP were dominant in feathers (110 and 91 ng/g dry weight, respectively), while TCIPP and TDCIPP were the only OPEs detected in plasma $(0.22 \mathrm{ng} / \mathrm{g}$ ww, each). Ma et al. (2013) recently reported OPE concentrations in muscle tissue of domestic chickens (Gallus gallus domesticus) and ducks (Anas platyrhynchos domesticus). TNBP, TCEP, TBOEP, and TPHP were present at highest concentrations (up to $281 \mathrm{ng} / \mathrm{g}$ lipid weight; 14 ng/g wet weight, ww). Limited studies have now investigated OPEs in herring gull eggs from the Great Lakes (Greaves et al., 2016; Chen et al., 2012; Su et al., 2015a). In general, TCIPP, TBOEP, and TCEP are the most commonly detected OPEs, with $\Sigma$ OPE concentrations ranging from 1.41 to $6.69 \mathrm{ng} / \mathrm{g}$ ww. 
To our knowledge, there are no published reports on OPE body compartment composition and in ovo or in utero transfer for any given wildlife species. One laboratory study with male Wistar rats showed that TMPP is distributed to the adipose, liver, and kidney shortly after acute exposure (Kurebayashi et al., 1985). The present study is a body compartment composition investigation on the deposition and burden of sixteen OPEs for which were analyzed in multiple tissues and blood (plasma and red blood cells) of female herring gulls (Lake Huron, Great Lakes of North America), as well as an examination of the in ovo transfer of these OPEs into yolk and albumen of their entire egg clutches.

\subsection{Results and Discussion}

\subsubsection{Tissue-Specific Accumulation of OPEs in Herring Gulls}

OPE concentrations varied greatly among body and egg compartments. $\Sigma$ OPE concentrations (mean $\pm \mathrm{SE}$ ) were highest in fat $(32.3 \pm 9.8 \mathrm{ng} / \mathrm{g} \mathrm{ww})$, followed by yolk (14.8 \pm $2.4 \mathrm{ng} / \mathrm{g} \mathrm{ww})$, albumen $(14.8 \pm 5.9 \mathrm{ng} / \mathrm{g} \mathrm{ww})$, and muscle (10.9 $\pm 5.1 \mathrm{ng} / \mathrm{g} \mathrm{ww})$. Red blood cells contained a low but quantifiable $\Sigma \mathrm{OPE}$ concentration $(1.00 \pm 0.62 \mathrm{ng} / \mathrm{g} \mathrm{ww})$, and blood plasma, liver, and brain all had OPE concentrations below the method limits of quantification (Table 4.1). The lack of OPEs in the brain strongly suggests that the blood-brain barrier, a highly selective barrier that filters incoming and outgoing blood to the brain, is effective at preventing OPEs from entering the brain. Furthermore, the presence of OPEs in fat and muscle (long-term storage tissues), but not in liver or blood plasma (short-term mobilization tissues) suggests rapid metabolism of OPEs. 
Table 4.1 Mean ( \pm standard error) OPE concentrations across all herring gull tissues. For compounds detected in less than half of samples for a given tissue, concentration ranges are shown ( $\min -\max )$, with detection frequency $(\%)$ in brackets. All concentrations are given in $\mathrm{ng} / \mathrm{g}$ wet weight.

\begin{tabular}{|c|c|c|c|c|c|c|c|c|c|}
\hline Compound & Full Name & $\begin{array}{c}\text { Yolk } \\
(\mathrm{n}=16)\end{array}$ & $\begin{array}{l}\text { Albumen } \\
(\mathrm{n}=16)\end{array}$ & $\begin{array}{c}\text { Fat } \\
(\mathrm{n}=8)\end{array}$ & $\begin{array}{l}\text { Muscle } \\
(\mathrm{n}=8)\end{array}$ & $\begin{array}{l}\text { Red Blood Cells } \\
\qquad(\mathrm{n}=8)\end{array}$ & $\begin{array}{l}\text { Blood Plasma } \\
\qquad(\mathrm{n}=8)\end{array}$ & $\begin{array}{l}\text { Liver } \\
(\mathrm{n}=8)\end{array}$ & $\begin{array}{l}\text { Brain } \\
(\mathrm{n}=8)\end{array}$ \\
\hline TBOEP & Tris(2-butoxyethyl) phosphate & $1.89 \pm 0.69$ & $8.09 \pm 2.49$ & $13.4 \pm 5.6$ & $1.37 \pm 0.78$ & n.d. $-4.69(38)$ & n.d. $-2.25(13)$ & n.d. & n.d. \\
\hline TCEP & Tris(2-chloroethyl) phosphate & $1.38 \pm 0.31$ & $1.46 \pm 0.77$ & $0.65 \pm 0.25$ & n.d. $-1.51(38)$ & n.d. & n.d. & n.d. & n.d. \\
\hline TCIPP & Tris(2-chloroisopropyl) phosphate & $6.05 \pm 1.36$ & $2.31 \pm 1.64$ & $2.14 \pm 0.73$ & $1.42 \pm 0.61$ & n.d. & n.d. & n.d. & n.d. \\
\hline TDCIPP & Tris(1,3-dichloro-2-propyl) phosphate & $0.93 \pm 0.34$ & $0.47 \pm 0.29$ & $4.43 \pm 1.87$ & $5.04 \pm 3.69$ & $1.00 \pm 0.62$ & n.d. $-0.10(13)$ & n.d. $-0.37(25)$ & n.d. $-1.28(25)$ \\
\hline TNBP & Tributyl phosphate & $3.63 \pm 0.58$ & n.d. $-28(25)$ & $2.02 \pm 0.91$ & $1.79 \pm 0.58$ & n.d. & n.d. & n.d. & n.d. \\
\hline TPHP & Triphenyl phosphate & $0.89 \pm 0.25$ & n.d. $-4.18(38)$ & $2.11 \pm 1.11$ & n.d. $-1.03(38)$ & n.d. $-1.00(13)$ & n.d. & n.d. & n.d. \\
\hline TEHP & Tris(2-ethylhexyl) phosphate & n.d. & n.d. $-1.94(31)$ & $7.49 \pm 6.48$ & n.d. $-0.22(25)$ & n.d. & n.d. & n.d. & n.d. \\
\hline TEP & Triethyl phosphate & n.d. $-0.81(38)$ & n.d. $-23.0(38)$ & n.d. $-5.89(25)$ & $0.68 \pm 0.36$ & n.d. & n.d. & n.d. $-0.93(13)$ & n.d. \\
\hline EHDPP & 2-Ethylhexyl-diphenyl phosphate & n.d. -2.49 (19) & n.d. $-10.9(25)$ & n.d. $-2.11(25)$ & $0.41 \pm 0.09$ & n.d. $-0.31(13)$ & n.d. $-0.18(25)$ & n.d. & n.d. \\
\hline ТРP & Tripropyl phosphate & n.d. & n.d. & n.d. & n.d. & n.d. & n.d. & n.d. & n.d. \\
\hline TMPP & Trimethylphenyl phosphate & n.d. & n.d. & n.d. & n.d. & n.d. & n.d. & n.d. & n.d. \\
\hline TDBPP & Tris(1,3-dibromo-2-propyl) phosphate & n.d. & n.d. & n.d. & n.d. & n.d. & n.d. & n.d. & n.d. \\
\hline T2B4MP & Tris(2-bromo-3-methylphenyl) phosphate & n.d. & n.d. & n.d. & n.d. & n.d. & n.d. & n.d. & n.d. \\
\hline T4B3MP & Tris(4-bromo-3-methylphenyl) phosphate & n.d. & n.d. & n.d. & n.d. & n.d. & n.d. & n.d. & n.d. \\
\hline T3B4MP & Tris(3-bromo-4-methylphenyl) phosphate & n.d. & n.d. & n.d. & n.d. & n.d. & n.d. & n.d. & n.d. \\
\hline V6 & $\begin{array}{l}\text { 2,2-bis(chloromethyl)propane-1,3-diyl } \\
\text { tetrakis(2-chloroethyl)bis(phosphate) }\end{array}$ & n.d. & n.d. & n.d. & n.d. & n.d. & n.d. & n.d. & n.d. \\
\hline$\Sigma$-OPEs & & $14.8 \pm 2.4$ & $14.8 \pm 5.9$ & $32.3 \pm 9.8$ & $10.9 \pm 5.1$ & $1.00 \pm 0.62$ & n.d. & n.d. & n.d. \\
\hline
\end{tabular}


OP triesters, like the ones analyzed in this study, are thought to be easily dealkylated to their respective diesters via hydrolysis in the body (Chu et al., 2011; Sasaki et al., 1984; Schindler et al., 2009). These triesters are assumed to dealkylate either spontaneously or enzymatically via $\alpha$-esterases and phosphorylphosphatases (Schindler et al., 2009). Many factors may affect their biodegradability, including bulky alcohol or halogenated moieties causing steric effects, and high lipophilicity (Reemtsma et al., 2008). Chu et al. (2011) recently demonstrated that rat liver microsomes metabolized TDCIPP to its diester, bis(1,3-dichloro-2-propyl) phosphate (BDCIPP), very rapidly and effectively (over 95\% conversion within 100 minutes). Sasaki et al. (1984) and Chapman et al. (1991) also assessed OP triester metabolism in rat liver microsomes, and found that TPHP was readily metabolized to diphenyl phosphate (DPHP), and TCEP was partially metabolized to bis(2-chloroethyl) phosphate (BCEP). TNBP was also partially metabolized to dibutyl-n-phosphate (DNBP), however its major metabolites were hydroxylated forms of TNBP (i.e., TNBP-OH, and TNBP-OH ${ }_{2}$ (Sasaki et al., 1984). Further evidence of metabolism has been seen in avian hepatocytes, zebrafish embryos, and chicken embryos, which when exposed to TDCIPP and/or TCIPP showed upregulation of phase 1 and/or phase 2 metabolism enzymes (Liu et al., 2012; Farhat et al., 2013; Crump et al., 2012). Although the metabolism of the OPEs under review in this study has yet to be tested in herring gulls, it is likely that these triesters are readily metabolized in these birds. Therefore, it is important to note that all OPE concentrations seen in this study are likely residual levels, the result of factors such as e.g. selective deposition to a given tissue, enzyme-mediated metabolism and/or chemical degradation in the body.

It has been shown that the first-laid egg in a clutch is always the largest and heaviest, and eggs sequentially laid are of decreasing weight, with up to a maximum of three eggs per clutch 
(Verreault et al., 2006). From the recorded egg lengths and masses of all collected eggs, it is possible to distinguish which of the two eggs from each clutch was laid first. The effect of laying order on OPE concentrations was examined across all egg clutches in the present study. No significant $(p<0.33)$ differences between first- and second-laid eggs were observed for the $\Sigma$ OPE concentration or for any individual OPE concentration. For Norwegian glaucous gulls (Larus hyperboreus), Verreault et al. (2006) reported that concentrations of $\Sigma$ PBDEs,

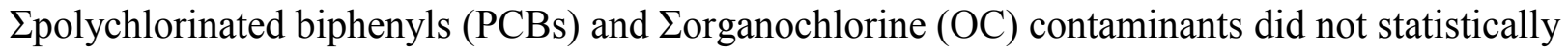
vary between first-, second-, or third-laid eggs in clutches. As Verreault et al. (2006) hypothesized, the lack of intra-clutch OPE variability could indicate constant movement and shuttling of these compounds in the body, as well as a constant exposure to these compounds via the environment and/or diet.

The OPEs detected and quantifiable in more than one body or egg compartment were TBOEP, TCEP, TCIPP, TDCIPP, TNBP and TPHP. These six OPEs are also the major ones that have been found in multiple abiotic studies worldwide, including surface water, sewage treatment plants, and sediment (van der Veen and de Boer, 2012; Cristale et al., 2013; Leonards et al., 2011; Reemtsma et al., 2008). Eulaers et al. (2014) very recently examined for six OPEs (TDCIPP, TCEP, TCIPP, TBOEP, TPHP and EHDPP) in feathers and blood plasma of whitetailed eagle nestlings from Norway. TCEP and TCIPP were dominant in feathers (110 and 91 ng/g dry weight, respectively), while TCIPP and TDCIPP were the only OPEs detected in plasma (0.22 ng/g ww, each). Salamova et al. (2014) found that these same six OPEs (TBOEP, TCEP, TCIPP, TDCIPP, TNBP and TPHP) were detected in the particle phase of air from five collection sites (in 2012) around the Great Lakes. Urbanized areas (i.e., Cleveland, and Chicago) contained overall higher $\Sigma$ OPE concentrations (maximum of 2,100 $\pm 400 \mathrm{pg} / \mathrm{m}^{3}$ ) than more 
remote areas (i.e., Sturgeon Point, Eagle Harbor, and Sleeping Bear; minimum of $120 \pm 18$

$\mathrm{pg} / \mathrm{m}^{3}$ ). Furthermore, in Chapter 3, it was found that these same six OPEs, in particular TBOEP, TCEP, and TCIPP, were found in multiple aquatic food web samples (including mysis, plankton, and multiple fish species) from the western Lake Erie and Ontario.

In the present herring gulls, all body and egg compartments contained different proportions of OPEs (Figure 4.1). For example, in the egg, TBOEP accounted for approximately $66 \%$ of the $\Sigma$ OPE concentration in albumen, but only for $13 \%$ in yolk; TNBP accounted for $25 \%$ of $\Sigma$ OPEs in yolk, but was not detected at all in albumen. In the maternal gull, TDCIPP accounted for $100 \%$ of the $\Sigma$ OPE concentration in red blood cells, but only approximately $46 \%$ in muscle, and only $14 \%$ in fat. The difference in OPE patterns between tissues is further illustrated in the PCA loading and score plots (Figure 4.2). PC 1 and PC 2 (38.6\% and 21.8\%) account for $>60 \%$ of the overall variability in the data. PCA showed that individual OPEs were generally well distributed across both factors, although TCEP, TCIPP, and TNBP were clustered together. The score plot (Figure 4.2) indicates that this clustering is driven by the yolk. Regardless, these tissue-specific accumulation patterns demonstrated that the depositional OPE patterns are to some extent body and egg compartment specific. 


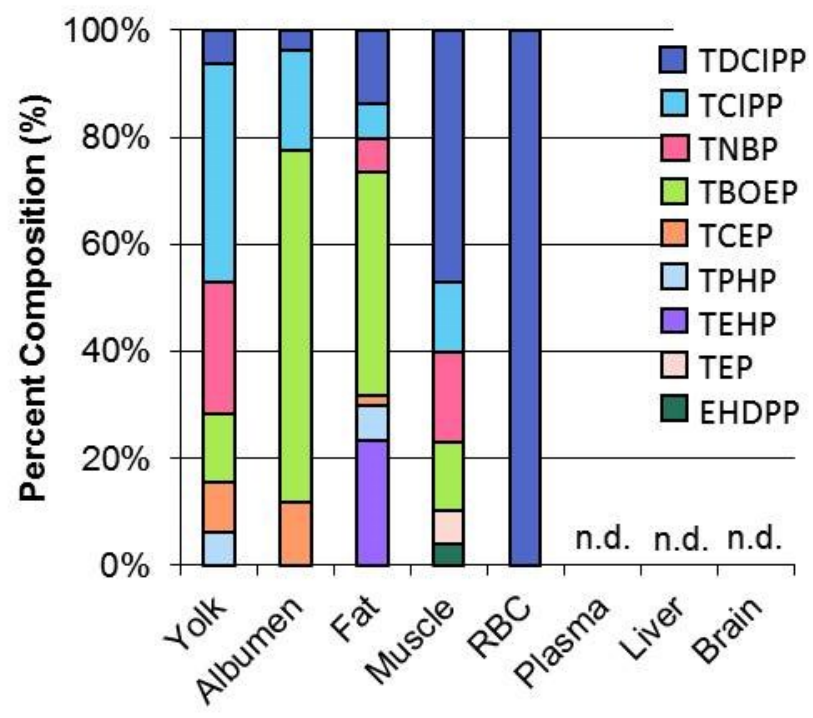

Figure 4.1 Percent proportions of the arithmetic mean $\Sigma$ OPE concentrations for each tissue $(\mathrm{n}=$ 16 for yolk and albumen, $\mathrm{n}=8$ for all other tissues). 

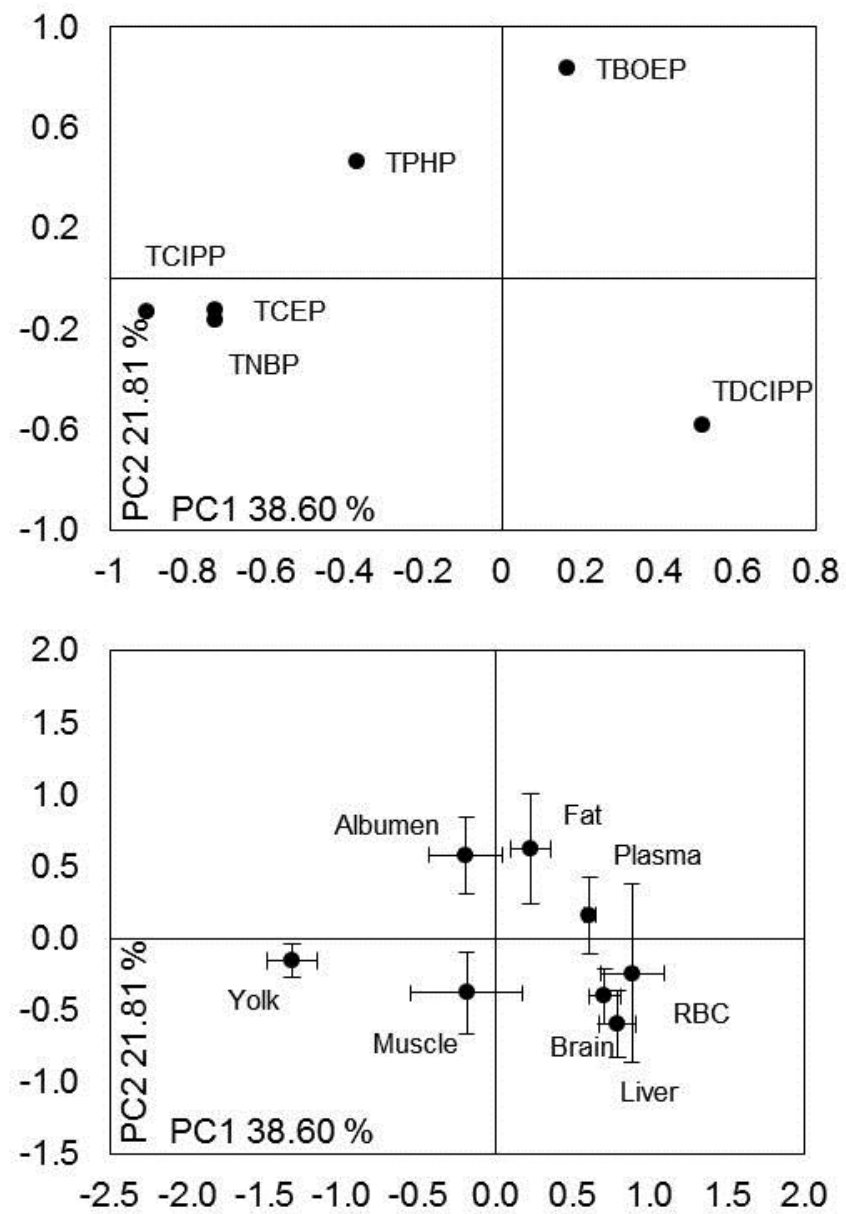

Figure 4.2 Principle Components Analysis (PCA) of the ratios of individual OPE to $\Sigma$ OPE concentrations and showing the first and second principle components; PC 1 and PC 2 (top). Mean ( \pm standard error) factor scores for all tissues are shown in the bottom plot. Variability associated with PC 1 and PC 2 are given. 
In an attempt to understand these OPE pattern differences between tissues, correlative relationships were examined among compound concentrations and various physical parameters (i.e., bioconcentration factors of OPEs, extractable lipid content in samples, and partition coefficients of OPEs). The bioconcentration factor (BCF) reflects the extent to which a compound will concentrate from the surrounding water into an aquatic organism. van der Veen and de Boer (2012) compiled a list of the known BCFs for OPEs, including the major OPEs detected in this study: TCEP, TCIPP, TDCIPP, TPHP, TNBP, and TBOEP. These six OPEs have a large range of $\mathrm{BCFs}$, from 1.37 for TCEP to 1080 for TBOEP. From examination of the correlations between OPE concentrations and their BCFs, a weak but significant correlation was observed in yolk ( $p=0.012, r=0.28$; Figure 4.3). A similar correlation was observed in albumen ( $p=0.006, r=0.39$ ), although no significant correlative relationships were observed in the maternal gull. Overall, and considering that herring gulls have a diet comprised mainly of fish, it appears that the BCFs do not play a significant role in the body compartment deposition and distribution of OPEs in herring gulls. 


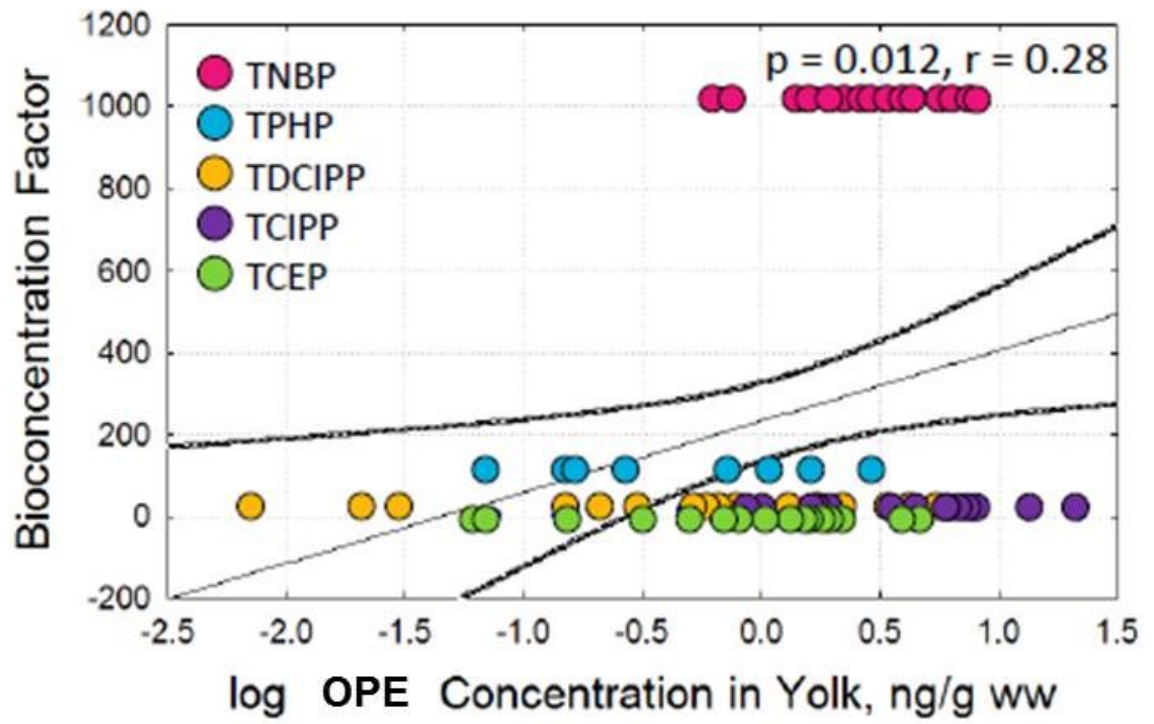

Figure 4.3 Example correlations between the bioconcentration factors (BCFs) of detected OPEs and their concentrations in a given herring gull tissue. The example provided is in yolk. Statistically significant relationships were observed in yolk and albumen, but not in any other tissue. 
Correlations between all OPE concentrations and the lipid content of individual samples were examined to determine if OPEs accumulated in a tissue as a function of extractable lipid content. Overall, only TDCIPP showed a significant but weak correlation with extractable lipid content $(p=0.01, r=0.43)$. The final correlative parameter to be examined was the octanolwater partition coefficient $\left(K_{O W}\right)$ of the OPEs. The $K_{O W}$ of a compound dictates the preference for compound accumulation in a polar versus a non-polar environment. Correlations between OPE concentrations and their $\log -K_{\mathrm{OW}}$ values showed no significant relationships $(p \geq 0.41)$. For example, even though the lipid content in yolk was more than 100 times higher than in albumen ( $31 \%$ vs. $0.2 \% \mathrm{w} / \mathrm{w}$, respectively), $\Sigma \mathrm{OPE}$ concentrations in the yolk and albumen were statistically identical ( $14.8 \pm 2.4 \mathrm{ng} / \mathrm{g}$ ww vs. $14.8 \pm 5.9 \mathrm{ng} / \mathrm{g}$ ww, respectively; $p=0.49)$.

Although hydrophobic in nature, OPE triesters do not behave like typical hydrophobic organic contaminants. Their equivalent concentrations in yolk and albumen (Table 4.1), regardless of the enormous difference in extractable lipid contents in these egg compartments suggests that their hydrophobicities do not play a role in their in ovo transfer and residue concentrations, but rather that other processes are at work such as protein-associated pathways.

To our knowledge, there has yet to be a study which investigates the binding affinity of OPEs with various transport proteins in the body. Such information would be useful in understanding how OPEs are distributed in the body, and why certain OPEs accumulate preferentially in one tissue over another as our present results demonstrate. Fang et al. (2013) showed that TPHP has a moderate binding affinity for the androgen receptor, yet has no binding affinity for the estrogen receptor. It has also been shown that TCEP has a weak binding affinity for acetylcholinesterase (Matthews et al., 1990). Multiple studies have examined the phenotypic effects of OPEs in rodents, birds and fish (Wang et al., 2013; Liu et al., 2012; Farhat et al., 2013; 
Liu et al., 2013; Umezu et al., 1998; Morales et al., 1980). In most of these studies, even though valuable information has been gained regarding phenotypic changes upon exposure to OPEs (such as endocrine disruption, developmental toxicity, and mRNA expression changes), very little is known regarding direct interactions between OPEs and specific biomolecules.

\subsubsection{Burden Estimate of Organophosphate Ester Flame Retardants}

The mass burdens of each OPE in all body and egg compartments (Table 4.2) were estimated based on OPE concentrations (Table 4.1), and a combination of sample collection data and estimated tissue masses (additional detail in section 2.4, Materials and Methods section). Overall the OPE tissue burdens were highest in fat $(2.5 \pm 0.7 \mu \mathrm{g})$, followed by muscle $(1.1 \pm 0.5$ $\mu \mathrm{g})$, yolk $(0.8 \pm 0.1 \mu \mathrm{g})$, albumen $(0.35 \pm 0.05 \mu \mathrm{g})$, and red blood cells $(0.02 \pm 0.01 \mu \mathrm{g})$, and were not detected in blood plasma, liver, and brain. These burdens were used to determine overall accumulation differences between mother (body) and offspring (egg) (Figure 4.4). It is important to note that the burden estimates for the mother are a lower bound estimate, since the tissues that were sampled in this study (i.e., fat, muscle, liver, blood plasma, red blood cells, and brain) only accounted for approximately $30 \%$ of the maternal gull's total body mass. Even so, body burden estimates were comparable or higher than egg burden estimates for most OPEs. 
Table 4.2 Mean ( \pm standard error) OPE mass burdens across all herring gull tissues. All burdens are given in ng.

\begin{tabular}{ccccccccc}
\hline & $\begin{array}{c}\text { Yolk } \\
(\mathrm{n}=16)\end{array}$ & $\begin{array}{c}\text { Albumen } \\
(\mathrm{n}=16)\end{array}$ & $\begin{array}{c}\text { Fat } \\
(\mathrm{n}=8)\end{array}$ & $\begin{array}{c}\text { Muscle } \\
(\mathrm{n}=8)\end{array}$ & $\begin{array}{c}\text { Red Blood } \\
\text { Cells } \\
(\mathrm{n}=8)\end{array}$ & $\begin{array}{c}\text { Blood } \\
\text { Plasma } \\
(\mathrm{n}=8)\end{array}$ & $\begin{array}{c}\text { Liver } \\
(\mathrm{n}=8)\end{array}$ & $\begin{array}{c}\text { Brain } \\
(\mathrm{n}=8)\end{array}$ \\
\hline TBOEP & $205 \pm 49$ & $94 \pm 26$ & $1017 \pm 409$ & $133 \pm 74$ & n.d. & n.d. & n.d. & n.d. \\
TCEP & $80 \pm 15$ & $33 \pm 6$ & $50 \pm 18$ & n.d. & n.d. & n.d. & n.d. & n.d. \\
TCIPP & $282 \pm 58$ & $120 \pm 26$ & $165 \pm 47$ & $140 \pm 59$ & n.d. & n.d. & n.d. & n.d. \\
TDCIPP & $44 \pm 14$ & $19 \pm 7$ & $341 \pm 143$ & $493 \pm 355$ & $23 \pm 14$ & n.d. & n.d. & n.d. \\
TNBP & $181 \pm 31$ & $74 \pm 12$ & $154 \pm 68$ & $180 \pm 58$ & n.d. & n.d. & n.d. & n.d. \\
TPHP & $41 \pm 7$ & $18 \pm 4$ & $157 \pm 80$ & n.d. & n.d. & n.d. & n.d. & n.d. \\
TEHP & n.d. & n.d. & $588 \pm 513$ & n.d. & n.d. & n.d. & n.d. & n.d. \\
TEP & n.d. & n.d. & n.d. & $70 \pm 38$ & n.d. & n.d. & n.d. & n.d. \\
EHDPP & n.d. & n.d. & n.d. & $42 \pm 9$ & n.d. & n.d. & n.d. & n.d. \\
LOPEs & $834 \pm 105$ & $358 \pm 49$ & $2472 \pm 723$ & $1057 \pm 488$ & $23 \pm 14$ & n.d. & n.d. & n.d. \\
\hline
\end{tabular}

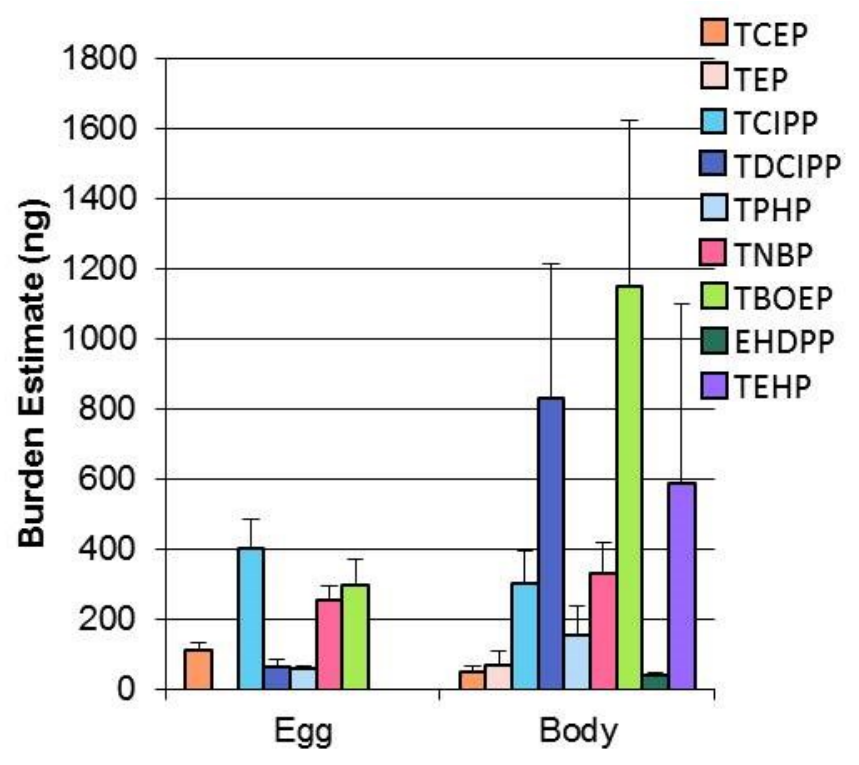

Figure 4.4 Combined arithmetic mean ( \pm standard error) OPE burdens for the egg (yolk and albumen), and maternal body (fat, muscle, red blood cells, plasma, liver and brain). 
It is highly probable that OPEs undergo rapid metabolism in the maternal gull.

Accumulated OPE burdens in the maternal gull are likely post-metabolic residues, found largely in storage tissues (e.g., fat), as opposed to high metabolic activity tissues (e.g., liver). These residues are subsequently transferred in ovo to their eggs. Therefore, all OPEs in the egg likely reflect to some extent residual OPE burdens in the maternal gull post-metabolism. It should be noted that in ovo transfer of OPEs seems to be to some degree compound-specific. Although the $\Sigma$ OPE burden was higher in the maternal gull, burdens in the gull were not proportional to burdens in the egg. For example, there was overall about one third as much TCIPP as TDCIPP in the maternal gull, although there was about six times more TCIPP as TDCIPP in the egg, indicating a preferential transfer of TCIPP in ovo.

The same eight individual herring gulls analyzed in this study were also analyzed for perfluoroalkyl substances (PFASs; Gebbink and Letcher 2012). PFASs are extremely stable to degradation, and have been shown to bioaccumulate and biomagnify in food webs, particularly perfluorooctane sulfonate (PFOS) (Gebbink and Letcher, 2012). Overall body burdens of $\Sigma$ PFASs and $\Sigma$ OPEs were very similar ( $4.0 \mu \mathrm{g}$ vs. $3.5 \mu \mathrm{g}$, respectively), but the egg burden of $\Sigma$ PFASs was much higher than that of $\Sigma$ OPEs ( $8.6 \mu \mathrm{g}$ vs. $1.2 \mu \mathrm{g}$, respectively). Female herring gulls typically lay three eggs per clutch. Based on these estimated burdens, female herring gulls clear approximately $50 \%$ of their $\Sigma \mathrm{OPE}$ burden per clutch, whereas they clear approximately $87 \%$ of their $\Sigma$ PFAS burden per clutch. These burdens indicate that although in ovo transfer of OPEs occurs to a much lesser extent than PFASs, in ovo transfer of OPEs is still a significant depuration pathway for female herring gulls. 


\subsection{Conclusions}

In this chapter, the accumulation patterns (and estimated burdens) of OPEs were assessed in eight different tissues of female herring gulls and their eggs. Burden estimates indicate that despite non-detectable OPE concentrations in the liver, overall $\Sigma$ OPE burdens in the maternal gulls and their eggs were significant $(3.5 \mu \mathrm{g}$ and $1.2 \mu \mathrm{g}$, respectively). These burdens indicate that in ovo transfer of OPEs is a significant depuration pathway in female herring gulls.

It was also determined that OP triesters accumulate preferentially in long-term storage tissues in maternal gulls. It was hypothesized that these accumulation patterns are a result of rapid OP triester metabolism in the liver, which would result in very low levels of OPEs in the liver, with higher concentrations in low-mobility, long-term storage tissues like fat and muscle, as observed in this chapter. OP diesters have consistently been shown to be either major or minor metabolites of OP triesters (van den Eede et al., 2013, 2015, 2016). As a result, using a newly developed method for the determination and quantification of OP diesters in biological samples, the blood plasma samples analyzed for OP triesters in this chapter will be re-analyzed for OP diesters in Chapter 5, with the goal of detecting metabolites of OP triesters in the gull, and strengthening the hypothesis regarding rapid OP triester metabolism in the liver. 


\section{CHAPTER 5}

Metabolites of Organophosphate Ester Flame Retardants in the Blood Plasma of Herring Gulls from the North American Great Lakes ${ }^{1}$

\footnotetext{
${ }^{1}$ Publication Associated with this Thesis Chapter:

G. Su, A.K. Greaves, L.T. Gauthier, R.J. Letcher. 2014. Journal of Chromatography A 1374, 85-92.
} 


\subsection{Introduction}

In Chapter 4, body and egg compartment distribution of OP triesters in female herring gulls from a Lake Huron colony site in the Great Lakes was reported (Greaves and Letcher, 2014). Concentrations of OPEs were highest in fat ( OOPE concentration of $32.3 \pm 9.8 \mathrm{ng} / \mathrm{g}$ wet weight), and were not detectable in liver, blood plasma, or brain. These concentrations in herring gulls are quite low considering their exposure. A recent study by Salamova et al. (2014) showed that concentrations of OPEs in particle phase samples from the Great Lakes atmosphere were very high and up to $2100 \pm 400 \mathrm{pg} / \mathrm{m}^{3}$, two to three orders of magnitude higher than other brominated flame retardants found in the same samples. The overall low levels of OP triesters in herring gull samples were hypothesized to be due to extensive metabolism in the exposed gulls.

There are a limited number studies that have examined OP triester metabolism. Using adult male Wistar Han and Fischer 344N rat liver microsomes, studies have consistently found that rapid conversion occurs in vitro for tris(1,3-dichloro-2-propyl) phosphate (TDCIPP) to bis(1,3-dicholoro-2-propyl) phosphate (BDCIPP), triphenyl phosphate (TPHP) to diphenyl phosphate (DPHP), and tri-n-butyl phosphate (TNBP) to di-n-butyl phosphate (DNBP) as well as to other hydroxylated metabolites of TNBP (Chu et al., 2011; Sasaki et al., 1984; Chapman et al., 1991). Su et al. (2014a, 2015b) very recently showed that TPHP metabolism is rapid in chicken embryonic hepatocytes. After 36 hours, only $0.2 \%$ of the original TPHP dose remained, while $17 \%$ of the original dose had been converted to DPHP.

Until very recently, a method did not exist for the quantification of OP flame retardant metabolites (herein referred to as OP diesters) for analysis of biological matrices. As such, the detection or determination of OP diesters in wildlife samples has, until now, not been possible. A 
part of this thesis work was to develop and validate an analytical method for the detection and quantification of six OP diesters in matrices of varying complexity, namely egg, liver, and serum (Su et al., 2014b). In the present study, we examine plasma samples of herring gulls from a colony site in eastern Lake Huron for OP diesters and compare to OP triesters to further our understanding of the metabolic susceptibility and fate of OPEs in herring gulls. These plasma samples are from the same gulls that were analyzed in Chapter 4.

\subsection{Results and Discussion}

Blood serum (plasma) is a very suitable tissue choice for determining the presence of OP diesters. Blood is constantly shuttling chemicals (both natural and xenobiotic in nature) throughout the body. Therefore, if the liver metabolizes OP triesters to OP diesters, diesters will likely be found in the blood, as they are shuttled to other tissues in the body (e.g., the kidneys). The six herring gull plasma samples analyzed in this study are the same samples analyzed in Chapter 4, and were analyzed based on the method described by Chen et al. (2012). OP triesters including TCIPP, TDCIPP, TPHP, TNBP, TBOEP and TEHP were all detected in Chapter 4, although none were detectable in plasma in relation to sample blank concentrations. This was in large part due to significant levels of OPE detected in the solvents used during analysis. These herring gull plasma samples were re-analyzed for OP triesters as part of the present study. Overall, by reducing the volume of solvent used in the sample preparation stage of the method, background contamination was reduced on average by $32 \pm 11 \%$. As a result, certain OP triesters (i.e., TPHP and TDCIPP), which were previously not quantifiable in Chapter 4 (Greaves and Letcher, 2014), were quantified in at least $50 \%$ of the same plasma samples, although at low 
levels ( 1.3 to $4.0 \mathrm{ng} / \mathrm{g} \mathrm{ww}$, and n.d. to $0.41 \mathrm{ng} / \mathrm{g}$ ww, respectively). Furthermore, although TBOEP was not detected in 5 of the 6 individuals, Herring Gull \#2 contained a quantifiable TBOEP concentration of $11.3 \mathrm{ng} / \mathrm{g}$ ww (Table 5.1). By comparison, in the same herring gulls, fat contained overall higher concentrations of TCIPP, TDCIPP, TPHP, TNBP, TBOEP and TEHP ( $\Sigma_{6} \mathrm{OPE}$ concentration $31.6 \pm 9.7 \mathrm{ng} / \mathrm{g} \mathrm{ww}$ ) (Greaves and Letcher, 2014).

Table 5.1 Complete list of organophosphate (OP) triester and OP diester concentrations (ng/g wet weight) in herring gull plasma samples $(\mathrm{n}=6)$, collected from Chantry Island, Lake Huron, in April 2010.

\begin{tabular}{ccccccc}
\hline $\begin{array}{c}\text { Individual } \\
\text { Plasma } \\
\text { Samples }\end{array}$ & $\begin{array}{c}\text { TCIPP / } \\
\text { BCIPP }\end{array}$ & $\begin{array}{c}\text { TPHP / } \\
\text { DPHP }\end{array}$ & $\begin{array}{c}\text { TDCIPP / } \\
\text { BDCIPP }\end{array}$ & $\begin{array}{c}\text { TNBP } / \\
\text { DNBP }\end{array}$ & $\begin{array}{c}\text { TBOEP } / \\
\text { BBOEP }\end{array}$ & $\begin{array}{c}\text { TEHP / } \\
\text { DEHP }\end{array}$ \\
\hline 1 & n.d. $/$ n.d. & $1.3 /$ n.d. & $0.41 / 3.18$ & n.d. $/<$ MLOQ & n.d. $/ 1.95$ & $<$ MLOQ / 0.18 \\
2 & n.d. $/$ n.d. & $2.4 /$ n.d. & $0.13 / 0.72$ & n.d. $/ 0.41$ & $11.25 / 29.43$ & n.d. $/ 0.15$ \\
3 & n.d. $/$ n.d. & $2.5 /$ n.d. & $0.11 / 1.79$ & n.d. $/$ n.d. & n.d. $/ 0.23$ & n.d. $/ 0.03$ \\
4 & n.d. $/$ n.d. & $2.3 /$ n.d. & n.d. $/ 1.03$ & n.d. $/$ n.d. & n.d. $/ 0.11$ & n.d. $/<$ MLOQ \\
5 & n.d. $/$ n.d. & $3.4 /$ n.d. & n.d. $/ 2.54$ & n.d. $/$ n.d. & n.d. $/ 0.08$ & $<$ MLOQ / n.d. \\
6 & n.d. $/$ n.d. & $4.0 /$ n.d. & n.d. $/ 3.49$ & n.d. $/<$ MLOQ & n.d. $/ 0.09$ & n.d. $/<$ MLOQ \\
\hline
\end{tabular}

The present herring gull plasma samples were further analyzed for OP diesters using our new method by Su et al. (2014b). BDCIPP (0.7 to $3.5 \mathrm{ng} / \mathrm{g} \mathrm{ww})$, BBOEP (0.08 to $29.4 \mathrm{ng} / \mathrm{g}$ ww) and DEHP (n.d. to $0.18 \mathrm{ng} / \mathrm{g} \mathrm{ww}$ ) were all detected in at least $50 \%$ of plasma samples (Table 5.1). The concentration of BBOEP in Herring Gull \#2 was $29.4 \mathrm{ng} / \mathrm{g}$ ww, which was one to two orders of magnitude higher than other detected OP diesters. To ensure its reliability, this sample was re-analyzed by both LC-ESI(-)-MS/MS and LC-Q-ToF-MS, which showed consistent confirmation of BBOEP in the same sample (Figure 5.1). To our knowledge, this is the first 
study to analyze for and/or detect OP diesters in any biota, and the first study to analyze for and/or detect BBOEP in any biotic or abiotic environmental sample. Our present findings confirm our previous hypothesis: the reason for such low OP triester concentrations in herring gull plasma (and in liver) was due to the efficient metabolism of OP triesters to their respective OP diesters (Greaves and Letcher, 2014). 


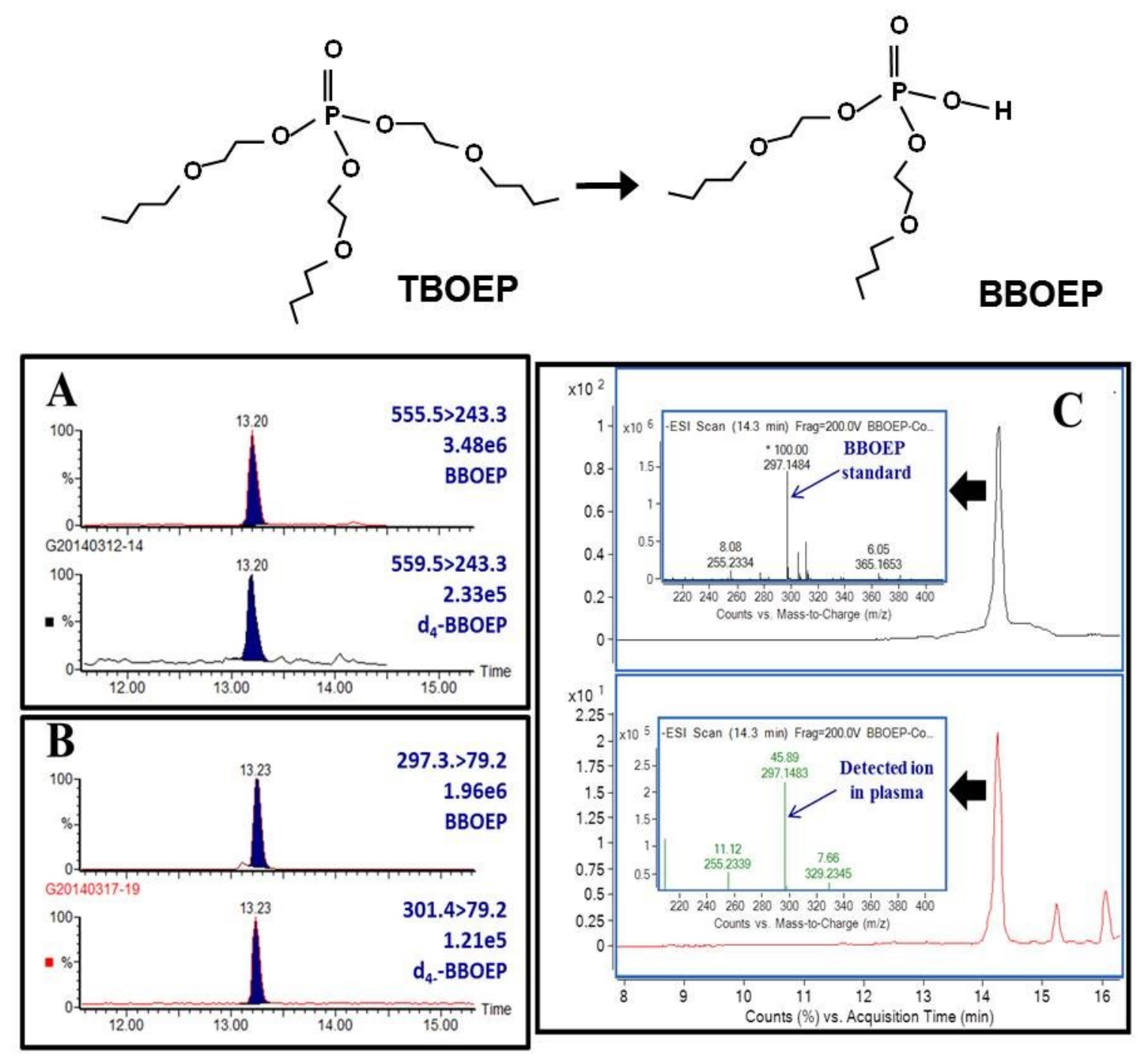

Figure 5.1 Extracted ion chromatograms of the detected BBOEP in plasma of Herring Gull \#2 (Table 5.1) by use of LC-ESI(+)-MS/MS (A), LC-ESI(-)-MS/MS (B) and LC-ESI(-)-Q-ToF-MS (C). The concentration of the spiked internal standard in A and B, $\mathrm{d}_{4}-\mathrm{BBOEP}$, was $20 \mathrm{ng} / \mathrm{mL}$. For comparison, the concentration of BBOEP in $\mathrm{C}$ was $500 \mathrm{ng} / \mathrm{mL}$. The structures of TBOEP and BBOEP are provided, and where the hydrogen atoms are omitted for clarity. 
A multitude of studies over the last three decades have reported the susceptibility of OP triesters to enzyme-catalyzed metabolism, in particular in lab-based dosing studies with male laboratory rats (Chu et al., 2011; Sasaki et al., 1981, 1984; Chapman et al., 1991; Farhat et al., 2013; Takahashi et al., 2010; Kurebayashi et al., 1985; Nomeir et al., 1981). These studies have shown that OP triesters are generally readily metabolized at the whole organism level although relative metabolic rates between OPEs tend to vary between species. For example, Sasaki et al. (1981) showed that killifish (Oryzias latipes) exposed to OPEs metabolized TPHP most quickly ( $>98 \%$ depletion in 70 hours), followed by TDCIPP and TNBP (approximately $90 \%$ and $60 \%$ depletion in 96 hours, respectively). Sasaki et al. (1984) performed microsomal metabolism assays using adult male Wistar rats, and found that TNBP was metabolized most rapidly (approximately 95\% depletion in $30 \mathrm{~min}$ ), followed by TPHP and finally TDCIPP (approximately $75 \%$ and 20\% depletion in $30 \mathrm{~min}$, respectively). Su et al. (2014a, 2015b) showed that $99.8 \%$ of a $10 \mu \mathrm{M}$ TPHP dose in chicken embryonic hepatocytes was metabolized within 36 hours. Similarly, Farhat et al. (2013) showed that chicken (Gallus gallus domesticus) embryos injected with TCIPP $(51,600 \mathrm{ng} / \mathrm{g}$ egg) or TDCIPP $(45,000 \mathrm{ng} / \mathrm{g}$ egg $)$ metabolized either compound quickly, and at virtually the same rate (>99\% depletion of both compounds between day 5 and day 19 of incubation). Recent investigations have examined OP diesters in human urine, with the major detectable OP diesters being DPHP, DEHP, BCIPP, BCEP, and BDCIPP (Reemtsma et al., 2011; van den Eede et al., 2013b; Meeker et al., 2013; Cooper et al., 2011; Schindler et al., 2009). BDCIPP (mean $0.13 \mathrm{ng} / \mathrm{mL}$ ) and DPHP (mean $0.31 \mathrm{ng} / \mathrm{mL}$ ) were detected in $91 \%$ and $96 \%$ of urine samples from 50 American males, with a weak though significant correlation between urinary BDCIPP concentrations and TDCIPP concentrations 
found in house dust (Meeker et al., 2013). All of the studies mentioned above have been extremely useful in understanding the potential for OP triester metabolism.

Where applicable for the present plasma samples, OP diester concentrations were higher than the concentrations of their OP triester precursors, with the exception of TPHP and DPHP. This may be due in part to structure influences on metabolism. TPHP and DPHP have aromatic alkyl moieties, whereas the other OP triester-diester pairs under study all have aliphatic alkyl moieties. Thus, the metabolic efficiencies of OP triester depletion and OP diester formation could differ among compounds. Su et al. (2014a, 2015b) recently completed a 36-hour in vitro metabolism study with TPHP using chicken embryonic hepatocytes. After 36 hours, TPHP had been depleted by $99.8 \%$ of the original dosing concentration. In total, final DPHP concentrations only accounted for $17 \%$ of the original dosing concentration, while para-OH-TPHP accounted for $60 \%$ of the original dosing concentration, indicating that DPHP is not the major metabolite of TPHP biotransformation. This may help to explain the lack of detection of DPHP in the present herring gull plasma samples, even though TPHP was quantifiable in all samples (Table 5.1).

\subsection{Conclusions}

This study is the first to analyze for and determine OP diesters in wildlife or any environmental biota. We have shown that some OP diesters (i.e., BBOEP, BDCIPP, and DEHP) are at quantifiable levels in herring gull plasma. However, it is presently not known what metabolic and depuration rates are for OP triesters and their metabolites in herring gulls. As such, it is difficult to conclude if the presence of OP diesters in these plasma samples is due to (1) rapid/efficient metabolism of their respective OP triester precursors, and/or (2) relatively 
slow metabolism and depuration of the OP diesters. Therefore, in Chapter 6, in vitro OPE metabolism in herring gull liver microsomes is examined to determine overall metabolic rates of OPE biotransformation. 


\section{CHAPTER 6}

Enzyme Kinetic Determination for the Metabolism of Organophosphate Triester Flame Retardants in Herring Gull Liver Microsomes ${ }^{1}$

\footnotetext{
${ }^{1}$ Publication Associated with this Thesis Chapter:
}

A.K. Greaves, G. Su, R.J. Letcher. 2016. Toxicology and Applied Pharmacology, Accepted. 


\subsection{Introduction}

In Chapter 3, weak OPE bioaccumulation was shown in herring gull (Larus argentatus) eggs from across the North American Great Lakes collected between 1990 to 2010, despite large OPE volume production changes over the same period. In general, $\Sigma$ OPE (triester) concentrations in 2010 were significantly higher than they were between 1990 and 2004 (4.06 vs. $1.55 \mathrm{ng} / \mathrm{g}$ ww, respectively), although tris(2-butoxyethyl) phosphate (TBOEP) concentrations apparently decreased over the twenty year period at the most urban site, Toronto Harbour. Similar low OP triester concentrations have been repeatedly observed in herring gulls and their eggs from the Great Lakes (Chapter 4; Chen et al., 2012; Su et al., 2015a). In a preliminary food web study from the Great Lakes which included herring gull eggs (Chapter 3), $\Sigma \mathrm{OPE}$ concentrations $(1.29-9.73 \mathrm{ng} / \mathrm{g} \mathrm{ww})$ were found to be low across all species, with TBOEP being the only OPE consistently detected. It was hypothesized that the lack of OP triester bioaccumulation in herring gulls and their eggs is due to the ability of the gulls to rapidly and efficiently metabolize many of the OP triesters to which they are exposed.

OP diesters have been characterized as either minor or major metabolites of OP triesters, as has been shown either qualitatively or semi-quantitatively in recent years in rat and human liver microsomal studies (Chu et al., 2011; van den Eede et al., 2013a; 2015; 2016). OP triester metabolism via dealkylation has also been shown to be structure-dependent. For example, Chu et al. (2011) showed rapid and complete depletion of tris(1,3-dichloro-2-propyl) phosphate (TDCIPP) within 100 minutes when incubated in a liver microsome suspension from adult male Wistar-Han rats, with $83 \%$ of the metabolized TDCIPP being dealkylated to bis(1,3-dichloro-2propyl) phosphate (BDCIPP). Sasaki et al. (1984) compared the metabolism of TDCIPP, tris(2chloroethyl) phosphate (TCEP), triphenyl phosphate (TPHP) and tri-n-butyl phosphate (TNBP) 
in male Wistar rats, and determined that TNBP was metabolized most rapidly, followed by TPHP, TDCIPP and finally TCEP. Very recently, van den Eede et al. $(2015 ; 2016)$ calculated the kinetics for the formation of TBOEP and tris(2-chloroisopropyl) phosphate (TCIPP) metabolites in human liver microsomes and serum. The TBOEP diester metabolite, bis(2butoxyethyl) phosphate (BBOEP), was not formed, while the TCIPP diester metabolite, bis(2chloroisopropyl) phosphate (BCIPP), was the major metabolite and formed at a maximal rate $\left(\mathrm{V}_{\max }\right)$ of $1470 \pm 110 \mathrm{pmol} / \mathrm{min} / \mathrm{mg}$ protein. These studies demonstrated that OP triesters can be metabolized via the dealkylation pathway; however, to our knowledge there are no reported studies on OP triester metabolism and kinetics in any avian and wildlife species.

The present study investigated the structure-dependent metabolism and kinetics, as well as OP diester formation of six environmentally relevant, halogenated, non-halogenated, and/or aromatic OP triesters (i.e., TDCIPP, TCIPP, TBOEP, TNBP, TPHP, and triethyl phosphate (TEP)) in an avian in vitro model system. The avian in vitro system was based on suspended liver microsomes from herring gulls from a breeding colony site in the Laurentian Great Lakes of North America.

\subsection{Results}

\subsubsection{Microsomal Protein Content and Enzyme Catalytic Activity}

Due to an insufficient amount of liver microsomes from each individual gull to allow for a meaningful inter-individual metabolism study, all microsomes were pooled into one large batch. Thus, average enzyme catalytic activity values for the Chantry Island female herring gull population were collected. Total protein content and cytochrome P450IA enzyme activity was 
determined using the well-established ethoxyresorufin-O-deethylase (EROD) assay, following the methods in Kennedy and Jones (1994). A total of $35.7 \mathrm{~g}$ of liver tissue was processed, with a microsomal protein content yield of $17.7 \mathrm{mg}$ microsomal protein per gram of liver tissue processed $(1.77 \%$ yield). This value is quite comparable to other microsome preparations, where yields in beluga whales, polar bears, ringed seals and ring-billed gulls have ranged from 0.16 to 1.9\% (McKinney et al., 2004; Chabot-Giguère et al., 2013; Letcher et al., 2014).

EROD activity was determined to verify the general hepatic CYP1A-like enzyme viability of the microsomes. CYP1A activity can be used as an indicator of the overall enzymatic viability of prepared microsomes (Chabot-Giguère et al., 2013, McKinney et al., 2004). CYP1A activity of the pooled microsomes from the present herring gull livers was $86 \pm 1 \mathrm{pmol} / \mathrm{min} / \mathrm{mg}$. This activity is dependent on numerous factors including the natural metabolic rate of the individuals, how quickly liver samples were harvested and snap-frozen post-mortem, and how quickly and deftly they were handled during the microsome preparation stage. The gull microsome CYP1A activity was comparable to values reported for beluga whale liver microsomes ( $87 \pm 15 \mathrm{pmol} / \mathrm{min} / \mathrm{mg}$ ) (McKinney et al., 2004), and somewhat lower than in ringbilled gull liver microsomes $(451 \pm 33.7 \mathrm{pmol} / \mathrm{min} / \mathrm{mg})$ (Chabot-Giguère et al., 2013). The microsomal protein yield and CYP1A activity confirmed that the present gull liver microsomes were prepared successfully, and were enzymatically viable.

\subsubsection{Enzyme Kinetic Parameters $\left(V_{\max }\right.$ and $\left.K_{M}\right)$ for OP Triesters in Gull Liver Microsomal Assays}


Michaelis-Menton kinetics is a widely used model in biochemistry. It relates the reaction rate of a system (in this case the enzyme-dependent depletion of OP triesters) to the concentration of the substrate. This model holds true assuming free diffusion within the system, as well assuming the enzyme concentration is much lower than the substrate concentration. In an in vitro assay such as the ones performed in this study, both of these assumptions hold true. Thus, all enzyme kinetics were assumed to follow the Michaelis-Menton model, which resulted into great goodness of fit for all Lineweaver-Burk plots ( $p \leq 0.015, r^{2} \geq 0.97$, Figure 6.1), with the exception of TNBP $\left(p=0.0582, r^{2}=0.89\right)$. The maximal biotransformation rate for a saturated enzyme system $\left(\mathrm{V}_{\max }\right)$ and the substrate concentration at $1 / 2$ of $\mathrm{V}_{\max }\left(\mathrm{K}_{\mathrm{M}}\right)$ were calculated for all OP triesters. $V_{\max }$ values ranged from $5.0-29 \mathrm{pmol} / \mathrm{min} / \mathrm{mg}$ protein, while $\mathrm{K}_{\mathrm{M}}$ values ranged from 9.8 - $189 \mathrm{nM}$ (Table 6.1). $\mathrm{V}_{\max }$ and $\mathrm{K}_{\mathrm{M}}$ values were highest for TBOEP, while they were lowest for TPHP. TEP showed no signs of depletion $(p>0.2)$, regardless of administered concentration $(0.01-10 \mu \mathrm{M})$. As a result, no further biotransformation assessment was done for TEP.

Table 6.1: Calculated Michaelis-Menton enzyme kinetic parameters for the metabolism of six organophosphate (OP) triesters in the herring gull liver microsomal assay. $\mathrm{V}_{\max }$ represents the maximal rate of OP triester metabolism for a saturated enzyme system. $K_{M}$ represents the OP triester concentration corresponding to $1 / 2$ of the $V_{\max }$ value. Triethyl phosphate (TEP) was not found to degrade. All errors are standard error.

\begin{tabular}{ccc}
\hline OP Triester & $\mathrm{V}_{\max }\left(\mathrm{pmol} \cdot \mathrm{min}^{-1} \cdot \mathrm{mg}^{-1}\right)$ & $\mathrm{K}_{\mathrm{M}}(\mathrm{nM})$ \\
\hline TDCIPP & $8.2 \pm 2$ & $81 \pm 27$ \\
TCIPP & $7.1 \pm 4.6$ & $60 \pm 4$ \\
TPHP & $5.0 \pm 0.4$ & $9.8 \pm 1$ \\
TBOEP & $29 \pm 18$ & $189 \pm 135$ \\
TNBP & $11 \pm 4$ & $44 \pm 27$ \\
TEP & Did not degrade \\
\hline
\end{tabular}




\section{TDCIPP}
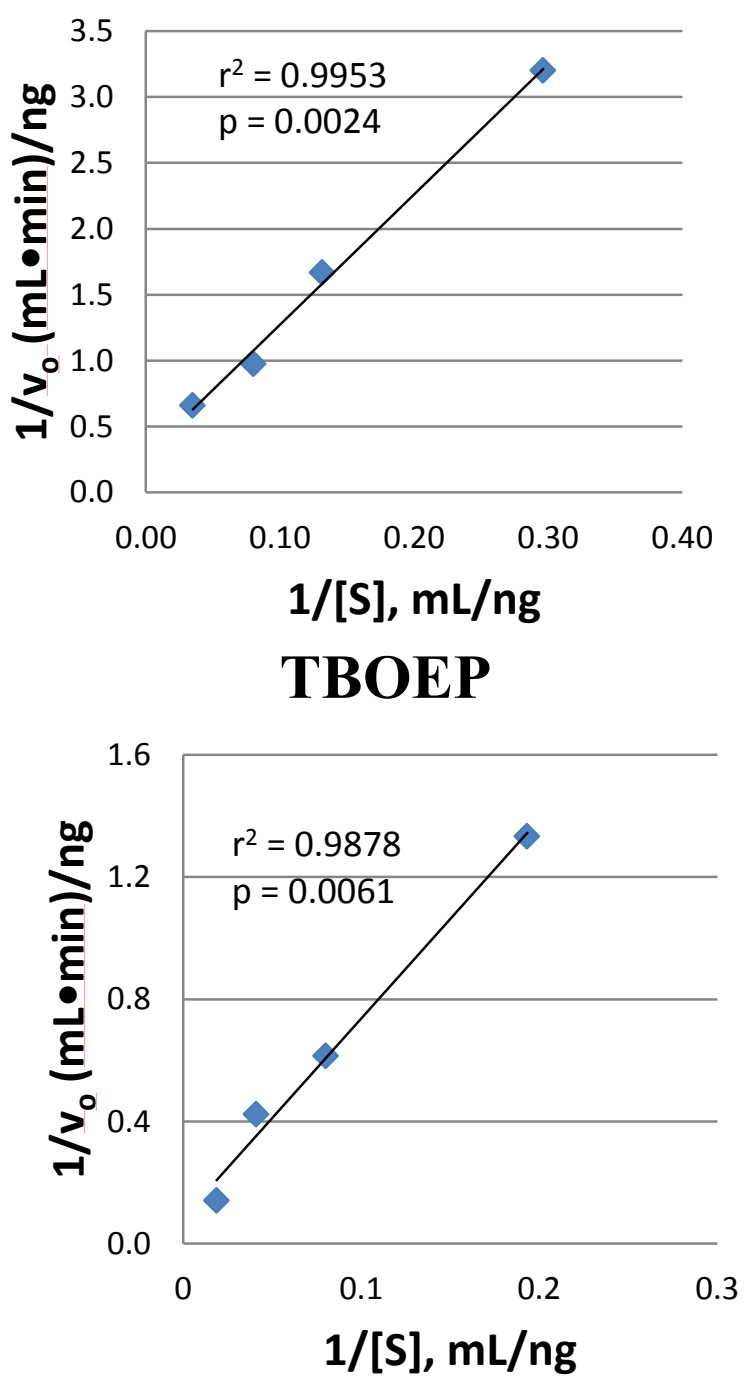

TPHP
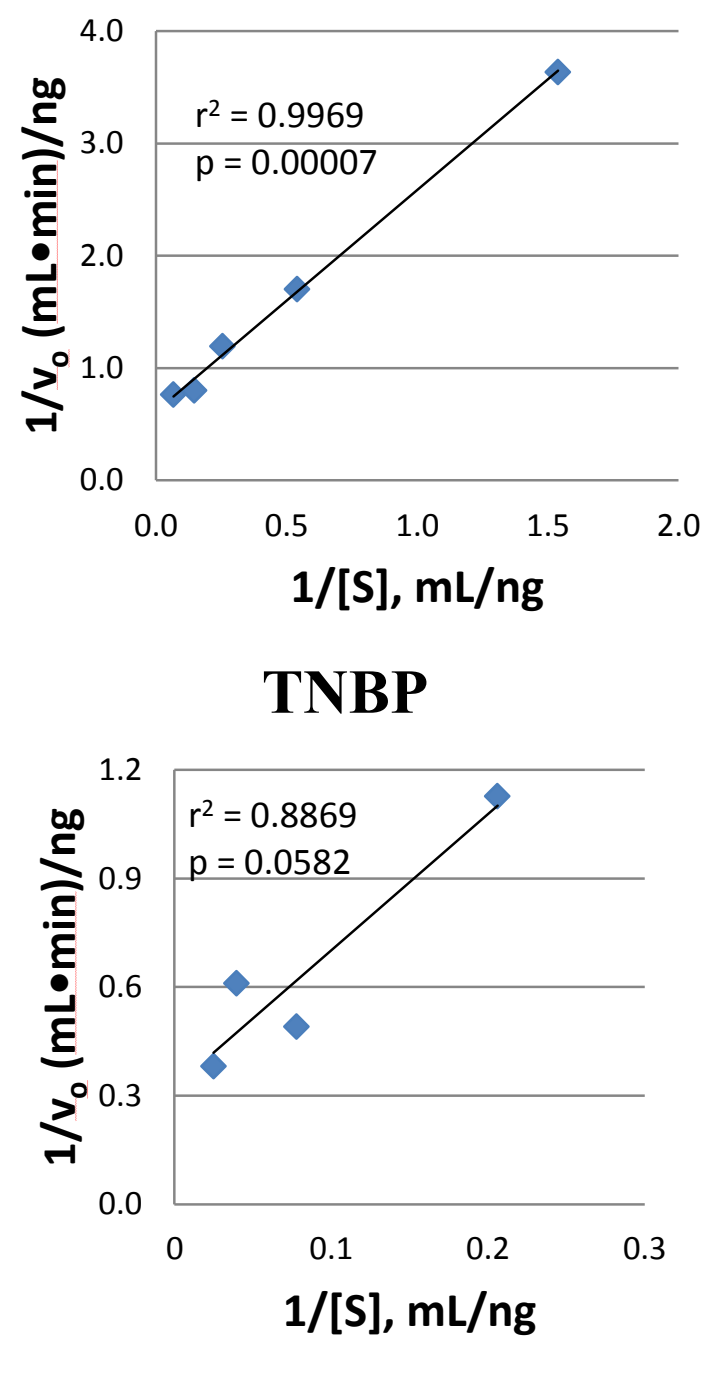

TCIPP

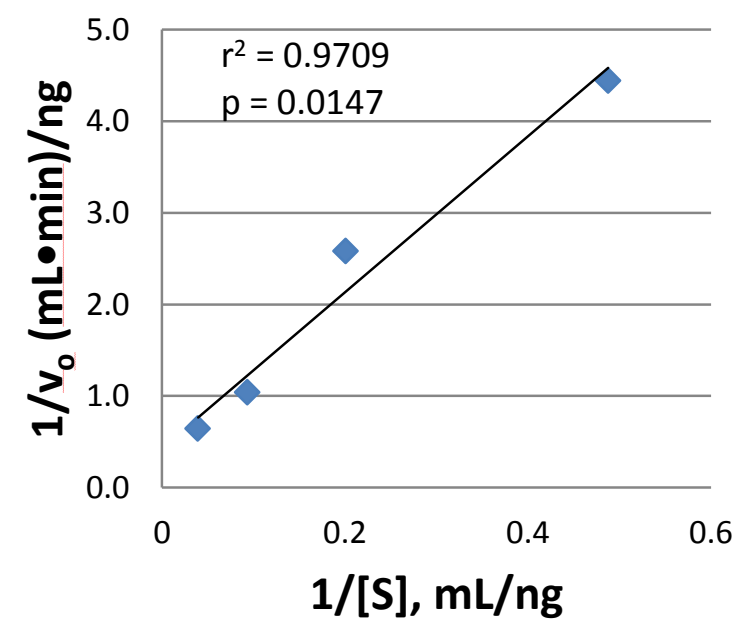

Figure 6.1: Lineweaver-Burk plots generated for all enzyme kinetic 2-minute incubation assays. 
$\mathrm{V}_{\max }$ and $\mathrm{K}_{\mathrm{M}}$ values for the OP triesters were calculated by plotting the inverse of the initial rate of reaction as a function of the inverse of the substrate concentration, where the metabolism period was set to 2 minutes. Two minutes was chosen as a compromise between keeping the observation period as short as possible (thus satisfying the definition of 'initial' reaction rate), while still observing quantifiable concentration changes over the observation period. Although useful in determining approximate reaction rates for the OP triesters, it should be noted that this method in determining the maximal reaction rate for an enzyme system assumes that the substrate is instantaneously in chemical equilibrium with the complex. This assumption holds true when the substrate concentration is much higher than the enzyme concentration, as is the case in this study. Regardless, the $\mathrm{V}_{\max }$ and $\mathrm{K}_{\mathrm{M}}$ values obtained here are useful in determining approximate overall OP triester metabolism rate, but an in-depth 100minute assay is required to properly determine the biotransformation rate. As such, it was expected that the $\mathrm{V}_{\max }$ values would be close to the reaction rates in the 100 minute assays, but would likely differ to some extent. By determining these kinetic parameters, it was assured that subsequent OP triester in vitro metabolism assays would be performed with dosing concentrations high enough to saturate the enzyme systems involved and thus approximate zeroorder kinetics.

Five OP triesters showed significant depletion over a 2 minute period (i.e., TNBP, TBOEP, TPHP, TCIPP, and TDCIPP; Table 6.1). The $\mathrm{K}_{\mathrm{M}}$ and $\mathrm{V}_{\max }$ values for the formation of TCIPP and TBOEP metabolites in human liver microsomes have been very recently reported (van den Eede et al., 2015; 2016), with values one to two orders of magnitude higher than the values obtained in the present in vitro study on herring gulls. For example, the formation of BCIPP had a $\mathrm{K}_{\mathrm{M}}$ of $96.1 \pm 14.5 \mu \mathrm{M}$ and a $\mathrm{V}_{\max }$ of $1470 \pm 110 \mathrm{pmol} / \mathrm{min} / \mathrm{mg}$ protein. Although 
there were small protocol differences between the current study and van den Eede et al. (2015; 2016) (i.e., a 2 minute incubation period compared to a 5 minute incubation period), the large differences in $\mathrm{K}_{\mathrm{M}}$ and $\mathrm{V}_{\max }$ values indicate that in vitro, humans may be able to metabolize OP triesters (and thus form OPE metabolites) more rapidly in vitro than in herring gulls. As a result, inter-species OPE metabolism studies are warranted at both the in vitro level and at the whole organismal in vivo level to assess differences in bioaccumulation potential among species.

\subsubsection{In Vitro OP Triester Metabolism and OP Diester Formation}

A positive control, based on the in vitro microsomal assay in Chu et al. (2011), was run with each batch and consisted of Wistar-Han rat liver microsomes administered $0.7 \mu \mathrm{M}$ TDCIPP. Chu et al. (2011) showed very rapid and complete depletion of TDCIPP in vitro in Wistar-Han rat liver microsomes over 100 minutes. Furthermore, $87 \%$ of the metabolized TDCIPP was converted to BDCIPP. Our positive controls very closely matched the Chu et al. results. The positive controls consistently depleted more than $99 \%$ of the administered TDCIPP in 100 minutes, and $84 \pm 3 \%$ of the metabolized TDCIPP was converted to BDCIPP.

Based on $\mathrm{K}_{\mathrm{M}}$ values, administered concentrations between $200 \mathrm{nM}$ and $5 \mu \mathrm{M}$ were tested in 100 minute herring gull microsomal assays. In each case, $3 \mu \mathrm{L}$ of a more concentrated solution was added to the reaction mixture, such that the final concentration in the reaction mixture (1 $\mathrm{mL}$ ) ranged from $200 \mathrm{nM}$ to $5 \mu \mathrm{M}$. Administered concentrations were chosen to be well within the zero-order kinetics range (i.e., much greater than 2 times the $\mathrm{K}_{M}$ value for each OP triester). Final administered concentrations between 2 and $5 \mu \mathrm{M}$ were chosen (Table 6.2) based on seeing between 45\% (TDCIPP) and 99\% (TNBP) depletion in 100 minutes. Figure 6.2 shows the 
depletion of all five OP triesters and corresponding formation of all five OP diesters over the course of the 100 minute assays. Apparent concentration differences were observed for many of the triesters tested, such that the OP triester concentration at $t=0$ min was often lower than the actual final administered concentration. For example, the actual administered concentration of TNBP was $4.38 \mu \mathrm{M}$ (as confirmed by separate UPLC-ESI(+)-MS/MS quantification), whereas at $\mathrm{t}=0 \mathrm{~min}$, the apparent TNBP concentration in the reaction mixture averaged $3.30 \mu \mathrm{M}$ (Figure 6.2). This difference may be due to OP triester adsorptive loses. As such, all microsomal reaction mixtures were vigorously vortexed for 10 seconds before every aliquot was removed.

Table 6.2: Summary of organophosphate ester (OPE) metabolism assays based on herring gull liver microsomes. Administered concentrations for each OP triester are given. All OP triester and diester concentrations are given at the 100 minute time points, and are an average of $n=5$ replicate samples. All errors are given as standard errors.

\begin{tabular}{|c|c|c|c|c|c|}
\hline $\begin{array}{c}\text { OP } \\
\text { Triester } \\
\text { or } \\
\text { Diester }\end{array}$ & $\begin{array}{l}\text { Administered } \\
\text { conc. }(\mu \mathrm{M})\end{array}$ & $\begin{array}{c}\text { Volume } \\
\text { added to } \\
\text { reaction } \\
\text { mixture }(\mu \mathrm{L})\end{array}$ & $\begin{array}{l}\text { OP Triester } \\
\text { Depletion } \\
(\text { nmol })\end{array}$ & $\begin{array}{l}\text { OP Diester } \\
\text { Formation } \\
\quad(\mathrm{nmol})\end{array}$ & $\%$ Conversion $^{\mathrm{a}}$ \\
\hline $\begin{array}{l}\text { TDCIPP } \\
\text { BDCIPP }\end{array}$ & 2.06 & 3 & $0.92 \pm 0.05$ & $0.81 \pm 0.04$ & $90 \pm 8$ \\
\hline $\begin{array}{l}\text { TCIPP } \\
\text { BCIPP }\end{array}$ & 2.35 & 3 & $1.90 \pm 0.05$ & $0.85 \pm 0.20$ & $56 \pm 10$ \\
\hline $\begin{array}{l}\text { TPHP } \\
\text { DPHP }\end{array}$ & 2.74 & 3 & $2.07 \pm 0.3$ & $0.26 \pm 0.01$ & $15 \pm 3$ \\
\hline $\begin{array}{l}\text { TBOEP } \\
\text { BBOEP }\end{array}$ & 3.57 & 3 & $2.85 \pm 0.28$ & $0.22 \pm 0.07$ & $9 \pm 4$ \\
\hline $\begin{array}{l}\text { TNBP } \\
\text { DNBP }\end{array}$ & 4.38 & 3 & $4.36 \pm 0.01$ & $0.60 \pm 0.09$ & $14 \pm 2$ \\
\hline
\end{tabular}

${ }^{\mathrm{a}}$ Conversion $=(\mathrm{OP}$ diester formed $) \div(\mathrm{OP}$ triester depleted $) \times 100 \%$ 
TDCIPP/BDCIPP

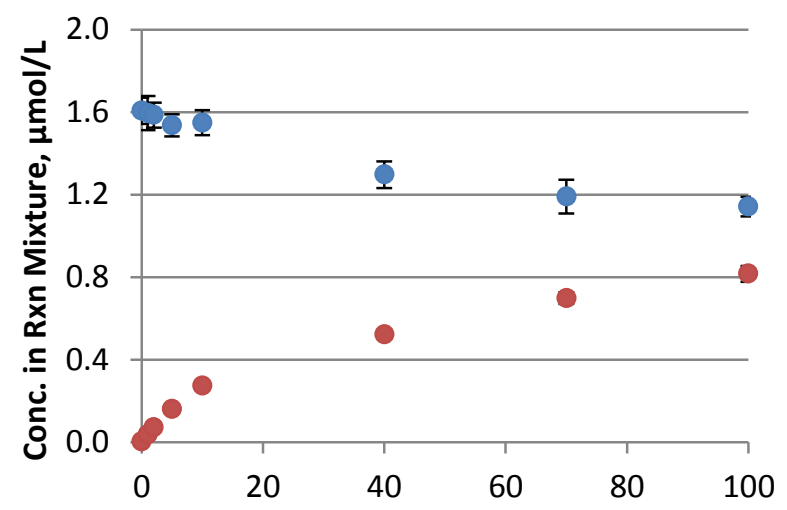

TBOEP/BBOEP

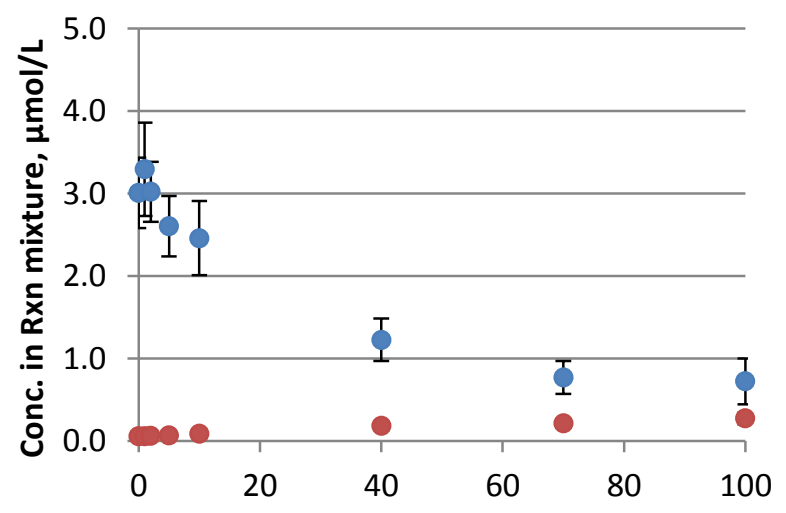

TPHP/DPHP

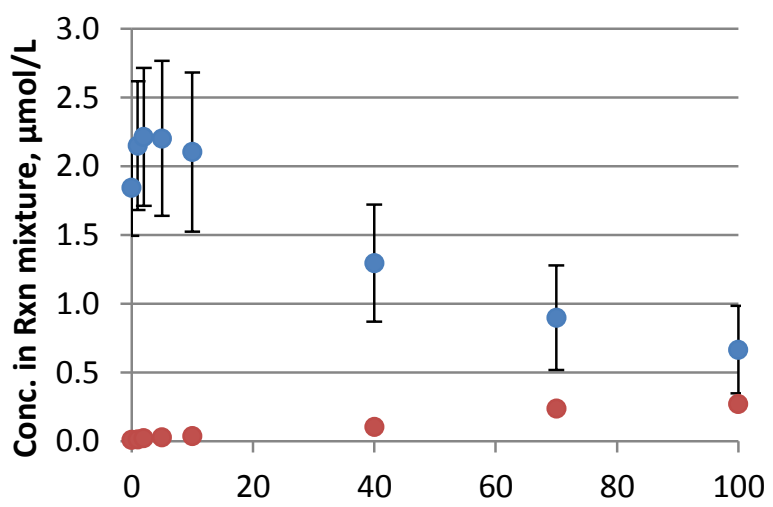

TNBP/DNBP

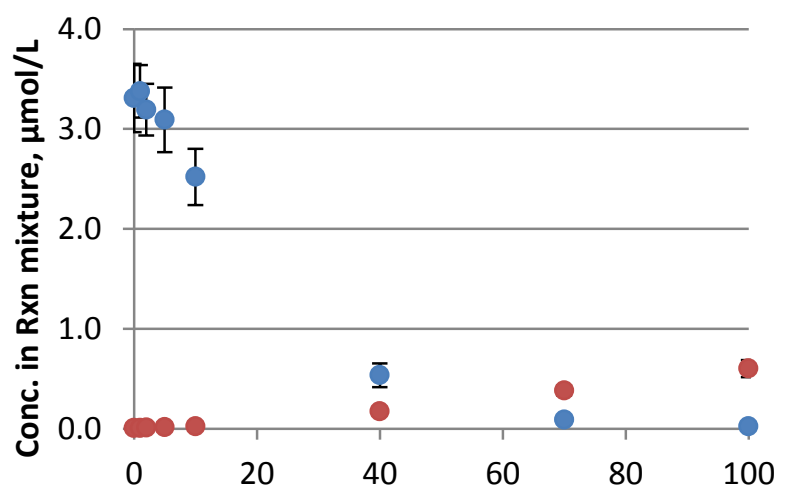

TCIPP/BCIPP

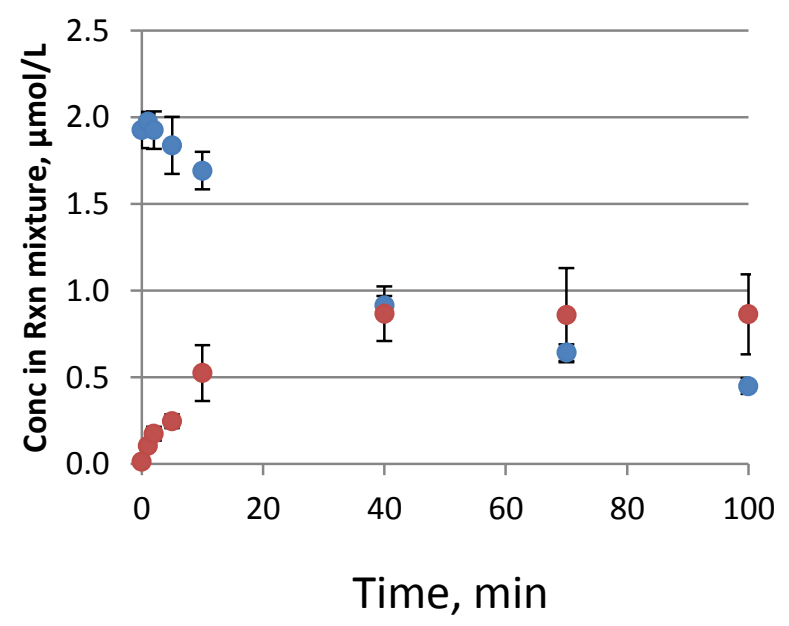

Figure 6.2: Depletion of OP triesters (blue) and formation of OP diesters (red) over a 100 minute assay with herring gull liver microsomes. Error bars represent the standard error of 5 replicate assays. 
All five OP triesters underwent rapid in vitro metabolism over the full term 100 minute incubation assays. Approximately linear depletion was observed for of all five OP triesters over the 0 to 40 min incubation period (Figure 6.2). Therefore, the depletion rate of each OP triester was based on the depletion observed between 0 and 40 minutes. The depletion rates between the OP triesters varied greatly; TNBP was depleted most rapidly $(72.8 \pm 4.1 \mathrm{pmol} / \mathrm{min} / \mathrm{mg})$, followed by TBOEP $(53.0 \pm 8.2 \mathrm{pmol} / \mathrm{min} / \mathrm{mg})$, TCIPP $(27.1 \pm 0.8 \mathrm{pmol} / \mathrm{min} / \mathrm{mg})$, TPHP $(21.9 \pm 2.2$ $\mathrm{pmol} / \mathrm{min} / \mathrm{mg})$, and finally TDCIPP $(7.6 \pm 1.0 \mathrm{pmol} / \mathrm{min} / \mathrm{mg})$ (Figure 6.3). This is further illustrated in Figure 6.4, which compares depletion among all five OP triesters. This structure dependence is similar to what has been observed in rat liver microsomes. Similarly, Sasaki et al. (1984) investigated TNBP, TPHP and TDCIPP metabolism in rat liver microsomes, and found that TNBP was metabolized most quickly, followed by TPHP and finally TDCIPP, which is consistent with the results obtained in this study.

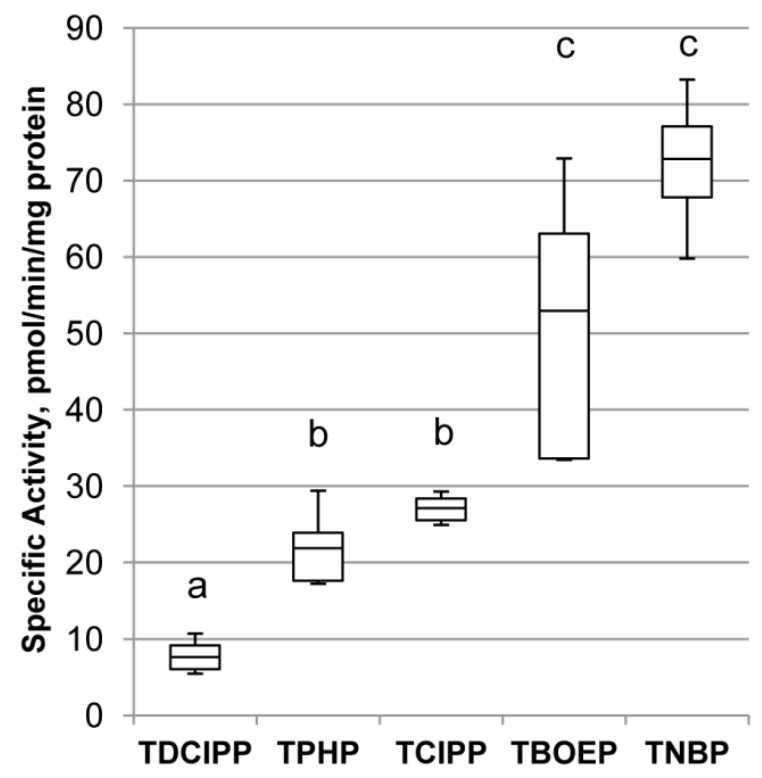

Figure 6.3: Specific rates of enzyme-mediated depletion of organophosphate (OP) triesters. The upper and lower bounds of the boxes represent the 75th and 25 th percentiles, respectively. The middle line in the box represents the median, and the error bars represent the minimum and maximum values. Letters $\mathrm{a}, \mathrm{b}$, and $\mathrm{c}$ represent statistically different specific activity rates $(p \leq$ $0.05)$. 


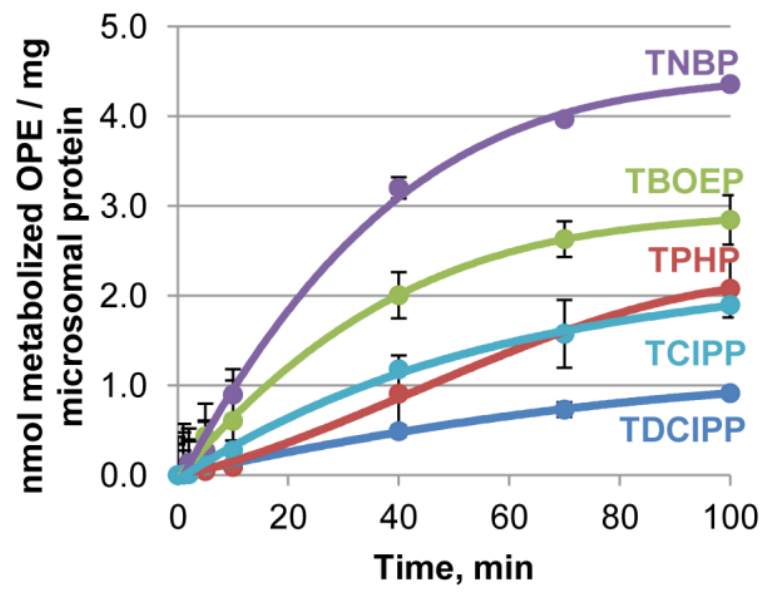

Figure 6.4: In vitro organophosphate (OP) triester metabolism in herring gull liver microsomes over a $100 \mathrm{~min}$ incubation period. Error bars represent standard error.

In general, non-halogenated OP triesters were metabolized faster than halogenated OP triesters, indicating a clear structure-specific metabolism differences in in vitro herring gulls. In the body of maternal gulls, we recently estimated that overall body burden of TBOEP was similar to that of TDCIPP (Chapter 4), despite the current in vitro study which shows that hepatic microsomes metabolize TBOEP approximately 7 times faster than TDCIPP. Similarly, in herring gull eggs collected from Chantry Island and other colonial nesting sites around the Great Lakes between 1990 and 2010, TCIPP concentrations were consistently shown to be comparable to TBOEP concentrations (Chapter 3; Chapter 4; Chen et al., 2012), even though the specific activity for TBOEP is twice that of TCIPP. These studies illustrate that the rate of OP metabolism is not the only factor determining overall concentrations in free-ranging gulls. 
Additional factors such as dietary exposure, OP deposition/mobilization within the body, and inovo transfer also play key roles in determining overall OP concentrations in biota.

The results of these depletion assays indicate that $\mathrm{OP}$ triester in vitro metabolism in herring gulls is (with the exception of TEP) very rapid. Significant $(p \leq 0.009)$ depletion of TDCIPP, TCIPP, TNBP and TBOEP was seen within the first 40 minutes. Over the 100 minute assays, between 0.92 and $4.36 \mathrm{nmol}$ of each triester was metabolized per mg of microsomal protein. By comparison, in hepatic in vitro assay studies, ring-billed gulls from the St. Lawrence River (Canada) showed no or very slow metabolism of BDE-153, BDE-209 and syn- and antiisomers of Dechlorane-Plus, while the gulls minimally metabolized BDE-15 (0.03 nmol per mg protein in 90 minutes) (Chabot-Giguère et al., 2013). From this, it is clear that in vitro metabolism of TNBP, TBOEP, TPHP, TCIPP and TDCIPP in the present herring gulls is 1 to 2 orders of magnitude faster than i.e., PBDE metabolism in other Canadian gulls. Similarly, McKinney et al. (2004) investigated PBDE and PCB metabolism in beluga whale liver microsomes, and found that in vitro metabolism ranged from n.d. to $0.06 \mathrm{nmol}$ per $\mathrm{mg}$ protein for PBDEs, and from n.d. to $0.09 \mathrm{nmol}$ per mg protein for PCBs over 100 minutes.

The extent of OP triester metabolism and OP diester formation varied greatly between compounds. For example, $90 \pm 8 \%$ of depleted TDCIPP was metabolized to BDCIPP, while only $9 \pm 4 \%$ of depleted TBOEP was metabolized to BBOEP (Table 6.2). In general in the gulls, halogenated OP triesters (i.e., TDCIPP, TCIPP) were metabolized in vitro to their respective OP diesters to a much larger extent than the non-halogenated OP triesters (i.e., TNBP, TBOEP), indicating clear structure-dependent metabolism pathways. Limited in vitro studies have examined the metabolism pathways of OP triesters in human liver microsomes and S9 preparations, chicken embryonic hepatocytes (CEHs), and rat liver microsomes (van den Eede et 
al., 2013b, 2015, 2016; Su et al., 2014a, 2015b; Sasaki et al., 1984). OP diesters have been shown to be a major metabolite of OP triesters, though to varying degrees depending on the OPE structure. For example, BDCIPP was found to be a major metabolite of TDCIPP in CEHs, rat and human liver microsomes, indicating metabolism via enzyme-mediated dealkylation (Farhat et al., 2014; Sasaki et al., 1984; van den Eede et al., 2013b). Similarly, TPHP has been shown to undergo enzyme-mediated dealkylation to form DPHP in CEHs, as well as rat and human liver microsomes, although it has also been shown to undergo enzyme-mediated hydroxylation to form mono- and dihydroxylated-TPHP in CEHs (Su et al., 2014a; Sasaki et al., 1984; van den Eede et al., 2013b). In human liver microsomes, the major metabolites of TBOEP were BBOEP and a hydroxylation metabolite, whereas the major metabolite of TCIPP was not BCIPP, but rather a product of oxidative dehalogenation (van den Eede et al., 2013b). Although OP diesters are often shown to be (major) metabolites of most of the OP triesters examined in this study, it is clear from past studies (and further supported by the present study) that not all OP triesters follow the same metabolism pathway, and that they instead undergo structure-dependent metabolism pathways.

The structure-dependent formation rates of OP diesters may help to explain recent and low OP triester concentrations reported in herring gulls. That is, as represented by the single microsome pool, the collective ability for the present female gulls $(n=8)$ to metabolize OP triesters so quickly is interesting considering the OP triester concentrations detected in freeranging herring gulls. In Chapter 4, we analyzed multiple tissues (i.e., liver, fat, muscle, brain, red blood cells, and blood plasma) of the same eight individual female herring gulls used in this study, for a suite of $16 \mathrm{OP}$ triesters. OP triesters were below the limit of detection in liver and brain samples (which is consistent with the rapid OP triester metabolism in liver microsomes 
shown in this study), but $\Sigma$ OPE concentrations were as high as $32.3 \pm 9.8 \mathrm{ng} / \mathrm{g} \mathrm{ww}$ in fat samples. From this, it appears that despite generally rapid OP triester metabolism in the liver, OP triesters are still accumulating in herring gulls, particularly in long-term storage (i.e., low metabolic activity) tissues such as fat. Thus, even though OP triester (except TEP) metabolism in vitro in herring gulls is rapid, this suggests that in wild birds the rate of uptake is greater than the rate of metabolism as residual levels of some OP triesters still accumulate in lipid-rich tissues such as fat.

In Chapter 5, the blood plasma of these same herring gulls under present study, for six OP triester/diester pairs (i.e., TCIPP/BCIPP, TPHP/DPHP, TDCIPP/BDCIPP, TBOEP/BBOEP, and TEHP/DEHP). The only OP triester/diester pair in which both were quantifiable in at least half of the samples was TDCIPP $(0.11 \pm 0.06 \mathrm{ng} / \mathrm{g} \mathrm{ww})$ and BDCIPP $(2.1 \pm 0.5 \mathrm{ng} / \mathrm{g} \mathrm{ww})$. The only other OP diester to be consistently detected was BBOEP $(5.3 \pm 4.8 \mathrm{ng} / \mathrm{g} \mathrm{ww})$, even though TBOEP concentrations were below the limit of detection in all samples. The current findings of this study indicate that BBOEP is formed at a much lower rate than BDCIPP. Therefore, since BBOEP concentrations in the blood plasma were somewhat higher than BDCIPP concentrations, despite a much lower formation rate in microsomes, likely indicates that the present herring gulls from Chantry Island were exposed to much higher levels of TBOEP in their diet compared to TDCIPP. This is supported by a recent food web study from the Great Lakes, which showed consistent detection of TBOEP in multiple fish species including rainbow smelt and alewife (significant food sources of Great Lakes herring gulls) while TDCIPP was not detected in any fish samples (Chapter 3).

The present study suggested that metabolism pathways in herring gulls may differ from human microsomes. $15 \%$ of the metabolized TPHP was converted to DPHP, closely matching 
what was recently observed in CEHs (17\%; Su et al., 2014b). Farhat et al. (2013) recently showed over 99\% depletion of TDCIPP $($ dose $=45,000 \mathrm{ng} / \mathrm{g}$ egg $)$ and TCIPP $($ dose $=51,600$ ng/g egg) in chicken embryos between incubation days 5 and 19. Similarly, CEHs administered $10 \mu \mathrm{M}$ TDCIPP showed complete biotransformation to BDCIPP within 36 hours (Farhat et al., 2014). Conversion of TDCIPP to BDCIPP in the present study (conversion rate 90\%) also closely mirrors what was shown in rat liver microsomes (83\%; Chu et al., 2011). However, BCIPP (which was considered a minor metabolite of TCIPP in human liver microsomes by van den Eede et al. (2013b)) was clearly a major metabolite in herring gull liver microsomes, with a TCIPP to BCIPP conversion of 45\%. Alternately, BBOEP was one of multiple major metabolites of TBOEP in human liver microsomes (van den Eede et al., 2013b), but was poorly transformed in the current herring gull microsomes (conversion rate 9\%). Future studies are warranted to compare the OP triester metabolism in herring gulls with their metabolism in a mammal or fish species to elucidate any class-related metabolic differences.

\subsection{Conclusions}

Rapid in vitro depletion of five OP triesters (TNBP, TBOEP, TPHP, TCIPP, and TDCIPP) was observed over 100-minute incubations, while TEP was not shown to degrade, regardless of administered concentration. In vitro biotransformation of OP triesters was clearly structure-dependent where non-halogenated alkyl OP triesters were metabolized more rapidly than halogenated alkyl triesters. Halogenated OP triesters were transformed to their respective diesters more efficiently relative to non-halogenated OP triesters. 
This was the first study to quantify relative OP triester metabolism rates for an avian or wildlife species. The rapid depletion of these triesters helps to explain the overall low OP triester concentrations observed in herring gulls and their eggs throughout Chapters 3, 4, and 5, and underlines the importance of elucidating OP metabolites, and their potential effects in the body (further discussed in Chapter 7). 
CHAPTER 7

Conclusions, Implications, and Future Directions 


\subsection{Conclusions and Implications}

Organophosphate esters (OPEs) were introduced as favourable alternative chemicals for use as flame retardant (FR) chemicals to replace environmentally persistent compounds such as polybrominated diphenyl ethers (PBDEs). In recent years, however, growing concern has arisen regarding their widespread distribution, and their neurotoxicity, developmental toxicity, carcinogenicity, and endocrine disruption such as via thyroid hormone pathways. Although studies have recently been reported regarding OPE monitoring in wildlife and fish, little is still known regarding the in vivo distribution of these contaminants, and their fate, both in the body and ultimately throughout the (aquatic) ecosystem.

This thesis investigated the pharmacokinetics of several environmentally relevant OPEs in herring gulls from the Laurentian Great Lakes of North America, as well as their persistence and distribution throughout the Great Lakes and in the aquatic food web. A brief summary of the work performed and its implications relating to the health of herring gulls and their ecosystem is

reviewed here. In Chapter 3, OP triester concentrations were quantified among herring gull eggs found across the Great Lakes over a 20 -year span. A preliminary food web study from Lake Ontario and Lake Erie was subsequently performed, in order to elucidate the source of OPE contamination in herring gulls and their eggs. In Chapter 4, multiple tissues from female herring gulls and their eggs (including liver, fat, muscle, brain, red blood cells, blood plasma, egg yolk, and egg albumen) were analyzed for OP triesters, with the goal of understanding the pharmacokinetics of OP triesters within the body, and their potential for in ovo transfer. In Chapter 5, the herring gull blood plasma samples were re-analyzed for OP triesters and diesters in order to confirm that the metabolism of OP triesters occurs in herring gulls in vivo. Subsequently in Chapter 6, the Michaelis-Menten enzyme kinetic parameters for OP triester 
depletion were determined, in order to approximate structure-dependent metabolism differences, and to properly configure the biotransformation assays. Finally, in Chapter 6, the biotransformation of five OP triesters to their respective OP diesters was monitored over 100minute periods, with the purpose of quantifying OP triester metabolism, and further understanding the OPE concentrations observed in wildlife samples.

This was the first study to monitor OPE concentration in wildlife tissue samples over a two-decade span, as well as the first study to examine the distribution of OPEs throughout multiple tissues in the body of any free-ranging species. Furthermore, this was the first study to quantify the metabolism of OP triesters in viable (herring gull) liver microsomes and to monitor their biotransformation to OP diesters. The main conclusions and broader implications stemming from the studies in this thesis are provided here.

\section{Limited information can be gained regarding OPE exposure in wildlife through the use of OP triester monitoring studies. In Chapters 3 and 4, it was demonstrated that OP triester} concentrations in herring gulls and their eggs remains quite low, despite high (and increasing) OP triester production volumes. These low concentrations in free-ranging gulls were explained in Chapters 5 and 6, where TDCIPP, TCIPP, TBOEP, TNBP and TPHP were all shown to be rapidly metabolized in vitro in herring gull liver microsomes, and where OP diesters were detected in herring gull blood plasma (albeit with low detection frequencies). It is clear from these studies that OPE concentrations observed in free-ranging gulls are in fact post-metabolic residual concentrations. Over the last decade, multiple studies have emerged detailing OPE concentrations in free-ranging biota, a number of which analyzed liver, blood plasma, muscle or 
egg samples. As such, the OPE concentrations detected in these studies are likely gross underestimates of OPE bioaccumulation and exposure. Throughout the works associated with this thesis, it has become evident that monitoring OP triester concentrations in biota does not accurately reflect OPE exposure, and as such provides minimal valuable information to regulators and policy makers.

This thesis was the first study to quantify OP diesters in free-ranging biota tissues, and strongly suggests that OP diesters should be quantified in future monitoring studies, along with OP triesters (as further discussed in section 7.2). Nonetheless, OP diesters are not the only metabolites of OP triesters. Studies have recently identified many significant hydroxylation and oxidative dehalogenation metabolites of OP triesters in both human liver microsomes, as well as chicken embryonic hepatocytes (van den Eede et al., 2013b, 2015, 2016; Su et al., 2015b). Though the toxicity effects and OP triester concentrations in free-ranging biota have been emerging for the last decade, very little is known concerning the toxicity and potential bioaccumulation of these various OPE metabolites. As such, current regulators may be missing crucial information with regards to the ultimate fate of OPEs in the environment and their safety in the aquatic ecosystem (as further discussed in section 7.2).

\section{The associated toxicities of OP triesters are not of great concern for herring gulls and their eggs due to their capacity to rapidly metabolize (many) OP triesters. Multiple studies have recently documented the often dose-dependent toxicity effects of multiple OP triesters in a variety of biota, including chicken, rat, mice, zebrafish, killifish, and Daphnia magna, (Sasaki et al., 1981; Li et al., 2015; Wang et al., 2013; Liu et al., 2013; Zhu et al., 2015; Morrissey et al., 1988; Farhat et al., 2013; Crump et al., 2012; Porter et al., 2014; Su et al., 2014a). Toxicity}


effects have included (among others) reduced hatching and survival rates, reduced heartbeat rates, and reduced $T_{4}$ and increased $T_{3}$ concentrations in developing embryos, as well as decreased sperm density and mobility, carcinogenicity, and neurotoxicity in adults, although no observable adverse effect levels (NOAELs) typically range from 15 to $690 \mathrm{mg} / \mathrm{kg}$ body weight/day. In Chapter 4, overall burdens of detected OP triesters ranged from 44 to $1200 \mathrm{ng} / \mathrm{kg}$ body weight in herring gulls, 4 to 7 orders of magnitude lower than expected NOAELs. It is therefore unlikely that herring gulls are at risk of OP triester toxicity.

However, recent studies have found high OP triester concentrations in both air ( $\mathrm{OPE}$ $120 \pm 18$ to $2100 \pm 400 \mathrm{pg} / \mathrm{m}^{3}$ ) and water ( $(\mathrm{OPE} 7.3 \pm 4.5$ to $96 \pm 43 \mathrm{ng} / \mathrm{L}$ ) samples from the Great Lakes, indicating that OP triester exposure is quite high for biota in the Great Lakes ecosystem (Salamova et al., 2014; Venier et al., 2014). Low tissue concentrations were explained in Chapter 6, where it was found that OP triesters are rapidly metabolized in vitro in herring gull liver microsomes, thus greatly reducing the risk of OP triester toxicity. OP metabolites are known to include both OP diesters (i.e., phosphoric acids), as well as a large suite of hydroxylated, dehalogenated, and conjugated compounds, many of which could pose their own toxicity risks in the body. For example, in chicken embryonic hepatocytes, the number of genes altered by $10 \mu \mathrm{M}$ DPHP (9 out of 27 genes) was greater than the number of genes altered by 10 $\mu \mathrm{M}$ TPHP ( 4 out of 27 genes), indicating that OP metabolites pose their own toxicity risks. Very little is known regarding toxicity effects of OP metabolites, as well as their effects levels. Future efforts should be made to understand the potential toxicity and effects levels of OP metabolites in biota (as is further discussed in section 7.2). 


\section{TNBP and TBOEP pose less exposure risk to herring gull health than TCIPP and TDCIPP.}

A wide variety of OP triesters are currently being produced worldwide. In North America, current annual production volumes of TCIPP, TDCIPP and TCEP were recently estimated at 22,000 tonnes, 16,000 tonnes, and 120 tonnes, respectively (Schreder et al., 2016), with $\Sigma O P E$ production in North America estimated at 75,000 tonnes per year.

In Chapter 6, it was shown that TNBP and TBOEP (both non-halogenated alkyl triesters) were metabolized 2 to 9 times faster than TCIPP and TDCIPP (both halogenated alkyl triesters), indicating structure-specific metabolism rate differences. Similar structure-specific metabolism rate differences were also observed in rat liver microsomes (Sasaki et al., 1984). By considering relative metabolism rates as well as the toxicity effects associated with various OP triesters, some general conclusions can be made regarding which OP triesters may be less environmentally taxing on herring gulls.

Numerous reports have shown that chlorinated OPEs (i.e., TDCIPP, TCEP, and TCIPP) cause developmental toxicity, reproductive toxicity, and are carcinogenic. For example, developmental effects were seen in zebrafish embryos when exposed to TDCIPP concentrations as low as $0.3 \mathrm{mg} / \mathrm{L}$ (Wang et al., 2013). Few toxicity studies have been performed on nonchlorinated alkyl triesters, although their effects in the body appear to be less potent than chlorinated alkyl triesters. For example, TNBP is suspected of being neurotoxic, and TNBP, TBOEP, and TEHP were all shown to cause hemolysis (i.e., rupture of red blood cells), although at concentrations many orders of magnitude higher than what is currently being seen in biota ( $\mathrm{EC}_{20}$ ranging 3 to $52 \mu \mathrm{g} / \mathrm{g}$ ww; Sato et al., 1997). Furthermore, metabolism of chlorinated alkyl triesters in herring gulls was shown to be significantly slower than the metabolism of nonchlorinated alkyl triesters (Chapter 6). As such, not only do chlorinated OPEs elicit multiple 
toxicity effects, they are also cleared from the herring gull body less quickly than other nonchlorinated alkyl OPEs. As such, TCIPP and TDCIPP pose greater exposure risks to herring gull health than do TNBP and TBOEP. However, little remains known about OPE metabolites and their own potential health effects and accumulation/excretion rates. As such, future studies should focus on understanding the potential negative health effects of OP metabolites, as is further discussed in section 7.2.

\subsection{Future Directions}

The results stemming from this project and their ensuing discussion identify some key research needs in this field, the most important of which are suggested here.

\section{Discrepancies between OPE concentrations in herring gulls and their prey should be}

further investigated. In Chapters 3 and 4, herring gulls and their eggs were found to contain a total of nine quantifiable OPEs, though their prey fish only contained quantifiable concentrations of TBOEP. Although herring gulls have traditionally fed primarily on alewife, rainbow smelt and capelin, recent reports have shown that many herring gulls in the Great Lakes ecosystem are shifting to more terrestrial-based food sources, perhaps due to recent declines in annual indices of prey fish abundance. Therefore, it is likely that herring gulls are not simply being exposed to OPEs through the aquatic food web, but are exposed to OPEs through the terrestrial ecosystem too. 
By better understanding where herring gulls are spending large amounts of time, and on what they primarily feed, researchers can better assess overall OPE exposure in these birds and better assess if the current regulations surrounding OPEs is adequate. Stable isotope analysis can provide crucial insight into food web dynamics and food source. Stable isotope analysis of herring gull muscle tissue along with visual observation of stomach contents and regurgitated pellets can give great insights into the types of food they consume (e.g., fish, songbirds, small mammals, invertebrates, vegetation, garbage). Furthermore, tagging and tracking herring gull movements over the course of months can further identify where they are spending large amounts of time, which can be related back to overall OPE exposure and ultimately bird health.

\section{The structure-specific OP triester metabolism differences observed in Chapter 6 should be} further investigated, and the enzymes responsible for metabolism should be fully

elucidated. Large in vitro metabolism differences were seen between multiple OP triesters in herring gull liver microsomes, clearly showing that metabolism pathways and rate kinetics vary between OP triesters. The structure specificity with which OP triesters were metabolized suggests that metabolizing enzymes have different affinities for non-chlorinated alkyl triesters vs. chlorinated alkyl triesters. Previous studies in chicken embryos and chicken embryonic hepatocytes have shown that exposure to either TDCIPP, TCIPP or TPHP leads to upregulation of two avian-specific cytochrome P450 isoforms, CYP 3A37 and CYP 2H1 (Su et al., 2014b; Crump et al., 2012; Porter et al., 2013). These isoforms are both oxidoreduction enzymes, which is consistent with the NADPH-dependent nature of OP triester metabolism. CYP 3A37 is an orthologue to the mammalian isoform CYP 3A4. CYP 3A4 is a versatile monooxygenase with a large binding site, capable of hydroxylation, as well as $O$-dealkylation and $O$-dearylation, all of 
which have been shown to be important pathways in OP triester metabolism. In fact, both CYP 3A37 and CYP 2H1 have been shown to also be upregulated upon exposure to both PBDEs and HBCDD, demonstrating how these enzymes are capable of metabolizing a wide variety of chemical structures.

Although it is likely that CYP $3 \mathrm{~A} 37$ and CYP $2 \mathrm{H} 1$ are indeed the enzymes responsible for catalyzing OP triester metabolism, future studies should confirm their participation in OP triester metabolism by creating an assay to expose various OP triesters to an in vitro system and systematically inhibiting CYP 3A37 and/or CYP 2H1. Furthermore, CYP 3A37 is activated by substrate binding to the pregnane $\mathrm{X}$ receptor, which serves as a generalized sensor for hydrophobic toxins. Therefore, it is possible that some of the structure specificity observed with OP triesters is due to their $\log K_{O W}$ values. Although there was not a direct correlation between the rate of OP triester metabolism and their $\log K_{O W}$ values (all of which ranged from 4.6 to 3.65), it is of interest that the only OPE not metabolized was TEP, which has a much lower log $K_{O W}(0.8)$. As such, it would also be worthwhile examining the metabolism of other OP triesters with low $\log K_{O W}$ values, notably V6, TCEP, and trimethyl phosphate ( $\log K_{O W}$ values of 1.9, 1.44 , and -0.65 , respectively). By understanding how OP triesters are metabolized, we can better predict how structurally similar chemical compounds will get metabolized in the body, and be able to make more informed manufacturing-focused regulations for the production and use of anthropogenic chemicals.

Future studies should examine OPE metabolism in vitro in herring gull hepatocytes, as well as in vivo in herring gulls, and should identify all major Phase I and Phase II metabolites. 
Valuable information was collected regarding phase I metabolism of OP triesters to OP diesters in Chapter 6, although the mass balance between depleted triesters and formed diesters was as low as $9 \%$. It has been shown in human liver microsomes as well as chicken embryonic hepatocytes that OP diesters are not the only metabolite of OP triesters, nor are they usually the major metabolite. A wide variety of hydroxylated, dealkylated, dearylated, and conjugated metabolites have been shown, depending on the OP triester. For example, in human liver microsomes, a total of 13 metabolites were identified for TBOEP, eight metabolites for TPHP, and five metabolites for TDCIPP (van den Eede et al., 2013b). Phase II metabolites have been observed for TPHP, TBOEP, and TDCIPP metabolism, in the form of glucuronide and sulfate conjugates (van den Eede et al., 2013b; Su et al., 2015b).

Although the metabolism of OP triesters was investigated preliminarily in herring gull liver microsomes, it would be of great interest to further study OP triester metabolism at a higher level of biological organization and at the cell level, e.g. herring gull hepatocytes. Studying OP triester metabolism in hepatocytes would allow the identification of all phase I and phase II metabolites. Furthermore, upon elucidation of the metabolites, their physico-chemical properties (e.g., $\log K_{O W}$ values) could be identified to better understand their pharmacokinetic properties, and their potential for bioaccumulation in the body. Useful information could also be obtained regarding both the rate of OPE uptake from the surrounding medium into the cells, as well as the rate of OPE excretion from the cells into the surrounding medium. This would help determine where various OP triesters and OP metabolites prefer to accumulate, and thus shed light on their pharmacokinetic behaviours.

Subsequently, once phase I and phase II metabolites have been identified in hepatocytes, a herring gull in vivo study could take place to further understand the pharmacokinetic behaviour 
of OP triesters and their metabolites. I recommend that herring gull eggs are removed from nests and incubated until hatching. After a brief (e.g., one week) non-exposure period to acclimate to their enclosure, a cocktail of OP triesters is incorporated into their food, and the gull hatchlings undergo a 14-day exposure period, followed by a 10 day depuration period. Hatchlings are sacrificed at various time points throughout the experiment, and multiple tissues (e.g., fat, muscle, blood, liver, kidney) are analyzed for both OP triesters, as well as the previously identified OP metabolites.

\section{The toxicity effects and transcriptional changes associated with OP metabolites should be}

investigated. As stated in section 7.1, it is likely that toxicity effects associated with OP triesters are not of concern for herring gulls, due to their ability to rapidly metabolize OP triesters. However, Su et al. (2014a) recently showed that OP metabolites may actually pose more risk in the body than OP triesters. Transcriptional mRNA changes of 27 target genes were quantified by a PCR array after exposure to either $10 \mu \mathrm{M}$ TPHP or DPHP in chicken embryonic hepatocytes. The study found that TPHP caused up/downregulation of 4 genes, while DPHP caused significant downregulation of 9 genes. Of the 9 genes affected, 2 genes were associated with the thyroid hormone pathway, 2 genes were associated with the cytochrome P450 pathway, and 4 genes were associated with lipid/cholesterol metabolism. In fact, DPHP caused downregulation in 4 of the 6 genes present in the PCR array associated with the lipid/cholesterol metabolism pathway, while TPHP did not affect any of the 6 genes. Therefore, it is possible that DPHP (and potentially other OP metabolites) could affect the lipid/cholesterol metabolism pathway, which should be further explored. A herring-gull specific PCR array could be created to test multiple genes associated with the lipid/cholesterol metabolism pathway (e.g., genes including ACSL5, 
HMGCR, SLCO1A2, CD36, FXR, LXR). From there, a wide variety of OP metabolites could be tested to determine potential up or downregulation of genes associated with this pathway, with the goal of identifying potential toxicity effects of OP metabolites. 


\section{REFERENCES}

Andresen, J. A.; Grundmann, A.; Bester, K. Organophosphorus flame retardants and plasticisers in surface waters. Science of the Total Environment 2004, 332, 155-166.

Bacaloni, A.; Cucci, F.; Guarino, C.; Nazzari, M.; Samperi, R.; Laganà, A. Occurrence of organophosphorus flame retardant and plasticizers in three volcanic lakes of central Italy. Environmental Science and Technology 2008, 42, 1898-1903.

Bester, K. Comparison of TCPP concentrations in sludge and wastewater in a typical German sewage treatment plant — comparison of sewage sludge from 20 plants. Journal of Environmental Monitoring 2005, 7, 509-513.

Borgå, K.; Kidd, K. A.; Muir, D. C. G.; Berglund, O.; Conder, J. M.; Gobas, F. A. P. C.; Kucklick, J. Malm, O.; Powell, D. E. Trophic magnification factors: Considerations of ecology, ecosystems, and study design. Integrated Environmental Assessment and Management 2011, 8, 64-84.

Brandsma, S. H.; Leonards, P. E. G.; Leslie, H. A.; de Boer, J. Tracing organophosphorus and brominated flame retardants and plasticizers in an estuarine food web. Science of the Total Environment 2015, 505, 22-31.

Camarasa, J.G.; Serra-Baldrich, E. Allergic contact dermatitis from triphenyl phosphate. Contact Dermatitis 1992, 26, 264-265.

Campone, L.; Piccinelli, A. L.; Östman, C.; Rastrelli, L. Determination of organophosphorous flame retardants in fish tissues by matrix solid-phase dispersion and gas chromatography. Analytical and Bioanalytical Chemistry 2010, 397, 799-806.

Canadian Fire Marshals and Fire Commissioners. Wijayasinghe, M. Fire Losses in Canada, Year 2007 and Selected Years. 2011.

Carrier, D.; Leon, L. R. Skeletal growth and function in the California gull (Larus californicus). Journal of Zoology 1990, 222, 375-389.

CEFIC, European Flame Retardants Association. 2012. Keeping fire in check in upholstered furniture and textiles (Brochure). http://www.cefic-efra.com/images/stories/IMG-BROCHURE2.4/uft_march2012.pdf Date accessed: March 1, 2016.

CEFIC, European Flame Retardants Association. 2015. Keeping fire in check in transport (Brochure). http://www.cefic-efra.com/images/stories/IMG-BROCHURE2.4/EFRA_Transport_Edition-2015.pdf Date accessed: March 1, 2016. 
Chapin, R.E.; Sloane, R.A.; Haseman, J.K. The relationships among reproductive endpoints in Swiss mice, using the reproductive assessment by continuous breeding database. Fundamental and Applied Toxicology 1997, 38, 129-142.

Chapman, D. E.; Michener, S. R.; Powis, G. Metabolism of the flame-retardant plasticizer tris(2chloroethyl)phosphate by human and rat-liver preparations. Fundamental and Applied Toxicology 1991. 17 (2), 215-224.

Chen, D.; Letcher, R. J.; Chu, S. Determination of non-halogenated, chlorinated and brominated organophosphate flame retardants in herring gull eggs based on liquid chromatography-tandem quadrupole mass spectrometry. Journal of Chromatography A 2012, 1220, 169-174.

Chu, S. G.; Chen, D.; Letcher, R. J. Dicationic ion-pairing of phosphoric acid diesters post-liquid chromatography and subsequent determination by electrospray positive ionization-tandem mass spectrometry. Journal of Chromatography A 2011, 1218, 8083-8088.

Chu, S.; Letcher, R.J. Determination of organophosphate flame retardants and plasticizers in lipid-rich matrices using dispersive solid-phase extraction as a sample cleanup step and ultrahigh performance liquid chromatography with atmospheric pressure chemical ionization mass spectrometry. Analytica Chimica Acta 2015, 885, 183-190.

Ciccioli, P.; Cecinato, A.; Brancaleoni, E.; Montagnoli, M.; Allegrini, I. Chemical composition of particulate organic matter (POM) collected at Terra Nova Bay in Antarctica. International Journal of Environmental Analytical Chemistry 1994, 55, 47- 59.

Cooper, E.M.; Covaci, A.; van Nuijs, A.L.N.; Webster, T.F.; Stapleton, H.M. Analysis of the flame retardant metabolites bis(1,3-dichloro-2-propyl) phosphate (BDCPP) and diphenyl phosphate (DPP) in urine using liquid chromatography- tandem mass spectrometry. Analytical and Bioanalytical Chemistry 2011, 401, 2123-2132.

Cristale, J.; García Vázquez, A.; Barata, C.; Lacorte, S. Priority and emerging flame retardants in rivers: Occurrence in water, sediment, Daphnia magna toxicity and risk assessment.

Environment International 2013, 59, 232-243.

Crump, D.; Chiu, S.; Kennedy, S.W. Effects of Tris(1,3-dichloro-2-propyl) phosphate and tris(1chloropropyl) phosphate on cytotoxicity and mRNA expression in primary cultures of avian hepatocytes and neuronal cells. Toxicological Sciences 2012, 126, 140-148.

Dishaw, L.; Powers, C.M.; Ryde, I.T.; Roberts, S.C.; Seidler, F.J.; Slotkin, T.A.; Stapleton, H.M. Is the PentaBDE replacement, tris (1,3-dichloropropyl) phosphate (TDCPP), a developmental neurotoxicant? Studies in PC12 cells. Toxicology and Applied Pharmacology 2011, 256, 281289. 
EPA, Great Lakes Facts and Figures. Environmental Protection Agency. 2015 http://www.epa.gov/greatlakes/great-lakes-facts-and-figures Date Accessed March 10, 2016.

Eulaers, I.; Jaspers, V. L. B.; Halley, D. J.; Lepoint, G.; Nygård, T.; Pinxten, R.; Covaci, A.; Eens, M. Brominated and phosphorus flame retardants in White-tailed Eagle Haliaeetus albicilla nestlings: Bioaccumulation and associations with dietary proxies $\left(\delta^{13} \mathrm{C}, \delta^{15} \mathrm{~N}\right.$ and $\left.\delta^{34} \mathrm{~S}\right)$. Science of the Total Environment 2014, 478, 48-57.

European Union. (2008a). European Union Risk Assessment Report: Tris(2- chloro-1methylethyl) Phosphate (TCPP). European Communities, Luxembourg. CAS No. 13674-84-5, EINECS No. 237-158-7.

European Union. (2008b). European Union Risk Assessment Report: Tris[2- chloro-1(chloromethyl)ethyl] Phosphate (TDCP). European Communities, Luxembourg. CAS No. 13674-87-8, EINECS No. 237-159-2.

Evenset, A.; Leknes, H.; Christensen, G. N.; Warner, N.; Remberger, M.; Gabrielsen, G. W. Screening of new contaminants in samples from the Norwegian Arctic. NIVA Report 4351-1, SPFO-Report 1049/2009, TA-2510/2009. 2009, ISBN: 978-82-449-0065-2.

Fang, M.; Webster, T. F.; Gooden, D.; Cooper, E. M.; McClean, M. D.; Makey, C.; Stapleton, H. M. Investigating a novel flame retardant known as V6: Measurements in baby products, house dust, and car dust. Environmental Science and Technology 2013, 47, 4449-4454.

Farhat, A.; Crump, D.; Chiu, S.; Williams, K.L.; Letcher, R.J.; Gauthier, L.T.; Kennedy, S.W. In ovo effects of two organophosphate flame retardants TCPP and TDCPP on pipping success, development, mRNA expression, and thyroid hormone levels in chicken embryos. Toxicological Sciences 2013, 134, 92-102.

Flaskos, J.; McLean, W.G.; Fowler, M.J.; Hargreaves, A.J. Tricresyl phosphate inhibits the formation of axon-like processes and disrupts neurofilaments in cultured mouse N2a and rat PC12 cells. Neuroscience Letters 1998, 242, 101-104.

Fries, E.; Püttmann, W. Monitoring of the three organophosphate esters TBP, TCEP and TBEP in river water and ground water (Oder, Germany). Journal of Environmental Monitoring 2003, 5, 346-352.

Gebbink, W. A.; Letcher, R. J. Comparative tissue and body compartment accumulation and maternal transfer to eggs of perfluoroalkyl sulfonates and carboxylates in Great Lakes herring gulls. Environmental Pollution 2012, 162, 40-47.

Greaves, A.K.; Letcher, R.J. Comparative body compartment composition and in ovo transfer of organophosphate flame retardants in North American Great Lakes herring gulls. Environmental Science and Technology 2014, 48, 7942-7950. 
Greaves, A.K.; Letcher, R.J.; Chen, D.; McGoldrick, D.J.; Gauthier, L.T.; Backus, S.M. Retrospective analysis of organophosphate flame retardants in herring gull eggs and relation to the aquatic food web in the Great Lakes. Environmental Research 2016, 150, 255-263.

Green, N.; Schlaback, M.; Bakke, T.; Brevik, E. M.; Dye, C.; Herzke, D.; Huber, S.; Plosz, B.; Remberger, M.; Schøyen, M.; Thelle Uggerud, H.; Vogelsang, C. Screening of selected metals and new organic contaminants 2007. NIVA Report 5569-2008, SPFO-Report 1014/2008, TA2367/2008. 2008. ISBN: 978-82-577-5304-7.

Hallanger, I. G.; Sagerup, K.; Evenset, A.; Kovacs, K. M.; Leonards, P.; Fuglei, E.; Routti, H.; Aars, J.; Strom, H.; Lyndersen, C.; Gabrielsen, G. W. Organophosphorous flame retardants in biota from Svalbard, Norway. Marine Pollution Bulletin 2015, 101, 442-447.

Hebert, C.E.; Shutt, J.L.; Hobson, K.A.; Weseloh, D.V.C. Spatial and temporal differences in the diet of Great Lakes herring gulls (Larus argentatus): Evidence from stable isotope analysis. Canadian Journal of Fisheries and Aquatic Sciences 1999a, 56, 323-338.

Hebert, C.E.; Norstrom, R.J.; Weseloh, D.V.C. A quarter century of environmental surveillance: The Canadian Wildlife Service's Great Lakes Herring Gull Monitoring Program. Environmental Reviews 1999b, 7, 147-166.

Hebert, C. E.; Hobson, K. A.; Shutt, J. L. Changes in food web structure affect rate of PCB decline in herring gull (Larus argentatus) eggs. Environmental Science and Technology 2000, 34, 1609-1614.

Hebert, C.E.; Art, M.T.; Weseloh, D.V.C. Ecological tracers can quantify food web structure and change. Environmental Science and Technology 2006, 40, 5618-5623.

Hebert, C. E.; Weseloh, D. V. C.; Idrissi, A.; Arts, M. T.; O’Gorman, R.; Gorman, O. T.; Locke, B.; Madenjian, C. P.; Roseman, E. F. Restoring piscivorous fish populations in the Laurentian Great Lakes causes seabird dietary change. Ecology 2008, 89, 891-897.

Ingerowski, G.; Friedle, A.; Thumulla, J. Chlorinated ethyl and isopropyl phosphoric acid triesters in the indoor environment - An inter-laboratory exposure study. Indoor Air 2001, 11, 145-149.

Jardine, T. D.; Kidd, K. A.; Fisk, A. T. Applications, considerations and sources of uncertainty when using stable isotope analysis in ecotoxicology. Environmental Science and Technology 2006, 40, 7501-7511.

Kelly, J.F.; Stable isotopes of carbon and nitrogen in the study of avian and mammalian trophic ecology. Canadian Journal of Zoology 2000, 78, 1-27.

Kelly, B., Dempson, J.B.; Power, M. The effects of preservation on fish tissue stable isotope signatures. Journal of Fish Biology 2006, 69, 1595-1611. 
Kennedy, S.W.; Jones, S.P. Simultaneous measurement of cytochrome P4501A catalytic activity and total protein concentration with a fluorescence plate reader. Analytical Biochemistry 1994, 222, 217-223.

Kim, J.-W.; Isobe, T.; Chang, K.-H.; Amano, A.; Maneja, R. H.; Zamora, P. B.; Siringan, F. P.; Tanabe, S. Levels and distribution of organophosphorus flame retardants and plasticizers in fishes from Manila Bay, the Philippines. Environmental Pollution 2011, 159, 3653-3659.

Kurebayashi, H.; Tanaka, A.; Yamaha, T. Metabolism and disposition of the flame retardant plasticizer tri- $p$-cresyl phosphate, in the rat. Toxicology and Applied Pharmacology 1985, 77, 395-404.

Leonards, P.; Steindal, E. H.; van der Veen, I.; Berg, V.; Ove Bustnes, J.; van Leeuwen, S. Screening of organophosphor flame retardants 2010. SPFO-Report 1091/2011. TA-2786/2011. 2011.

Li, H.; Su, G.; Zou, M.; Yu, L.; Letcher, R.J.; Yu, H.; Giesy, J.P.; Zhou, B.; Liu, C. Effects of tris(1,3-dichloro-2-propyl) phosphate on growth, reproduction, and gene transcription of Daphnia magna at environmentally relevant concentrations. Environmental Science and Technology 2015, 49, 12975-12983.

Liu, X.; Ji, K.; Choi, K. Endocrine disruption potentials of organophosphate flame retardants and related mechanisms in H295R and MVLN cell lines in zebrafish. Aquatic Toxicology 2012, 114$115,173-181$.

Liu, C.; Wang, Q.; Liang, K.; Liu, J.; Zhou, B.; Zhang, X.; Liu, H.; Geisy, J.P.; Yu, H. Effects of tris(1,3-dichloro-2-propyl) phosphate and triphenyl phosphate on receptor-associated mRNA expression in zebrafish embryos/larvae. Aquatic Toxicology 2013, 128-129, 147-157.

Ma, Y.; Cui, K.; Zeng, F.; Wen, J.; Liu, H.; Zhu, F.; Ouyang, G.; Luan, T.; Zeng, Z. Microwaveassisted extraction combined with gel permeation chromatography and silica gel cleanup followed by gas chromatography-mass spectrometry for the determination of organophosphorus flame retardants and plasticizers in biological samples. Analytica Chimica Acta 2013, 786, 4753.

Marklund, A.; Andersson, B.; Haglund, P. Organophosphorus flame retardants and plasticizers in Swedish sewage treatment plants. Environmental Science and Technology 2005, 39, 7423-7429.

Martínez-Carballo, E.; González-Barreiro, C.; Sitka, A.; Scharf, S.; Gans, O. Determination of selected organophosphate esters in the aquatic environment of Austria. Science of the Total Environment 2007, 388, 290-299. 
Matthews, H. B.; Dixon, D.; Herr, D. W.; Tilson, H. Subchronic toxicity studies indicate that tris(2-chloroethyl)phosphate administration results in lesions in the rat hippocampus. Toxicology and Industrial Health 1990, 6, 1-15.

McGoldrick, D.J.; Clark, M.G.; Keir, M.J.; Backus, S.M.; Malecki, M.M. Canada's national aquatic biological specimen bank and database. Journal of Great Lakes Research 2010, 36, 393398.

McGoldrick, D.J.; Letcher, R.J.; Barresi, E.; Keir, M.J.; Small, J.; Clark, M.G.; Backus, S.M. Organophosphate flame retardants and organosiloxanes in predatory freshwater fish from locations across Canada. Environmental Pollution 2014a, 193, 254-261.

McGoldrick, D.J.; Chan, C.; Drouillard, K.G.; Keir, M.J.; Clark, M.G. Concentrations and trophic magnifications of cyclic siloxanes in aquatic biota from the Western Basin of Lake Erie, Canada. Environmental Pollution 2014b, 186, 141-148.

Meeker, J.D.; Stapleton, H.M. House dust concentrations of organophosphate flame retardants in relation to hormone levels and semen quality parameters. Environmental Health Perspectives 2010, 118, 318-323.

Meeker, J.D.; Cooper, E.M.; Stapleton, H.M.; Hauser, R. Urinary metabolites of organophosphate flame retardants: Temporal variability and correlations with house dust concentrations. Environmental Health Perspectives 2013, 121, 580-585.

Meyer, J.; Bester, K. Organophosphate flame retardants and plasticisers in wastewater treatment plants. Journal of Environmental Monitoring 2004, 6, 599-605.

Morales, N.M.; Matthews, H.B. In vivo binding of the flame retardants tris(2,3-dibromopropyl) phosphate and tris(1,3-dichloro-2-propyl) phosphate to macromolecules of mouse liver, kidney and muscle. Bulletin of Environmental Contamination and Toxicology 1980, 25, 34-38.

Morrissey, R.E.; Schwetz, B.A.; Lamb IV, J.C.; Ross, M.D.; Teague, J.L.; Morris, R.W. Evaluation of rodent sperm, vaginal cytology, and reproductive organ weight data from National Toxicology Program 13-week studies. Fundamental and Applied Toxicology 1988, 11, 343-358.

Ni, Y.; Kumagai, K.; Yanagisawa, Y. Measuring emissions of organophosphate flame retardants using a passive flux sampler. Atmospheric Environment 2007, 41, 3235-3240.

NOAA, Great Lakes Food Web Diagrams. National Oceanic and Atmospheric Administration. 2015. http://www.glerl.noaa.gov/res/projects/food_web/food_web.html Date accessed: April 8, 2016.

NOAA, About Our Great Lakes: Ecology. National Oceanic and Atmospheric Administration. http://www.glerl.noaa.gov/pr/ourlakes/ecology.html Date accessed: March 10, 2016. 
Nomeir, A.A.; Kato, S.; Matthews, H.B. The metabolism and disposition of tris(1,3-dicholoro-2propyl) phosphate (Fyrol FR-2) in the rat. Toxicology and Applied Pharmacology 1981, 57, 401413.

Norstrom, R. J.; Clark, T. P.; Kearney, J. P.; Gilman, A. P. Herring gull energy requirements and body constituents in the Great Lakes. Ardea 1986, 72, 1-23.

NWF, Great Lakes. National Wildlife Research Foundation 2016.

http://www.nwf.org/Wildlife/Wild-Places/Great-Lakes.aspx Date accessed: March 10, 2016.

O’Brien, J.W.; Thai, P.K.; Brandsma, S.H.; Leonards, P.E.G.; Ort, C.; Mueller, J.F. Wastewater analysis of Census day samples to investigate per capita input of organophosphorus flame retardants and plasticizers into wastewater. Chemosphere 2015, 138, 328-334.

Pakalin, S.; Cole, T.; Steinkellner, J.; Nicolas, R.; Tissier, C.; Munn, S.; Eisenreich, S. 2007, Review on production processes of decabromodiphenyl ether (decaBDE) used in polymeric applications in electrical and electronic equipment, and assessment of the availability of potential alternatives to decaBDE, European Report EUR 22693 EN, Brussel, Belgium.

Parsons, J. Factors determining the number and size of eggs laid by the herring gull. The Condor 1976, 78, 481-492.

Paterson, G.; Rush, S. A.; Arts, M. T.; Drouillard, K. G.; Haffner, G. D.; Johnson, T. B.; Lantry, B. F.; Hebert, C. E.; McGoldrick, D. J.; Backus, S. M.; Fisk, A. T. Ecological tracers reveal resource convergence among prey fish species in a large lake ecosystem. Freshwater Biology 2014, 59, 2150-2161.

Porter, E.; Crump, D.; Egloff, E.; Chiu, S.; Kennedy, S.W. Use of an avian hepatocyte assay and the avian ToxChip polymerase chain reaction assay for testing prioritization of 16 organic flame retardants. Environmental Toxicology and Chemistry 2014, 33, 573-582.

Reemtsma, T.; Quintana, J. B.; Rodil, R.; Garcia-Lopez, M.; Rodriguez, I. Organophosphorus flame retardants and plasticizers in water and air I. Occurrence and fate. Trends in Analytical Chemistry 2008, 27 (9), 727-737.

Reemtsma, T.; Lingott, J.; Roegler, S. Determination of 14 monoalkyl phosphates, dialkyl phosphates and dialkyl thiophosphates by LC-MS/MS in human urinary samples. Science of the Total Environment 2011, 409, 1990-1993.

Rodil, R.; Quintana, J.B.; Reemtsma, T. Liquid chromatography-tandem mass spectrometry determination of nonionic organophosphorus flame retardants and plasticizers in wastewater samples. Analytical Chemistry 2005, 77, 3083-3089.

Rush, S. A.; Paterson, G.; Johnson, T. B.; Drouillard, K. G.; Haffner, G. D.; Hebert, C. E.; Arts, M. T.; McGoldrick, D. J.; Backus, S. M.; Lantry, B. F.; Lantry, J. R.; Schaner, T.; Fisk, A. T. 
Long-term impacts of invasive species on a native top predator in a large lake system. Freshwater Biology 2012, 57, 2342-2355.

Saeger, V.W.; Hicks, O.; Kaley, R.G.; Michael, P.R.; Mieure, J.P.; Tucker, E.S. Environmental fat of selected phosphate esters. Environmental Science and Technology 1979, 13, 840-844.

Salamova, A.; Ma, Y.; Venier, M.; Hites, R. A. High Levels of Organophosphate Flame Retardants in the Great Lakes Atmosphere. Environmental Science and Technology Letters 2014, $1,8-14$.

Sasaki, K.; Tadeka, M.; Uchiyama, M. Toxicity, absorption and elimination of phosphoric acid triesters by killifish and goldifish. Bulletin of Environmental Contamination and Toxicology 1981, 27, 775-782.

Sasaki, K.; Suzuki, T.; Takeda, M.; Uchiyama, M. Metabolism of phosphoric-acid triesters by rat-liver homogenate. Bulletin of Environmental Contamination and Toxicology 1984, 33, 281288.

Schindler, B. K.; Forster, K.; Angerer, J. Determination of human urinary organophosphate flame retardant metabolites by solid-phase extraction and gas-chromatography-tandem mass spectrometry. Journal of Chromatography B 2009, 877 (4), 375-381.

Shah, M.; Meija, J.; Cabovska, B.; Caruso, J.A. Determination of phosphoric acid triesters in human plasma using solid-phase microextraction and gas chromatography coupled to inductively coupled plasma mass spectrometry. Journal of Chromatography A 2006, 1103, 329-336.

Shaw, S.; Blum, A.; Weber, R.; Kannan, K.; Rich, D.; Lucas, D.; Koshland, C.; Dobraca, D.; Hanson, S.; Birnbaum, L. Halogenated flame retardants: Do the fire safety benefits justify the risks?. Reviews on Environmental Health 2010, 25, 261-305.

Stackelberg, P.E.; Furlong, E.T.; Meyer, M.T.; Zaugg, S.D.; Henderson, A.K.; Reissman, D.B. Persistence of pharmaceutical compounds and other organic wastewater contaminants in a conventional drinking-water treatment plant. Science of the Total Environment 2004, 329, 99113.

Stapleton, H.M.; Klosterhaus, S.; Eagle, S.; Fuh, J.; Meeker, J.D.; Blum, A.; Webster, T.F. Detection of organophosphate flame retardants in furniture foam and U.S. house dust. Environmental Science and Technology 2009, 43, 7490-7495.

Stapleton, H.M.; Klosterhaus, S.; Keller, A.; Ferguson, P.L.; van Bergen, S.; Cooper, E.; Webster, T.F.; Blum, A. Identification of flame retardants in polyurethane foam collected from baby products. Environmental Science and Technology 2011, 45, 5323-5331. 
Su, G.; Crump, D.; Letcher, R. J.; Kennedy, S. W. Rapid metabolism in vitro of triphenyl phosphate flame retardant and effects on cytotoxicity and mRNA expression in chicken embryonic hepatocytes. Environmental Science and Technology 2014a, 48, 13511-13519.

Su, G.; Greaves, A.K.; Gauthier, L.T.; Letcher, R.J. Liquid chromatography-electrospraytandem mass spectrometry method for determination of organophosphate diesters in biotic samples including Great Lakes herring gull plasma. Journal of Chromatography A 2014b, 1374, $85-92$.

Su, G.; Letcher, R. J.; Moore, J. N.; Williams, L. L.; Martin, P. A.; de Solla, S. R.; Bowerman, W. W. Spatial and temporal comparisons of legacy and emerging flame retardants in herring gull eggs from colonies spanning the Laurentian Great Lakes of Canada and United States.

Environmental Research 2015a, 142, 720-730.

Su, G.; Letcher, R. J.; Crump, D.; Gooden, D. M.; Stapleton, H. M. In vitro metabolism of the flame retardant triphenyl phosphate in chicken embryonic hepatocytes and the importance of the hydroxylation pathway. Environmental Science and Technology Letters 2015b, 2, 100-104.

Sundkvist, A. M.; Olofsson, U.; Haglund, P. Organophosphorus flame retardants and plasticizers in marine and fresh water biota and in human milk. Journal of Environmental Monitoring 2010, $12,943-951$.

Takahashi, S.; Satake, I.; Konuma, I.; Kawashima, K.; Kawasaki, M.; Mori, S.; Morino, J.; Mori, J.; Xu, H.; Abe, K.; Yamada, R.-h.; Kera, Y. Isolation and identification of persistent chlorinated organophosphorus flame retardant-degrading bacteria. Applied and Environmental Microbiology 2010, 76, 5292-5296.

Umezu, T.; Yonemoto, J.; Soma, Y.; Suzuki, T. Tris(2-chloroethyl)phosphate increases ambulatory activity in mice: Pharmacological analyses of its neurochemial mechanism. Toxicology and Applied Pharmacology 1998, 148 (1), 109-116.

van den Eede, N.; Dirtu, A.C., Neels, H., Covaci, A. Analytical developments and preliminary assessment of human exposure to organophosphate flame retardants from indoor dust.

Environment International 2011, 37, 454-461.

van den Eede, N.; Neels, H.; Jorens, P.G.; Covaci, A. Analysis of organophosphate flame retardant diester metabolites in human urine by liquid chromatography electrospray ionisation tandem mass spectrometry. Journal of Chromatography A 2013a, 1303, 48-53.

van den Eede, N.; Maho, W.; Erratico, C.; Neels, H.; Covaci, A. First insights in the metabolism of phosphate flame retardants and plasticizers using human liver fractions. Toxicology Letters 2013b, 223, 9-15. 
van der Veen, I.; de Boer, J. Phosphorus flame retardants: Properties, production, environmental occurrence, toxicity and analysis. Chemosphere 2012, 88, 1119-1153.

Venier, M.; Dove, A.; Romanak; K.; Backus, S.; Hites, R. A. Flame retardants and legacy chemicals in Great Lakes' water. Environmental Science and Technology 2014, 48, 9563-9572.

Verreault, J.; Villa, R. A.; Gabrielsen, G. W.; Skarre, J. U.; Letcher, R. J. Maternal transfer of organohalogen contaminants and metabolites to eggs of Arctic-breeding glaucous gulls. Environmental Pollution 2006. 144, 1053-1060.

Verreault, J.; Letcher, R.J.; Sonne, C.; Dietz, R. In vitro metabolism of polychlorinated biphenyls and cytochrome P450 monooxygenase activities in dietary-exposed Greenland sledge dogs. Comparative Biochemistry and Physiology C 2009, 150, 91-100.

Wang, Q.; Liang, K.; Liu, J.; Yang, L.; Guo, Y.; Liu, C.; Zhou, B. Exposure of zebrafish embryos/larvae to TDCPP alters concentrations of thyroid hormones and transcriptions of genes involved in the hypothalamic-pituitary-thyroid axis. Aquatic Toxicology 2013, 126, 207-213.

Zheng, X.; Xu, F.; Luo, X.; Mai, B.; Covaci, A. Phosphate flame retardants and novel brominated flame retardants in home-produced eggs from an e-waste recycling region in China. Chemosphere 2016, 150, 545-550.

Zhu, Y.; Ma, X.; Su, G.; Yu, L.; Letcher, R.J.; Hou, J.; Yu, H.; Giesy, J.P.; Liu, C. Environmentally relevant concentrations of the flame retardant tris(1,3-dichloro-2-propyl) phosphate inhibit growth of female zebrafish and decrease fecundity. Environmental Science and Technology 2015, 49, 14579-14587. 


\section{APPENDIX 1}

OPE concentrations ( $\mathrm{ng} / \mathrm{g}$ ww) among all herring gull pooled egg homogenates from five colonial nesting sites in the Laurentian Great Lakes between 1990 and 2010.

\begin{tabular}{|c|c|c|c|c|c|c|c|}
\hline Colony & Lake & Year & TCEP & TCIPP & TPHP & TBOEP & इOPFR \\
\hline \multirow[t]{11}{*}{ Chantry Island } & Huron & 1990 & n.d. & n.d. & n.d. & n.d. & n.d. \\
\hline & & 1992 & n.d. & n.d. & n.d. & n.d. & n.d. \\
\hline & & 1994 & n.d. & n.d. & n.d. & n.d. & n.d. \\
\hline & & 1996 & 0.48 & 0.41 & n.d. & 0.48 & 1.38 \\
\hline & & 1998 & n.d. & 0.70 & n.d. & 0.63 & 1.32 \\
\hline & & 2000 & n.d. & n.d. & n.d. & 0.20 & 0.20 \\
\hline & & 2002 & n.d. & 0.43 & n.d. & 0.36 & 0.79 \\
\hline & & 2004 & 0.07 & 1.46 & n.d. & 0.60 & 2.12 \\
\hline & & 2006 & n.d. & 0.54 & n.d. & 0.34 & 0.88 \\
\hline & & 2008 & 0.22 & 0.45 & 0.22 & 0.07 & 0.97 \\
\hline & & 2010 & 0.55 & 0.43 & 0.34 & 0.69 & 2.02 \\
\hline \multirow[t]{10}{*}{ Gull Island } & Michigan & 1990 & n.d. & n.d. & n.d. & n.d. & n.d. \\
\hline & & 1992 & n.d. & n.d. & n.d. & 0.13 & 0.13 \\
\hline & & 1994 & 1.22 & 0.54 & n.d. & 0.54 & 2.30 \\
\hline & & 1996 & 1.05 & 0.40 & n.d. & 0.79 & 2.24 \\
\hline & & 1998 & 1.14 & 0.51 & n.d. & 0.38 & 2.02 \\
\hline & & 2000 & 0.69 & 0.28 & n.d. & 0.14 & 1.11 \\
\hline & & 2002 & 0.70 & 0.70 & n.d. & 0.14 & 1.54 \\
\hline & & 2004 & 0.83 & 0.69 & n.d. & 1.11 & 2.63 \\
\hline & & 2006 & 0.94 & 1.21 & n.d. & 0.67 & 2.82 \\
\hline & & 2008 & 0.68 & 0.81 & 0.81 & 1.49 & 3.80 \\
\hline
\end{tabular}




\begin{tabular}{|c|c|c|c|c|c|c|c|}
\hline & & 2010 & 0.41 & 0.61 & 0.30 & 3.80 & 5.11 \\
\hline \multirow[t]{11}{*}{ Toronto Harbour } & \multirow[t]{11}{*}{ Ontario } & 1990 & n.d. & 0.84 & n.d. & 1.68 & 2.52 \\
\hline & & 1992 & n.d. & n.d. & n.d. & 2.76 & 2.76 \\
\hline & & 1994 & n.d. & n.d. & n.d. & 1.87 & 1.87 \\
\hline & & 1996 & n.d. & n.d. & n.d. & 0.84 & 0.84 \\
\hline & & 1998 & 0.28 & n.d. & n.d. & 0.55 & 0.83 \\
\hline & & 2000 & 1.59 & 0.18 & n.d. & 1.24 & 3.00 \\
\hline & & 2002 & 1.25 & n.d. & n.d. & 0.83 & 2.08 \\
\hline & & 2004 & 0.92 & n.d. & n.d. & 0.66 & 1.58 \\
\hline & & 2006 & 1.37 & 0.82 & n.d. & 0.68 & 2.87 \\
\hline & & 2008 & 1.50 & 0.14 & n.d. & 0.55 & 2.18 \\
\hline & & 2010 & 1.10 & 0.45 & n.d. & 0.55 & 2.10 \\
\hline \multirow[t]{11}{*}{ Agawa Rocks } & \multirow[t]{11}{*}{ Superior } & 1990 & n.d. & n.d. & n.d. & 0.54 & 0.54 \\
\hline & & 1992 & 0.35 & n.d. & n.d. & 0.64 & 0.99 \\
\hline & & 1994 & 0.70 & 1.97 & n.d. & 0.87 & 3.53 \\
\hline & & 1996 & 0.34 & n.d. & n.d. & 0.40 & 0.74 \\
\hline & & 1998 & 0.11 & n.d. & n.d. & 0.37 & 0.48 \\
\hline & & 2000 & 0.59 & 0.20 & n.d. & 0.83 & 1.61 \\
\hline & & 2002 & 0.56 & n.d. & n.d. & 0.72 & 1.28 \\
\hline & & 2004 & 0.44 & n.d. & n.d. & 0.27 & 0.71 \\
\hline & & 2006 & 0.35 & n.d. & n.d. & 0.76 & 1.11 \\
\hline & & 2008 & 1.11 & 0.56 & n.d. & 0.97 & 2.64 \\
\hline & & 2010 & 3.32 & 2.67 & n.d. & 0.71 & 6.69 \\
\hline Fighting Island & Erie & 1990 & n.d. & 0.11 & n.d. & 0.33 & 0.44 \\
\hline
\end{tabular}




\begin{tabular}{|lllllll}
1992 & n.d. & 0.76 & n.d. & 0.54 & 1.30 \\
1994 & 0.55 & 1.87 & n.d. & 0.88 & 3.30 \\
1996 & 0.11 & 1.48 & n.d. & 0.80 & 2.39 \\
1998 & n.d. & 0.78 & n.d. & 0.22 & 1.00 \\
2000 & n.d. & 0.11 & n.d. & 0.11 & 0.23 \\
2002 & n.d. & 2.84 & n.d. & 0.11 & 2.95 \\
2004 & 0.11 & 0.46 & n.d. & 0.34 & 0.91 \\
2006 & n.d. & 0.55 & n.d. & n.d. & 0.55 \\
2008 & 0.32 & 1.18 & n.d. & n.d. & 1.51 \\
2010 & 2.71 & 0.83 & n.d. & 0.83 & 4.37 \\
\hline
\end{tabular}




\section{APPENDIX 2}

Stable isotope analysis data for herring gull pooled egg homogenates from five colonial nesting sites in the Laurentian Great Lakes between 1981 and 2008.

\begin{tabular}{|c|c|c|c|c|}
\hline Colony & Year & $\begin{array}{l}\text { Trophic } \\
\text { Position }\end{array}$ & $\delta^{15} \mathbf{N}(\%)$ & $\delta^{13} \mathrm{C}(\%)$ \\
\hline Agawa Rocks & 1981 & 3.550 & 9.930 & -22.400 \\
\hline \multirow[t]{27}{*}{ (Lake Superior) } & 1982 & 3.503 & 9.770 & -24.830 \\
\hline & 1983 & 3.509 & 9.790 & -24.990 \\
\hline & 1984 & 3.803 & 10.790 & -24.260 \\
\hline & 1985 & 3.741 & 10.580 & -24.330 \\
\hline & 1986 & 3.782 & 10.720 & -23.430 \\
\hline & 1987 & 3.747 & 10.600 & -22.610 \\
\hline & 1988 & 3.829 & 10.880 & -24.910 \\
\hline & 1989 & 3.991 & 11.430 & -24.610 \\
\hline & 1990 & 3.694 & 10.420 & -22.550 \\
\hline & 1991 & 3.732 & 10.550 & -23.480 \\
\hline & 1992 & 4.056 & 11.650 & -25.840 \\
\hline & 1993 & 3.515 & 9.810 & -20.930 \\
\hline & 1994 & 3.718 & 10.500 & -23.280 \\
\hline & 1995 & 3.274 & 8.990 & -21.280 \\
\hline & 1996 & 3.385 & 9.370 & -22.680 \\
\hline & 1997 & 3.479 & 9.690 & -21.580 \\
\hline & 1998 & 3.329 & 9.180 & -22.200 \\
\hline & 1999 & 3.653 & 10.280 & -23.310 \\
\hline & 2000 & 3.262 & 8.950 & -21.810 \\
\hline & 2001 & 3.535 & 9.880 & -23.220 \\
\hline & 2002 & 3.512 & 9.800 & -22.700 \\
\hline & 2003 & 3.247 & 8.900 & -22.000 \\
\hline & 2004 & 3.200 & 8.740 & -23.660 \\
\hline & 2005 & 3.315 & 9.130 & -23.780 \\
\hline & 2006 & & 9.790 & -20.937 \\
\hline & 2007 & & 8.987 & -21.423 \\
\hline & 2008 & & 9.168 & -20.990 \\
\hline \multirow{9}{*}{$\begin{array}{l}\text { Chantry Island } \\
\text { (Lake Huron) }\end{array}$} & 1981 & 3.274 & 10.210 & -23.230 \\
\hline & 1982 & 3.262 & 10.170 & -23.480 \\
\hline & 1983 & 3.438 & 10.770 & -24.080 \\
\hline & 1984 & 3.371 & 10.540 & -24.120 \\
\hline & 1985 & 4.218 & 13.420 & -25.150 \\
\hline & 1986 & 3.694 & 11.640 & -23.960 \\
\hline & 1987 & 3.124 & 9.700 & -22.870 \\
\hline & 1988 & 3.797 & 11.990 & -25.880 \\
\hline & 1989 & 3.897 & 12.330 & -25.800 \\
\hline
\end{tabular}




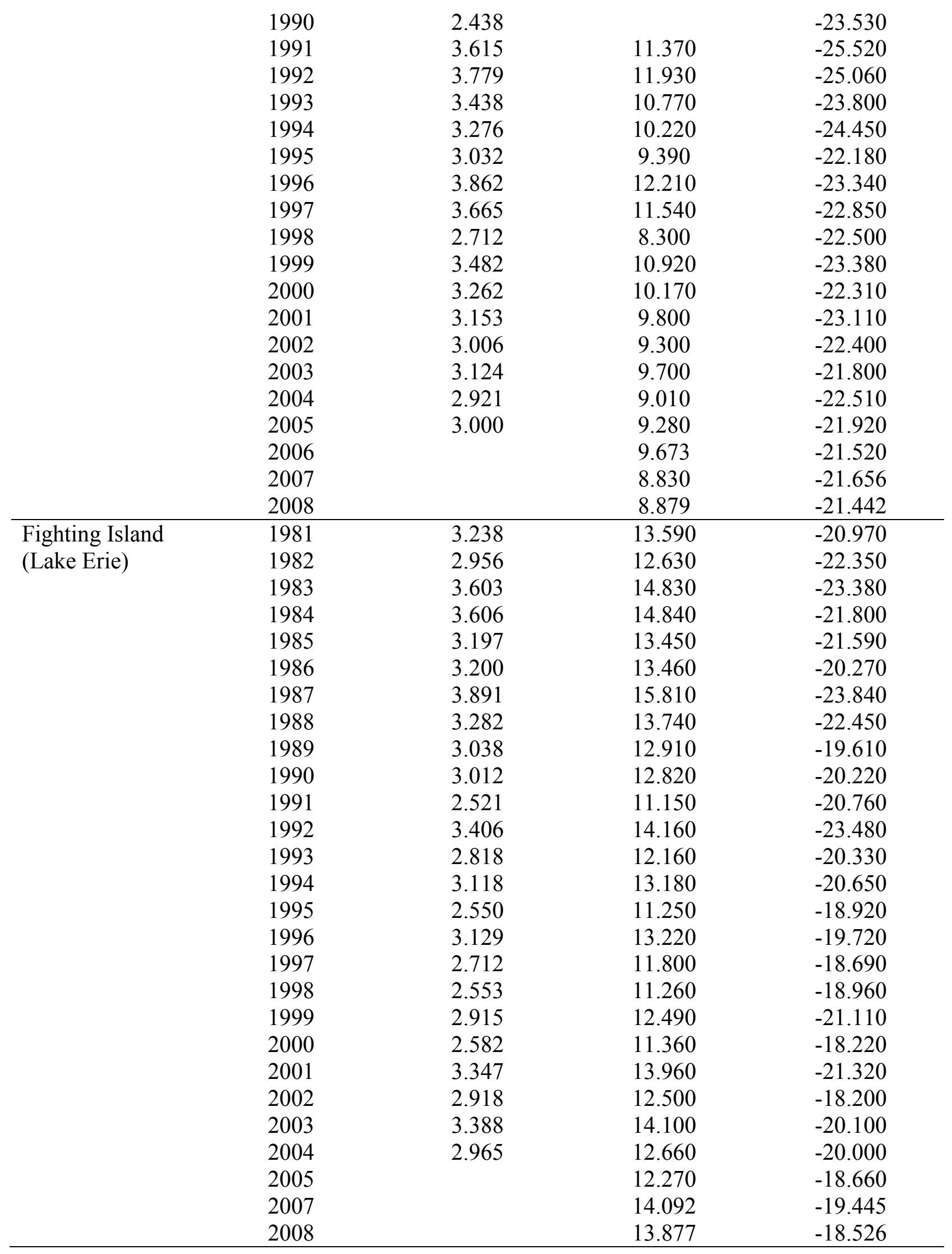




\begin{tabular}{|c|c|c|c|c|}
\hline Gull Island & 1981 & 4.176 & 13.170 & -22.610 \\
\hline \multirow[t]{27}{*}{ (Lake Michigan) } & 1982 & 3.841 & 12.030 & -25.300 \\
\hline & 1983 & 3.879 & 12.160 & -26.680 \\
\hline & 1984 & 4.347 & 13.750 & -25.310 \\
\hline & 1985 & 4.262 & 13.460 & -25.200 \\
\hline & 1986 & 4.029 & 12.670 & -23.190 \\
\hline & 1987 & 4.215 & 13.300 & -24.300 \\
\hline & 1988 & 4.474 & 14.180 & -24.710 \\
\hline & 1989 & 4.244 & 13.400 & -26.400 \\
\hline & 1990 & 4.226 & 13.340 & -26.690 \\
\hline & 1991 & 4.097 & 12.900 & -23.700 \\
\hline & 1992 & 3.218 & 9.910 & -22.940 \\
\hline & 1993 & 4.271 & 13.490 & -23.970 \\
\hline & 1994 & 4.282 & 13.530 & -26.330 \\
\hline & 1995 & 3.462 & 10.740 & -22.040 \\
\hline & 1996 & 4.365 & 13.810 & -23.000 \\
\hline & 1997 & 3.968 & 12.460 & -23.230 \\
\hline & 1998 & 3.894 & 12.210 & -22.970 \\
\hline & 1999 & 4.494 & 14.250 & -24.950 \\
\hline & 2000 & 3.844 & 12.040 & -22.700 \\
\hline & 2001 & 4.450 & 14.100 & -24.860 \\
\hline & 2002 & 3.597 & 11.200 & -21.000 \\
\hline & 2003 & 4.274 & 13.500 & -23.600 \\
\hline & 2004 & 3.582 & 11.150 & -21.990 \\
\hline & 2005 & 3.835 & 12.010 & -22.430 \\
\hline & 2006 & & 11.309 & -20.587 \\
\hline & 2007 & & 11.388 & -20.548 \\
\hline & 2008 & & 12.701 & -21.714 \\
\hline \multirow{18}{*}{$\begin{array}{l}\text { Toronto Harbour } \\
\text { (Lake Ontario) }\end{array}$} & 1981 & 3.832 & 15.850 & -20.990 \\
\hline & 1982 & 3.674 & 15.310 & -22.790 \\
\hline & 1983 & 4.088 & 16.720 & -20.850 \\
\hline & 1984 & 3.538 & 14.850 & -20.850 \\
\hline & 1985 & 3.453 & 14.560 & -20.920 \\
\hline & 1986 & 3.350 & 14.210 & -21.440 \\
\hline & 1987 & 3.344 & 14.190 & -21.050 \\
\hline & 1988 & 3.326 & 14.130 & -21.530 \\
\hline & 1989 & 2.465 & 11.200 & -22.930 \\
\hline & 1990 & 3.335 & 14.160 & -22.370 \\
\hline & 1991 & 2.768 & 12.230 & -21.570 \\
\hline & 1992 & 3.406 & 14.400 & -21.870 \\
\hline & 1993 & 3.218 & 13.760 & -23.460 \\
\hline & 1994 & 3.288 & 14.000 & -22.480 \\
\hline & 1995 & 2.906 & 12.700 & -20.080 \\
\hline & 1996 & 3.112 & 13.400 & -20.530 \\
\hline & 1997 & 3.068 & 13.250 & -20.890 \\
\hline & 2000 & 3.356 & 14.230 & -21.540 \\
\hline
\end{tabular}




\begin{tabular}{llll}
2001 & 3.803 & 15.750 & -23.050 \\
2002 & 3.288 & 14.000 & -21.700 \\
2003 & 3.406 & 14.400 & -20.500 \\
2004 & 2.888 & 12.640 & -21.420 \\
2005 & 2.976 & 12.940 & -21.890 \\
2006 & & 14.288 & -20.334 \\
2007 & & 12.838 & -20.393 \\
2008 & & 12.637 & -19.775 \\
\hline
\end{tabular}




\section{APPENDIX 3}

OPE concentrations (ng/g ww) in food webs from Lake Erie and Lake Ontario collected in 2010.

\section{Number}

\section{Location}

Common Name

Indiv. in Composite
Percent

Lipi
TBOEP

n.d.

\section{W. Basin (Erie)}

W. Basin (Erie)

W. Basin (Erie)

W. Basin (Erie)

W. Basin (Erie)

W. Basin (Erie)

Dunkirk (Erie)

Dunkirk (Erie)

Dunkirk (Erie)

Dunkirk (Erie)

Dunkirk (Erie)

Dunkirk (Erie)

Dunkirk (Erie)
Emerald Shiner

Emerald Shiner

Emerald Shiner

Freshwater Drum

Freshwater Drum

Freshwater Drum

Lake Trout

Lake Trout

Lake Trout

Lake Trout

Lake Trout

Lake Trout

Lake Trout

22

25

28

2

2

1

1

1

1

1

2.2

n.d.

n.d.

2.0

n.d.

$1.3 \quad 2.23$

$2.8 \quad 1.51$

$3.4 \quad 4.77$

$16.6 \quad 1.41$

$\begin{array}{ll}16.8 & 0.78\end{array}$

$19.3 \quad$ n.d.

$\begin{array}{lll}1 & 15.6 & 1.31\end{array}$

n.d.

2.0

4.42

n.d.

n.d.

n.d.

n.d. n.d.

n.d. n.d.

n.d. n.

n.d. n.

$15.5 \quad 0.92$

n.d. n.d.

$\begin{array}{cccccccc}\text { n.d. } & \text { n.d. } & \text { n.d. } & \text { n.d. } & 0.92 & -26.631 & 16.562 & 4.3271 \\ \text { n.d. } & \text { n.d. } & \text { n.d. } & \text { n.d. } & \text { n.d. } & -27.157 & 17.187 & 4.5109 \\ \text { n.d. } & \text { n.d. } & \text { n.d. } & \text { n.d. } & 1.31 & -25.169 & 18.572 & 4.9182\end{array}$

$\begin{array}{lll}1 & 16.7 & 4.57 \\ 1 & 19.9 & 0.92\end{array}$

$\begin{array}{llllllll}\text { n.d. } & \text { n.d. } & \text { n.d. } & \text { n.d. } & 4.57 & -26.848 & 17.479 & 4.5968 \\ \text { n.d. } & \text { n.d. } & \text { n.d. } & \text { n.d. } & 0.92 & -27.516 & 17.038 & 4.4671\end{array}$




\begin{tabular}{|c|c|c|c|c|c|c|c|c|c|c|c|c|}
\hline Dunkirk (Erie) & Lake Trout & 1 & 12.7 & 0.86 & n.d. & n.d. & n.d. & n.d. & 0.86 & -25.586 & 18.182 & 4.8035 \\
\hline W. Basin (Erie) & Rainbow Smelt & 15 & 24.7 & 3.75 & n.d. & n.d. & n.d. & n.d. & 3.75 & -25.837 & 13.429 & 3.4056 \\
\hline W. Basin (Erie) & Rainbow Smelt & 17 & 5.4 & 1.72 & n.d. & n.d. & n.d. & n.d. & 1.72 & -25.754 & 13.817 & 3.5197 \\
\hline W. Basin (Erie) & Rainbow Smelt & 19 & 16.6 & 2.46 & n.d. & n.d. & n.d. & n.d. & 2.46 & -26.132 & 13.758 & 3.5024 \\
\hline W. Basin (Erie) & Round Goby & 71 & 0.8 & 6.76 & n.d. & n.d. & n.d. & n.d. & 6.76 & -21.843 & 12.265 & 3.0632 \\
\hline W. Basin (Erie) & Round Goby & 21 & 0.6 & n.d. & n.d. & n.d. & n.d. & n.d. & n.d. & -21.646 & 11.943 & 2.9685 \\
\hline W. Basin (Erie) & Round Goby & 7 & 0.7 & n.d. & n.d. & n.d. & n.d. & n.d. & n.d. & -21.313 & 11.919 & 2.9615 \\
\hline W. Basin (Erie) & Trout Perch & 38 & 0.4 & 1.74 & 1.13 & n.d. & n.d. & n.d. & 2.87 & -21.114 & 13.672 & 3.4771 \\
\hline W. Basin (Erie) & Trout Perch & 26 & 0.6 & 0.10 & 1.01 & n.d. & n.d. & n.d. & 1.11 & -21.417 & 13.386 & 3.3929 \\
\hline W. Basin (Erie) & Trout Perch & 14 & 0.8 & 3.92 & 4.31 & n.d. & n.d. & n.d. & 8.23 & -21.613 & 13.411 & 3.4003 \\
\hline W. Basin (Erie) & Walleye & 1 & 14.8 & 5.18 & 3.12 & n.d. & n.d. & n.d. & 8.30 & -24.869 & 16.007 & 4.1638 \\
\hline W. Basin (Erie) & Walleye & 1 & 11.5 & 1.69 & 0.48 & n.d. & n.d. & n.d. & 2.17 & -27.729 & 14.728 & 3.7876 \\
\hline W. Basin (Erie) & Walleye & 1 & 12.7 & 1.84 & n.d. & n.d. & n.d. & n.d. & 1.84 & -23.417 & 16.002 & 4.1624 \\
\hline W. Basin (Erie) & Walleye & 1 & 10.3 & 1.83 & n.d. & n.d. & n.d. & n.d. & 1.83 & -24.856 & 16.596 & 4.3371 \\
\hline W. Basin (Erie) & Walleye & 1 & 10.2 & 3.67 & 1.29 & n.d. & n.d. & n.d. & 4.96 & -24.792 & 13.791 & 3.5121 \\
\hline W. Basin (Erie) & Walleye & 1 & 8.3 & 3.21 & n.d. & n.d. & n.d. & n.d. & 3.21 & -23.586 & 14.062 & 3.5918 \\
\hline W. Basin (Erie) & Walleye & 1 & 4.4 & 2.98 & 0.10 & n.d. & n.d. & n.d. & 3.08 & -23.921 & 14.920 & 3.8441 \\
\hline W. Basin (Erie) & Walleye & 1 & 5.2 & n.d. & 1.30 & n.d. & n.d. & n.d. & 1.30 & -23.679 & 14.398 & 3.6906 \\
\hline W. Basin (Erie) & Walleye & 1 & 2.0 & 3.24 & 1.04 & n.d. & n.d. & n.d. & 4.28 & -23.331 & 14.104 & 3.6041 \\
\hline W. Basin (Erie) & Walleye & 1 & 4.5 & 6.02 & n.d. & n.d. & n.d. & n.d. & 6.02 & -22.886 & 13.851 & 3.5297 \\
\hline
\end{tabular}




\begin{tabular}{|c|c|c|c|c|c|c|c|c|c|c|c|c|}
\hline W. Basin (Erie) & White Perch & 5 & 4.2 & 7.96 & n.d. & n.d. & n.d. & n.d. & 7.96 & -24.803 & 15.376 & 3.9782 \\
\hline W. Basin (Erie) & White Perch & 4 & 4.8 & 13.53 & 0.68 & n.d. & n.d. & n.d. & 14.21 & -24.965 & 15.793 & 4.1009 \\
\hline W. Basin (Erie) & White Perch & 3 & 6.9 & 2.57 & n.d. & n.d. & n.d. & n.d. & 2.57 & -25.489 & 16.072 & 4.1829 \\
\hline W. Basin (Erie) & Yellow Perch & 4 & 0.9 & 6.66 & n.d. & n.d. & n.d. & n.d. & 6.66 & -21.804 & 13.877 & 3.5374 \\
\hline W. Basin (Erie) & Yellow Perch & 4 & 0.7 & n.d. & n.d. & n.d. & n.d. & n.d. & n.d. & -20.471 & 13.263 & 3.3568 \\
\hline W. Basin (Erie) & Yellow Perch & 3 & 0.9 & n.d. & n.d. & n.d. & n.d. & n.d. & n.d. & -21.194 & 13.880 & 3.5382 \\
\hline Port Credit (Ontario) & Alewife & 1 & 16.7 & 0.18 & n.d. & n.d. & n.d. & 0.06 & 0.24 & -27.823 & 11.691 & 2.8944 \\
\hline Port Credit (Ontario) & Alewife & 1 & 10.3 & 2.81 & n.d. & n.d. & n.d. & n.d. & 2.81 & -27.465 & 12.200 & 3.0441 \\
\hline Port Credit (Ontario) & Deepwater Sculpin & 15 & 5.5 & 4.00 & n.d. & n.d. & n.d. & n.d. & 4.00 & -27.753 & 15.083 & 3.8921 \\
\hline Port Credit (Ontario) & Deepwater Sculpin & 3 & 6.4 & 3.29 & n.d. & n.d. & n.d. & n.d. & 3.29 & -27.865 & 15.328 & 3.9641 \\
\hline Niagara On The Lake (Ontario) & Lake Trout & 1 & 16.2 & 2.90 & n.d. & n.d. & n.d. & n.d. & 2.90 & -27.715 & 15.625 & 4.0515 \\
\hline Niagara On The Lake (Ontario) & Lake Trout & 1 & 13.3 & 1.70 & n.d. & n.d. & n.d. & n.d. & 1.70 & -26.482 & 17.270 & 4.5353 \\
\hline Port Hope (Ontario) & Lake Trout & 1 & 12.0 & 1.79 & n.d. & n.d. & n.d. & n.d. & 1.79 & -26.466 & 17.175 & 4.5074 \\
\hline Port Hope (Ontario) & Lake Trout & 1 & 19.3 & 3.31 & n.d. & n.d. & n.d. & n.d. & 3.31 & -28.270 & 16.326 & 4.2576 \\
\hline Port Hope (Ontario) & Lake Trout & 1 & 10.9 & n.d. & n.d. & n.d. & n.d. & n.d. & n.d. & -25.660 & 18.504 & 4.8982 \\
\hline Port Hope (Ontario) & Lake Trout & 1 & 9.5 & 9.81 & n.d. & n.d. & n.d. & n.d. & 9.81 & -26.257 & 17.562 & 4.6212 \\
\hline Port Credit (Ontario) & Lake Trout & 1 & 34.6 & 0.53 & 0.26 & n.d. & n.d. & n.d. & 0.79 & -26.664 & 16.437 & 4.2903 \\
\hline Port Credit (Ontario) & Lake Trout & 1 & 24.8 & n.d. & n.d. & n.d. & n.d. & n.d. & n.d. & -27.446 & 16.292 & 4.2476 \\
\hline Port Credit (Ontario) & Lake Trout & 1 & 23.0 & n.d. & n.d. & n.d. & n.d. & n.d. & n.d. & -27.935 & 16.817 & 4.4021 \\
\hline Port Credit (Ontario) & Lake Trout & 1 & 25.3 & n.d. & n.d. & n.d. & n.d. & n.d. & n.d. & -28.021 & 16.572 & 4.3300 \\
\hline
\end{tabular}




\begin{tabular}{|c|c|c|c|c|c|c|c|c|c|c|c|c|}
\hline Port Credit (Ontario) & Lake Trout & 1 & 15.8 & n.d. & n.d. & n.d. & n.d. & n.d. & n.d. & -25.127 & 17.208 & 4.5171 \\
\hline Port Credit (Ontario) & Lake Trout & 1 & 23.8 & n.d. & n.d. & n.d. & n.d. & n.d. & n.d. & -27.388 & 16.621 & 4.3444 \\
\hline Port Credit (Ontario) & Lake Trout & 1 & 17.5 & 0.71 & n.d. & n.d. & n.d. & n.d. & 0.71 & -26.089 & 16.786 & 4.3929 \\
\hline Port Credit (Ontario) & Lake Trout & 1 & 18.5 & n.d. & n.d. & n.d. & n.d. & 0.20 & n.d. & -27.599 & 17.093 & 4.4832 \\
\hline Port Credit (Ontario) & Lake Trout & 1 & 19.4 & n.d. & n.d. & n.d. & n.d. & n.d. & n.d. & -26.721 & 15.926 & 4.1400 \\
\hline Port Credit (Ontario) & Lake Trout & 1 & 8.2 & 0.72 & n.d. & n.d. & n.d. & n.d. & 0.72 & -25.703 & 16.701 & 4.3679 \\
\hline Port Credit (Ontario) & Mysis & N/A & 5.3 & 0.71 & 2.35 & 0.95 & n.d. & 1.12 & 5.13 & $-28.420^{\mathrm{a}}$ & $10.060^{\mathrm{a}}$ & 2.4147 \\
\hline Port Credit (Ontario) & Net Plankton & N/A & 2.3 & 1.08 & n.d. & 0.67 & 0.63 & 0.63 & 3.01 & $-24.390^{\mathrm{a}}$ & $8.650^{\mathrm{a}}$ & 2.000 \\
\hline Niagara On The Lake (Ontario) & Rainbow Smelt & 2 & 8.0 & 7.00 & n.d. & n.d. & n.d. & n.d. & 7.00 & -24.568 & 15.894 & 4.1306 \\
\hline Port Credit (Ontario) & Rainbow Smelt & 9 & 4.0 & 0.64 & n.d. & n.d. & n.d. & n.d. & 0.64 & -26.395 & 15.007 & 3.8697 \\
\hline Niagara On The Lake (Ontario) & Round Goby & 6 & 0.4 & 6.08 & n.d. & n.d. & n.d. & n.d. & 6.08 & -22.031 & 14.284 & 3.6571 \\
\hline Port Credit (Ontario) & Round Goby & 2 & 0.4 & 1.68 & n.d. & n.d. & n.d. & n.d. & 1.68 & -22.628 & 14.344 & 3.6747 \\
\hline Niagara On The Lake (Ontario) & Slimy Sculpin & 8 & 4.4 & 2.94 & n.d. & n.d. & n.d. & n.d. & 2.94 & -27.136 & 16.957 & 4.4432 \\
\hline Port Credit (Ontario) & Slimy Sculpin & 4 & 3.8 & 4.10 & n.d. & n.d. & n.d. & n.d. & 4.10 & -25.630 & 17.161 & 4.5032 \\
\hline
\end{tabular}


